\title{
Following the Leaders: Issue Attention and Agenda Dynamics in Women's Health Care Policy
}

\author{
Kara Anne Fisher \\ kfishe19@mix.wvu.edu
}

Follow this and additional works at: https://researchrepository.wvu.edu/etd

Part of the American Politics Commons

\section{Recommended Citation}

Fisher, Kara Anne, "Following the Leaders: Issue Attention and Agenda Dynamics in Women's Health Care Policy" (2019). Graduate Theses, Dissertations, and Problem Reports. 4072.

https://researchrepository.wvu.edu/etd/4072

This Dissertation is protected by copyright and/or related rights. It has been brought to you by the The Research Repository @ WVU with permission from the rights-holder(s). You are free to use this Dissertation in any way that is permitted by the copyright and related rights legislation that applies to your use. For other uses you must obtain permission from the rights-holder(s) directly, unless additional rights are indicated by a Creative Commons license in the record and/ or on the work itself. This Dissertation has been accepted for inclusion in WVU Graduate Theses, Dissertations, and Problem Reports collection by an authorized administrator of The Research Repository @ WVU.

For more information, please contact researchrepository@mail.wvu.edu. 
Following the Leaders:

Issue Attention and Agenda Dynamics in Women's Health Care Policy

\author{
Kara Fisher \\ Dissertation submitted \\ to the Eberly College of Arts and Sciences \\ at West Virginia University \\ Doctor of Philosophy in \\ Political Science \\ Jeff Worsham, Ph.D., Chair \\ John Kilwein, Ph.D. \\ Matthew Jacobsmeier, Ph.D. \\ Simon Haeder, Ph.D. \\ L. Chris Plein, Ph.D. \\ Department of Political Science
}

in partial fulfillment of the requirements for the degree of

Morgantown, West Virginia

2019

Keywords: Women's Health Care, Issue Attention, Agenda Setting, Public Policy

Copyright 2019 Kara Fisher 


\begin{abstract}
Following the Leaders:

Issue Attention and Agenda Dynamics in Women's Health Care Policy
\end{abstract}

\author{
Kara Fisher
}

This dissertation focuses on shifts in issue attention in the policy process and examines policy changes. Describing agenda setting is important not only for understanding congressional behavior in general but also for understanding the institutional context of other political behavior. I focus on the processes of positive feedback to explain periods of dramatic policy changes observed over a long period of time.

The purpose of this study is to examine the changes in the politics of health policy which opened the door to women's health care as an important feature of health politics. Thus, my research is motivated by three questions: (1) How do women's health concerns get on the agenda? (2) Does positive feedback through legislative entrepreneurship and composition of Congress shift attention? (3) How has women's health care policy evolved over time? The results of this study not only contribute to the agenda setting literature but also have important implications for practitioners, professional organizations and associations, researchers, patients, and others who contribute to the policy community. 


\section{ACKNOWLEDGEMENTS}

Thank you to my committee for their patience, guidance, and willingness to see me through this process: Committee Chair, Dr. Jeff Worsham, Dr. John Kilwein, Dr. Matthew Jacobsmeier, Dr. Simon Haeder, and Dr. Chris Plein.

I am especially grateful to my family, dear friends, and colleagues who challenged me to stay to the course. 


\section{TABLE OF CONTENTS}

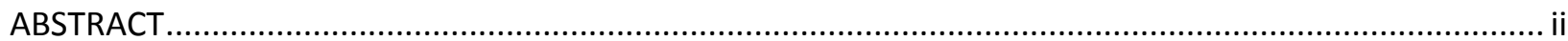

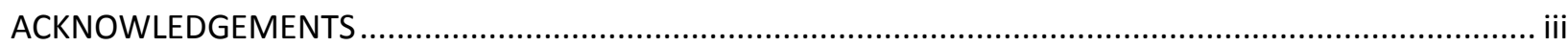

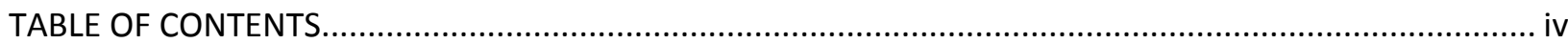

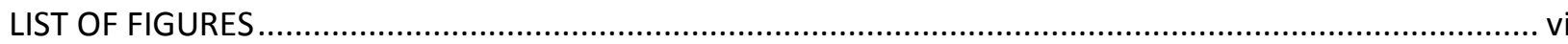

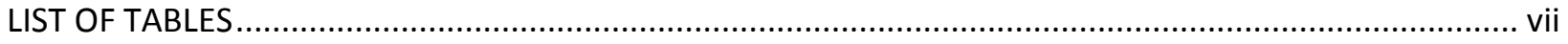

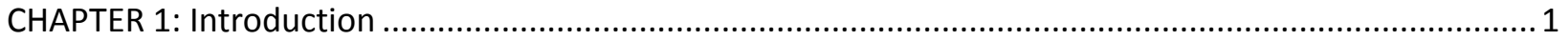

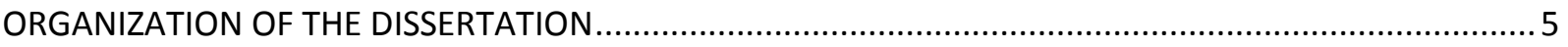

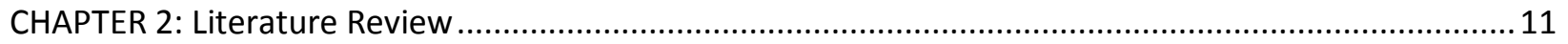

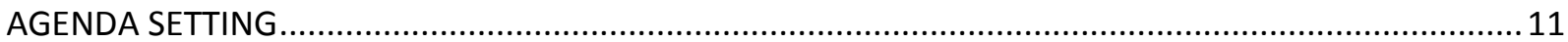

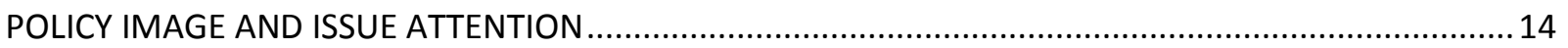

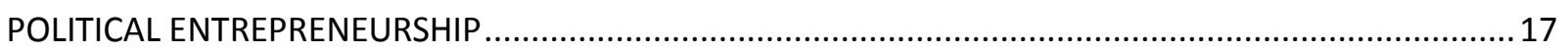

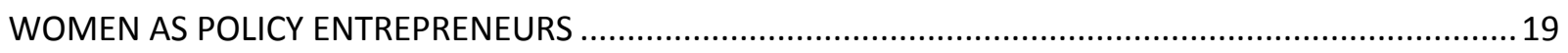

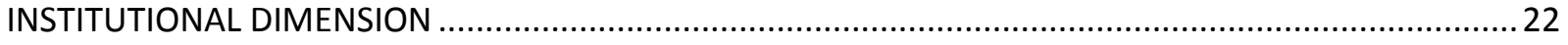

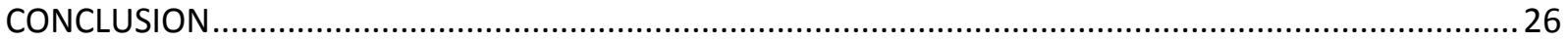

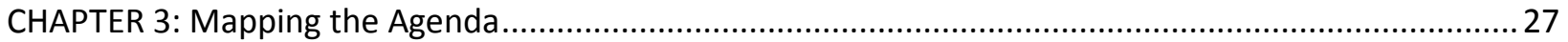

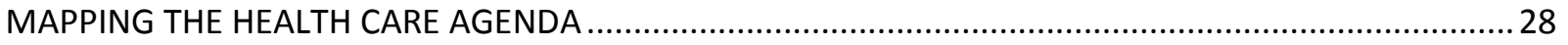

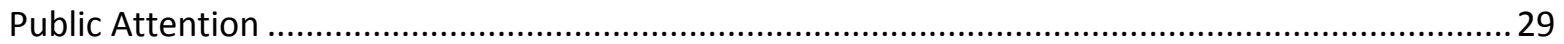

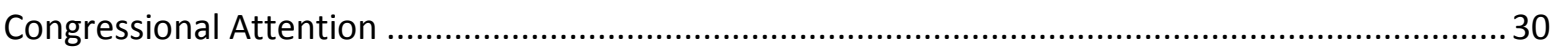

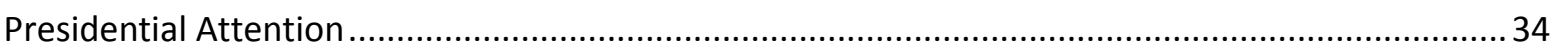

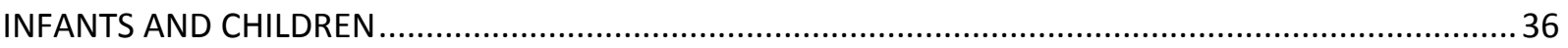

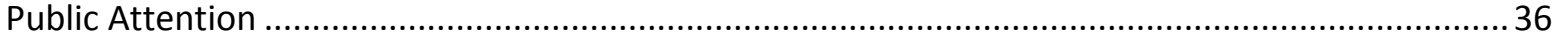

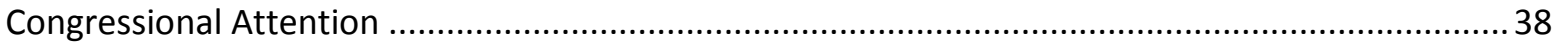

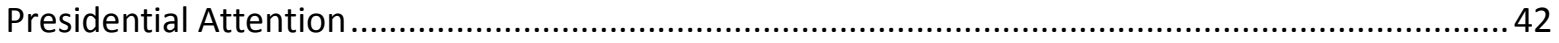

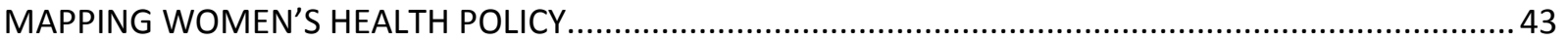

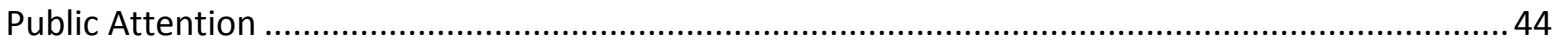

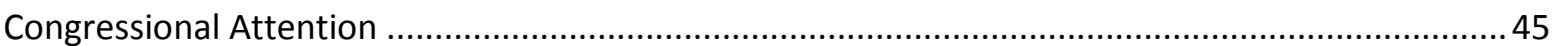

Central Themes Women's Health Bills Introduced ........................................................................ 48

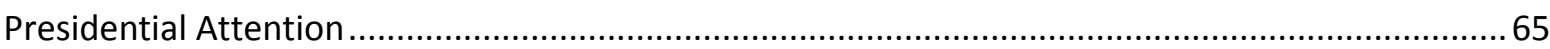

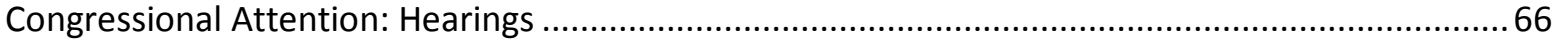

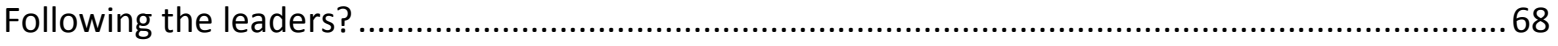


Congressional Attention: Legislation Passed …......................................................................... 70

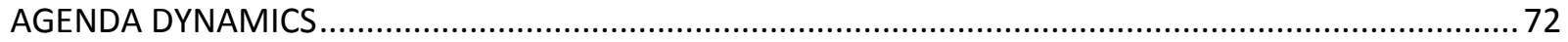

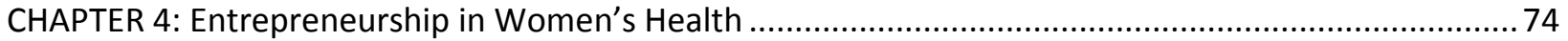

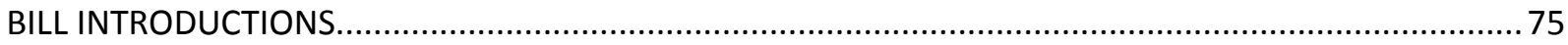

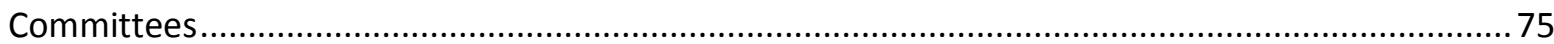

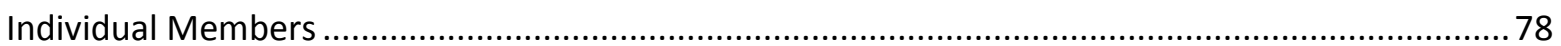

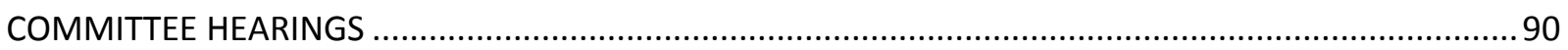

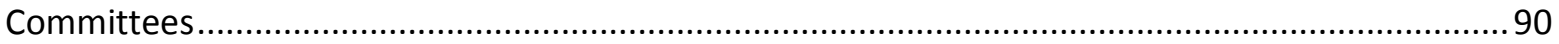

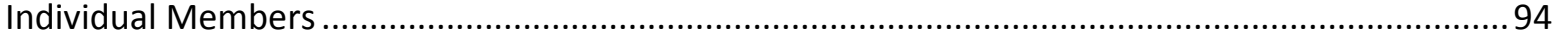

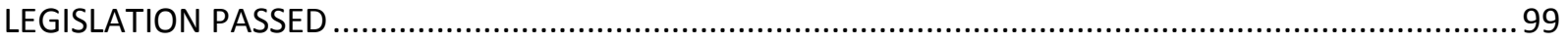

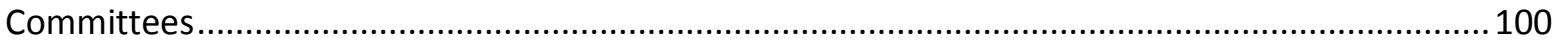

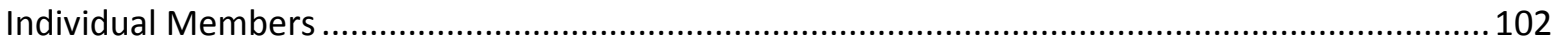

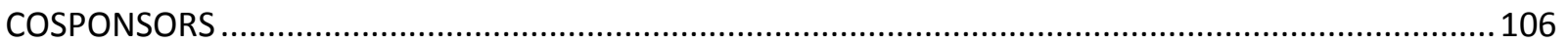

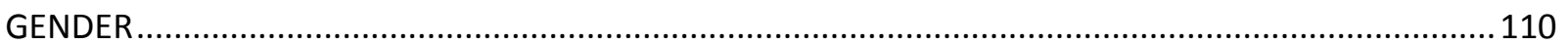

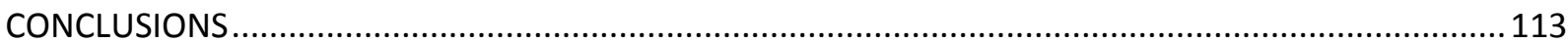

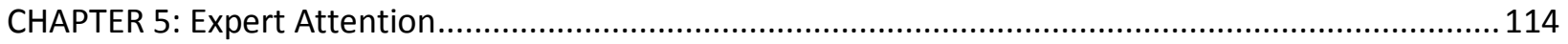

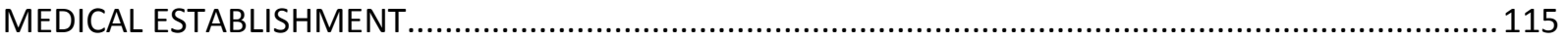

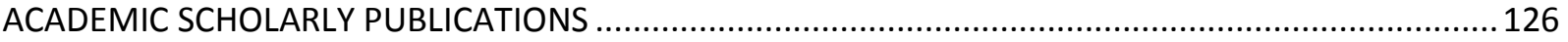

EXPERT ATTENTION AND CONGRESSIONAL ATTENTION .............................................................. 127

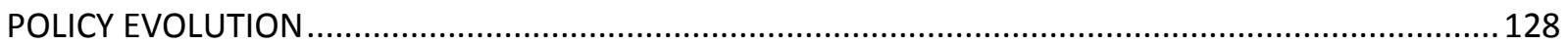

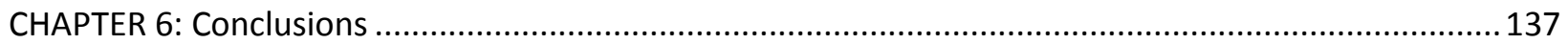

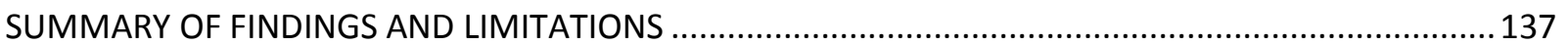

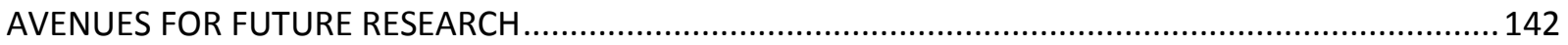

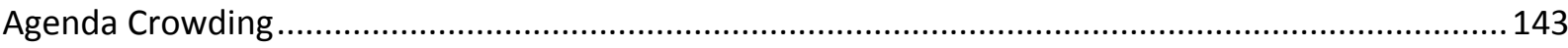

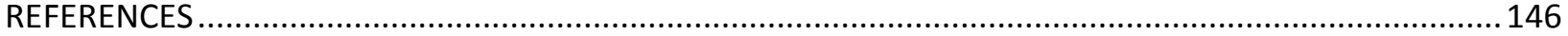

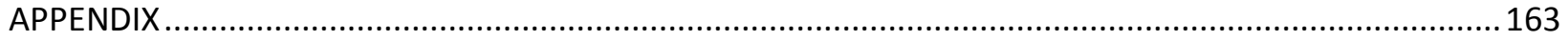




\section{LIST OF FIGURES}

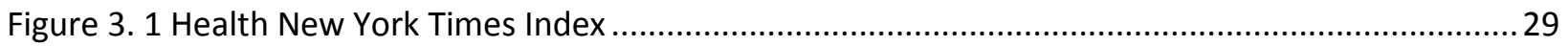

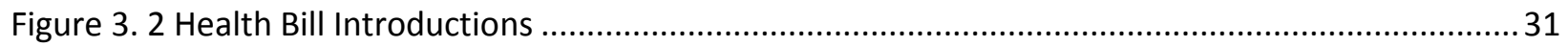

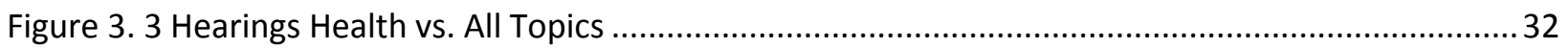

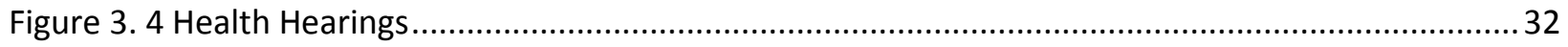

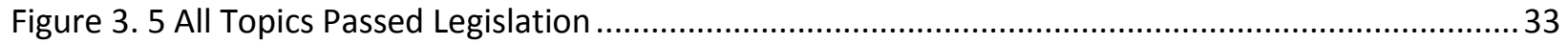

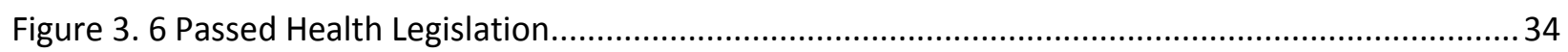

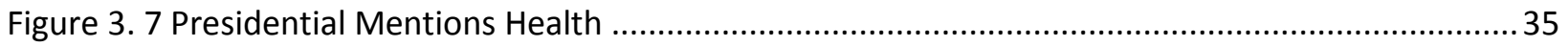

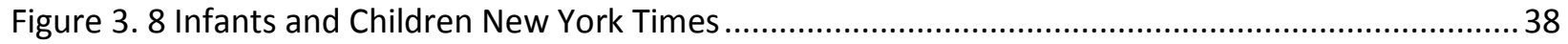

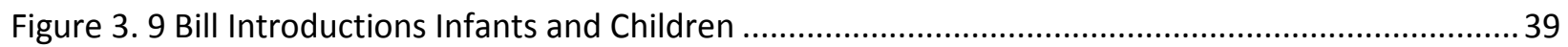

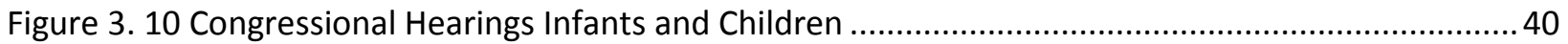

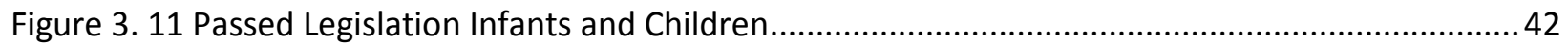

Figure 3. 12 Executive Orders Infants and Children vs. All Health...................................................... 43

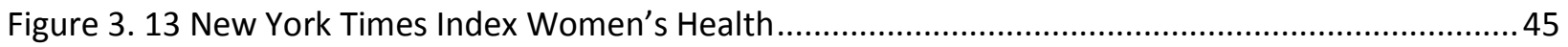

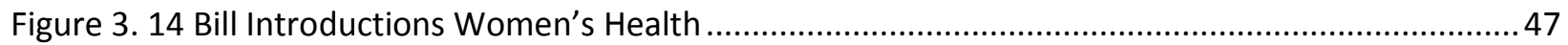

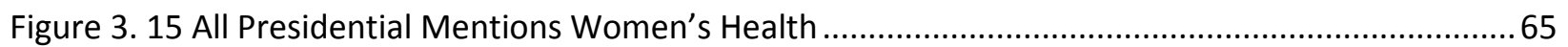

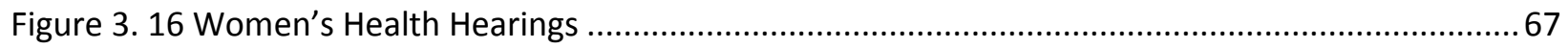

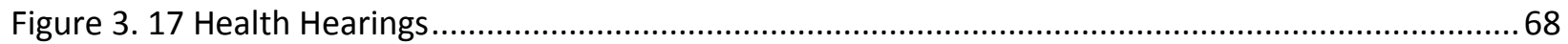

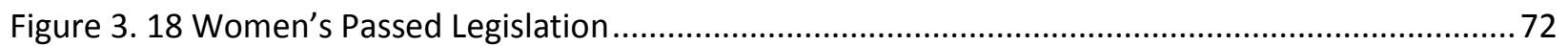

Figure 4. 1 House Committees Bills Referred 1973-2018 ….............................................................. 76

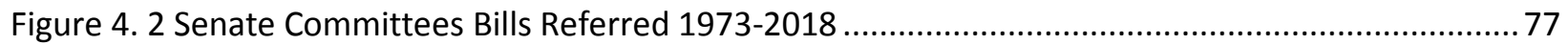

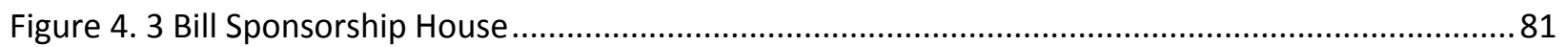

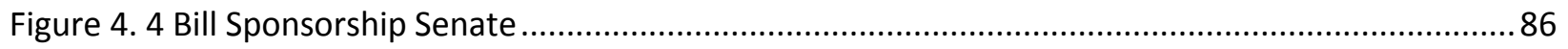

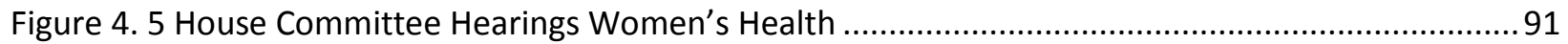

Figure 4. 6 Senate Committee Hearings Women's Health .................................................................. 93

Figure 4. 7 Laws Passed House Committees 1973-2018............................................................................. 100

Figure 4. 8 Laws Passed Senate Committees 1973-2018................................................................... 101

Figure 4. 10 Women's Health Bills Introduced/Women's Health Bills Passed Into Law........................109

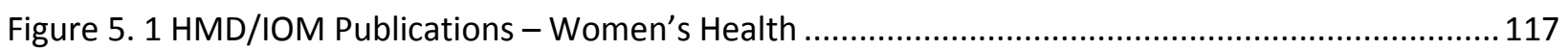

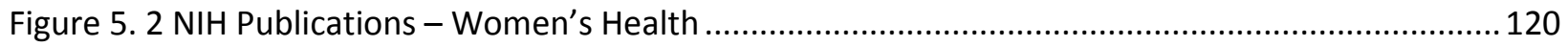

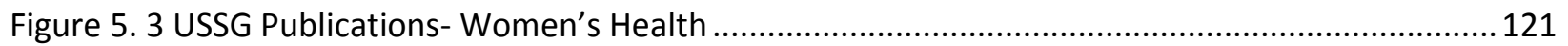

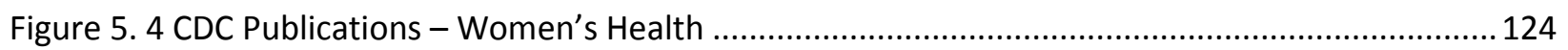

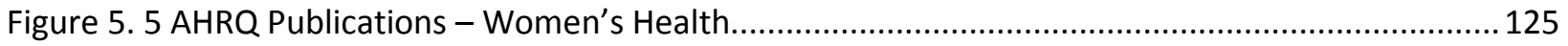

Figure 5. 6 PbuMed Publications - Women's Health ......................................................................... 127

Figure 5. 7 Who Pays Attention to Women's Health ............................................................................. 128 


\section{LIST OF TABLES}

Table 4. 1 House Bill Sponsorship and \% Sponsored of Total Bills Introduced in House............................82

Table 4. 2 Senate Bill Sponsorship and \% Sponsored of Total Bills Introduced in Senate .......................... 86

Table 4. 3 Top Bill Sponsors (House) Committee Assignments ............................................................ 88

Table 4. 4 Top Bill Sponsors (Senate) Committee Assignments ............................................................... 89

Table 4. 5 House Committee Hearings (Excluding Appropriations) .........................................................92

Table 4. 6 Senate Committee Hearings (Excluding Appropriations) ….................................................... 93

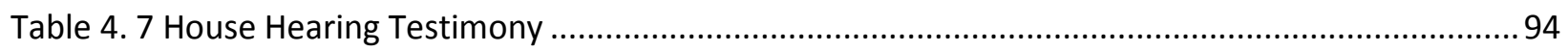

Table 4. 8 Senate Hearing Testimony ……................................................................................... 99

Table 4. 9 Laws Passed House Committees (Excluding Appropriations) …............................................. 101

Table 4. 10 Laws Passed from Senate Committees (Excluding Appropriations) .....................................102

Table 4. 11 Passed Legislation by Chamber per House Member (top tier) ........................................... 103

Table 4. 12 Passed Legislation by Chamber per Senate Member (top tier) ...........................................105

Table 4. 13 House Gender Distribution of Most Entrepreneurial Activity............................................. 110

Table 4. 14 Senate Gender Distribution of Most Entrepreneurial Activity ...........................................110

Table 4. 15 Proportion of Women by Chamber and Total Congress ..................................................... 111

Table 4. 16 House Gender Party Sponsorship................................................................................... 112

Table 4. 17 Senate Gender Party Sponsorship.............................................................................. 113

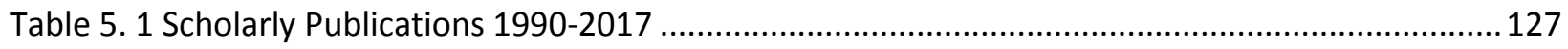




\section{CHAPTER 1: Introduction}

On June 18, 2019 women in Congress played against the women in media as part of the 11th annual Congressional Women's Softball Game. This annual bipartisan softball game is a powerful symbol for many of the key players in women's health care policy. The event brings together influential women focused on this common cause, and it benefits the Young Survival Coalition, an organization that raises money to address the unique needs of young adults affected by breast cancer. According to the Center for Disease Control (2019), breast cancer is the most common cancer in women and the second most common cause of death for women.

Congressional and public attention to breast cancer, however, extends beyond the playing field. In 2017 Congress passed key funding legislation (H.J. Res. 31) that required the Food and Drug Administration to include patient notification of breast density in the Mammography Quality Standards Act (first passed in 1992) regulations. Unfortunately, Nancy Cappello, PhD, who led the push for legislation to provide women with more information about breast density did not get to share in this victory. She founded the advocacy group Are you Dense? and was considered by many as the leader of a movement to educate women about breast density. Nancy Cappello died in November 2018 of complications from cancer treatment. These and other issues of women's health policy are of critical importance across the spectrum of health care providers, policymakers, and those impacted by its effects.

In order to study how women's health policy has developed and continues to evolve, I turn to the literature of agenda setting and issue attention. Much of the early research in public policy, or more specifically policy change, focuses on either periods of rapid change or relative 
stability. Baumgartner and Jones' $(1993 ; 1995 ; 2002)$ treatment combines both periods to integrate the nuances of positive feedback and negative feedback models, or rather the explanations for major disruptions in the policy landscape and the mechanisms to maintain stability. They also argue that the policy process itself can alter the performance of institutions.

This research focuses on shifts in issue attention in the policy process and its importance in deriving policy changes. Previous research in agenda setting demonstrates that effective definition (Rochefort \& Cobb 1994) of a policy problem creates opportunities for change across a policy area (Baumgartner \& Jones 1993; King 1997). Not only change in how the policy is defined but also in the narratives that tell the story of winners, losers, victors, and victims (Stone 1989). These "causal stories" can be used to further competition for a championed solution and expand the audience so that those previously uninvolved become interested (Schattschneider 1960; Stone 1989; Rochefort and Cobb, 1994). In this study, I propose an investigation of the long-term (post WWII) policy dynamics focused on the area of women's health care policy.

Women's health care was initially defined in the literature and understood by policymakers as a part of social welfare policy (Gordon 1990). As individual leaders and as group participants, women were influential in organizing and nationalizing movements for public health. In the late nineteenth and early twentieth centuries women who supported the general welfare movement advocated specifically for women's welfare (Sapiro 1990).

The secondary status of women ensured that there was little information about women (and children) as a separate class much before 1900. Even as individuals and institutions began to consider that the medical and welfare needs for women and children might require special 
consideration, information was intermittent and inconsistent historically. Initial concerns about the health and welfare of women and children grew out the hazards caused by forced proximity in urban centers at the turn of the twentieth century. Industrialization and labor demands brought women and children to the forefront of these concerns.

The creation of the Maternal and Child Health Bureau (MCHB) was one of the first federal efforts to address child mortality and the general welfare of children. Born out of concerns over endemic child labor and the dangers to the livelihoods of children in its initial organization in 1912, this association has grown in complexity and scope through time. The Social Security Act of 1935 and the advent of Title V ensured that the MCHB would serve to address the broad welfare concerns of women and children throughout the last century and beyond (Schuman 2017).

Similarly, in 1909, the White House held its first ever meeting related to the welfare of women and children titled: The White House Conference on the Care of Dependent Children. This conference led to the establishment of the Children's Bureau in 1912 which was charged with children's welfare matters including health, childcare, child labor, fostering and adoption, juvenile delinquency, neglect and abuse, among many other such related topics (The Children's Bureau 2018). The Children's Bureau has improved the lives of children since its inception by raising awareness, promoting best practices, and influencing policy on such critical issues as nutrition, hygiene, and health education. Additionally, the Children's Bureau contributed significantly to the surveillance of births (National Birth Registry), as well as promotion and cataloguing of maternal and infant and mortality and morbidity. The 1914 Pamphlet on Infant Care, a publication of the Children's Bureau, was created to advise parents about breastfeeding, 
nutrition, infant care, and the medical needs of children (Children's Bureau 2018). This pamphlet was adapted to reflect best care practices for over 50 years and distributed some 45 million times (Deavers and Kavanaugh 2010).

In 1921, the Sheppherd-Towner Act was passed by Congress as one of the first efforts to formalize best practices to promote maternal and infant health. This policy initiative grew directly out of the work of the Children's Bureau. It was the first major federal grant program related to health and was the first federally funded effort to ensure monies were available to promote maternal and child care welfare issues (Haeder and Weimer 2015). Further, over 3000 prenatal clinics were established through this program and its creation transformed access to antenatal care. It was one of the first acts of Congress that fully addressed women as a distinct group with distinct needs and tied health policy to motherhood making social protection a gender benefit. Federal funds were expressly intended to address dismal rates of maternal and infant mortality (Schlesinger 1967, 1034). For example, providing for professional instruction of expectant mothers in prenatal and infant care (Mink 1990).

The Social Security Act of 1935 and its amendments further expanded the federal government's role in health care (Haeder and Weimer 2015). During World War II, utilizing funds from the Maternal and Child Health Program through the Social Security Act, Congress authorized the Emergency Maternal Infant Care (EMIC) program. The goal of EMIC was to address the emergent, wartime needs for the infants and children of those married to servicepeople (men) who had been deployed. Sentiment in this nationalistic time prioritized the family as an "integral component of national security" (Tempkin 1999, 588). At the time of its inception, the EMIC program was considered the largest public health program ever 
undertaken in the United States. Before World War II, most bills introduced either ignored women as a class or focused on a narrow margin of their concerns. Over time, government has identified women's traditional activities as guardians of health and morals through their roles as wife and mother (Mink 1990).

Understanding of women's health care, however, has expanded to include health concerns for women beyond motherhood. The National Academy on Women's Health Medical Education defines women's health to include the screening, diagnosis, and management of conditions that are unique in women, more common in women, and are more serious in women (Charney, 2000). Though this definition is broad in its scope, it is particularly applicable for this general study of the comprehensive policy umbrella. Policymakers and practitioners are influenced by problems of coverage, access, and affordability of health care for women as evidenced by the 2017 Kaiser Women's Health Survey. This survey is a nationally representative survey of women ages 18 to 64 on their coverage, use, and access to health care services (Kaiser Women's Health Survey 2017).

\section{ORGANIZATION OF THE DISSERTATION}

The purpose of this study is to examine the changes in public policy in women's health care post World War II. My research is motivated by three questions: (1) How do women's health concerns get on the agenda? (2) Does positive feedback through legislative entrepreneurship and composition of Congress shift attention? (3) How has women's health care policy evolved over time? The results of this study not only contribute to the agenda setting literature but also have important implications for practitioners, professional 
organizations and associations, researchers, patients, and others who contribute to the policy community.

My dissertation is informed by three connected areas of scholarship. In chapter two, I highlight the broader context of agenda setting to illuminate how an issue is placed on the agenda and discuss the general features of issue attention. Also, I concentrate on political entrepreneurship as it relates to women's health policy. I use the findings from this literature to describe periods of increased activity and rapid change fueled by policymaker's behavior and their ability to shift attention. Finally, I focus on the composition of legislatures and the influence of women in Congress as legislative entrepreneurs.

The creation, manipulation, and transformation of public policy, however, is not limited to activity in Congress. Sometimes it is best understood through the nature of relationships between political institutions (Sheingate 2001). Women's health policy clearly originates in many other venues. The courts, executive, federal agencies, and states are all prominent actors. New policy proposals may be advanced through the legislature or entirely through bureaucratic channels and mechanisms. It is not always the case that Congress imposes meaningful restrictions on bureaucratic policymaking, as it leaves many blanks to be filled at the discretion of bureaucratic agencies (Moe 1994; Kettl 2000; Huber, Shipan, and Pfaler 2001; Volden 2002; Boehmke et. al 2005; Peters 2018). This is demonstrated through the use of tools ranging from sunshine laws to public notice and comment as part of administrative rulemaking, which allows citizens to interact directly with public agencies without politicians serving as policy mediators (Krause 2013). 
Although I am chiefly concerned with arenas for issue attention, it is equally important to note Congress' relevance in controlling the budget (Banks 1989; Bendor, Taylor, and Van Gaalen 2001). Congressional activity is necessary to authorize and fund programs and to set the expectations for intended outcomes. While acknowledging this means of control, it's not without consideration that each member of Congress has policies that he or she is primarily interested in and consequently attempts to expand through substantial appropriations (Ferejohn and Krehbiel 1987; Wehner (2010). The interaction of multiple institutions in the policy process impacts the roles that each play in policy making (Boehmke, Gailmard, \& Patty 2006).

Congress, however, is a powerful force in controlling and shaping the agenda over time (Baumgartner and Jones 1993; 2002). For my specific research interests, Congress is the appropriate venue considering the availability of analytical tools and resources and the rich literature supporting it. The Policy Agendas Project, in particular, allows researchers to investigate trends in policy making across time and between multiple indicators of attention. It classifies policy activities into a single, universal, and consistent coding scheme in over twenty major policy areas and nearly two hundred sub categories. The Policy Agendas Project uses a reliable and valid procedure for describing and tracking attention to the content of public policies as they change over time.

Baumgartner and Jones' Policy Agendas Project has been an important tool for evaluating issue attention in multiple venues, for various policy topics, and over a long period of time. Most would agree that the process of coding public, congressional, and presidential attention is not without error, and Baumgartner and Jones' tool is not without limitations. My 
work not only helps to expand understanding of women's health policy and bolster the available data, but I also carefully consider the study of issue attention to identify areas for more nuanced analysis.

Considering the policy dynamics of women's health care on the agenda, I first examine what proportion of the United States health debate is taken up by topics that deal with women. In chapter three, I map the women's health policy agenda using Baumgartner and Jones' (2002) Policy Agendas Project. In order to track issue attention for health, specifically women's health care, I begin with policy related to infants and children, which casts women as caregivers. The Policy Agendas Project data does not distinguish women's health as a discrete subtopic. I will supplement what is available in The Policy Agendas Project to create a fuller and more complete look at the area of women's health care. Using indicators outlined by the Kaiser Women's Health Survey as a guide, I collect data using "women's health" as a general search term. I trace public attention using ProQuest Historical digitized newspaper archives of The New York Times. Additionally, I collect data demonstrating congressional attention (bill introductions, bill referrals, committee hearings, and passed legislation) using ProQuest Congressional and Congress.gov. Finally, I track presidential attention using presidential papers through data available in The American Presidency Project. To further investigate the dynamics of the health care agenda, I compare The Agendas Project data for other subfields of health and the data I compile on women's health care. Given that the congressional agenda has a limited capacity, I describe how much room there is (and isn't) for women's health issues.

However, describing the agenda is important not only for understanding congressional behavior in general but also for understanding the institutional context of other political 
behavior. I specifically focus on the processes of positive feedback among elites to explain periods of dramatic policy changes observed over a long period of time. Positive feedback has been characterized as conflict expansion, mobilization of enthusiasm, and punctuated equilibrium (Schattschneider 1960; Downs 1972; Cobb \& Elder 1972; Baumgartner \& Jones 1993; Kingdon 1995). Past research indicates that positive feedback processes often arise when issues are redefined, when institutional arrangements are transformed, and when policymakers recognize that other policymakers may be looking at old issues in new ways (Baumgartner \& Jones 2002).

To expand this discussion, chapter four focuses on indicators of legislative entrepreneurship in the area of women's health care policy and specifically examines whether entrepreneurial activity and gender distribution matter. Entrepreneurship can occur at the committee level as well as the individual level, so I consider both the behavior of congressional committees and individual members. I analyze entrepreneurial activity in three stages including the following: committee referrals and bill sponsorship, congressional hearings and testimony, and passed legislation.

Congressional scholars also consider "who" holds office, descriptive representation, and whether it affects the types of policies supported (Pitkin 1967; Childs \& Krook 2009; Swers 2013). From subsystem politics, we know that as the cast of characters changes, so do the policy dynamics (Baumgartner \& Jones 2002; King 1997; Worsham 1998). As such, I also study what role gender plays, if any.

In chapter five, I construct a qualitative meta-analysis tracing the evolution of the women's health care policy. I focus on the discussion in Congress detailing shifts in policy image 
and issue definition using CQ Weekly Reports (CQ Magazine) as an indicator. In order to gauge the overall picture of women's health care policy, I also include the influence of outside actors (Cobb, Ross, and Ross 1976; Kingdon and Thurber 1984; Rochetfort and Cobb, 1994) and focus on expert and technical media (Walker 1977). I specifically track the attention of the medical establishment and academic and scholarly publications as an indicator of attention in women's health policy. I identify key players in women's health policy who produce publications as a measure of expert media attention, professional and scholarly contributions, and agency activity. I track attention in the professional and expert community from 1945-2018.

The final chapter discusses key findings from the research and summarizes the overall study. I also offer a discussion the future research that I consider as a result. Ultimately, my work examines how women's health care became an important facet of health policy and continues to evolve today. The research builds on the work of Baumgartner and Jones' (2005; 2013) Policy Agendas Project, creating a more defined picture of health policy by including women's health care. Tracking entrepreneurship and exploring elements of gender in Congress is especially important as the number of female legislators is increasing. As is the case with any complex policy environment, the explanation of women's health policy is most fully understood in context of its history. 


\section{CHAPTER 2: Literature Review}

My dissertation is informed by three connected areas of scholarship. First, the larger context of agenda setting helps to answer how an issue is placed on the agenda and the nature of issue attention. Next, I focus on periods of increased activity and rapid change fueled by policymakers' behavior and their ability to shift attention, described as entrepreneurship. Finally, I focus on the composition of legislatures and the influence of women and legislative entrepreneurs.

\section{AGENDA SETTING}

Roger Cobb, Jeannie Keith-Ross and Marc Howard Ross (1976) describe agenda building as "the process by which demands of various groups in the population are translated into items vying for serious attention of public officials" (p. 126). They recognize that there are multiple avenues for political leaders and the general public to become aware of and participate in political issues. The literature in agenda setting demonstrates that there are multiple venues by which political actors and the public become aware of policies.

Similarly, limited agenda space often means that one dimension or single issue will dominate the public agenda indefinitely (Kingdon 1995; Baumgartner and Jones 2002). Agenda entrance is often a matter of which policy makers are raising awareness of the issue and how long it can hold that attention (Hunt, 2002). The question is then, why do some problems occupy an official's attention rather than others?

Policy formulation often occurs through a policy community, sometimes referred to as a subsystem, of specialists including lawmakers, bureaucrats, academics, interest groups, and specialized media who generate proposals to address a policy problem (Walker 1977; Worhsam 
1998; Workman \& Shafran 2015). Likewise, problems become salient when they attract the right attention, often as a result of the convergence of what Kingdon $(1984,1995)$ terms multiple streams (policy, political, and problem). This convergence described as a policy window, or an opportunity for asserting proposals when conditions are appropriate for raising an issue on the agenda (Kingdon 1995). Windows are opened for only a short time, and they can open and close in the agenda setting cycle. Some solutions are selected while others are not. Selection could be based on technical feasibility, congruence with the values of community members, and anticipation of future constraints (Kingdon 1995).

The politics stream, sensitive to swings in national mood, public opinion, changes in administration or control of Congress, is determined by the nature of its participants and the availability of "choice opportunities" (Cohen, March, and Olsen 1972). Changes in each stream occur largely independent of one another, so political environment and timing can impact whether or not an issue enters the agenda. The streams are constrained further by costs of attention, which can move items higher or lower on the agenda. The problem stream relies on institutions such as the media to recognize problems based upon feedback or, in some cases, critical events.

When the three streams converge solutions are paired, or "coupled," with problems. These additions and omissions to the agenda generate periods with the most change, sometimes through the help of outside actors. Not all issues make the agenda, as individual actors and groups often work to keep topics from being addressed through the policy process (Cobb and Ross 1997). Agenda denial, or "the political process by which issues that one would 
expect to get meaningful consideration from the political institution in a society fail to get taken seriously" (Cobb and Elder 1997, xi).

Cobb, Ross, and Ross (1976) categorize these interests as groups outside the sphere of government that communicate a problem, block solutions, expand public support, or seek the support of political leaders in order to help place an issue on the formal agenda for consideration. They recognize the multiple avenues for political leaders and the general public to become aware of and participate in political issues. These issues can be separated into two parts: issues of high public interest and visibility are known as the "public agenda" and the list of items that political leaders have formally accepted for serious decision-making comprise the “formal agenda" (Cobb et. al 1976, p. 126).

Cobb, Ross, and Ross (1976) identified three modes for setting the agenda. In the "outside initiative model" issues arise on the public agenda and then move onto the government agenda, usually as a result of the efforts of organized interests. In the "mobilization model" issues are initiated by policymakers who try to expand them to the larger public to gain support for their policy solution. Lastly, in the "inside initiative model" issues are elevated to the agenda, often without public feedback. In an attempt to reduce participation of the general public and gain ready access to the formal agenda, a group or an agency, may work closely with the government, introducing policy to a small group of legislators (Cobb et. al 1976, p. 126). Issues are prioritized strategically to widen the scope of conflict or to include more than just the initial participants (Schattschneider 1960; Nowlin 2016).

Walker (1977) also concludes that outside attention can influence a policy network and specifically notes the importance of the expert and technical media. According to Walker 
(1977), those directly involved in the policy area are often best organized in order to shape and influence congressional behavior. He notes that agencies, professional groups, and clients exercise a compelling claim on the attention of key members who attempt to control and oversee legislation.

At times, however, policymakers may be forced to focus on one dimension they had previously ignored because of a crisis or because of the behavior of other policymakers (Birkland 1998; Baumgartner \& Jones 2002; Birkland 2017). Swers (2005) notes that changes in the exogenous political environment often alter the legislative priorities of members of Congress. Nevertheless, new policy alternatives gain momentum when preferences begin to change or attentions shift (MacLeod 2002). Shifts in attention for policy decision makers can lead to volatile and disruptive changes in policy (Baumgartner \& Jones 1993). Baumgartner and Jones $(1993 ; 2002 ; 2005 ; 2009)$ categorize these periods of rapid change through the process of positive feedback. These mechanisms include escalating behaviors that heighten rather than stabilize a trend. Research indicates that positive feedback processes often arise when issues are redefined, when institutional arrangements are transformed, and when policymakers recognize that other policymakers may be looking at old issues in new ways (Baumgartner \& Jones 2002).

\section{POLICY IMAGE AND ISSUE ATTENTION}

Given my attention to women's health care in particular, it is important to consider how a policy image evolves. Hunt (2002) points out, "policy issues are inherently multi-dimensional" (p.73). In order to study agenda setting for women's health care, I turn to Baumgartner and Jones (2002). Rather than review the policy trajectory for a single institution, they examine how 
various institutions shift their attention throughout the policy realm. Further, it is clear in any policy area, the dominant public policy image is often one-dimensional, while the underlying issues of concern are multi-dimensional (Baumgartner \& Jones 2002; MacLeod 2002; Kingdon 1984; Nelson 2016). The policy image, therefore, can be defined as the contributing set of ideas shaping how policymakers depict and debate a policy (Baumgartner \& Jones 2002).

Considering the policy image in a complex policy area requires not only understanding what is important but also who creates its importance. Issue attention and agenda entrance are only one part of the policy process. Issue framing focuses on how particular frames, or how issues are explained and identified, come to control the policy discussion (Plein 1991). Metaphors, symbols, and "causal stories" can be used to widen the scope of the policy area so that political actors previously uninvolved become interested (Schattschneider 1960, Cobb and Ross 1997, Rochefort and Cobb 1994; Stone 1989; Jones \& Mortensen 2018). In her study of the political nature of public policy choices, Stone (1997) noted that, "problem definition is a matter of representation because the description of a situation is a portrayal from only one many points" (p. 133). Individuals actors, issue groups, and government agencies will portray an issue strategically in order to promote the course of action they perceive to be most to their advantage. In turn, the process of issue redefinition enables a policy to attract the attention of new groups by expanding the conflict associated with a particular dimension, narrative, or question (Stone, 1989).

In particular, media attention can encourage or contribute to shifts in attention, positive feedback, and large-scale policy change (Wolfe 2012; Nelson 2016). In measuring attention in the agenda setting process, tracking press coverage offers a measure of salience as well. Using 
the New York Times offers a way to track public attention, and tracking attention in professional journals offers an indicator of expert attention (Baumgartner \& Jones 2009; Wolfe 2012).

Recognizing that shifts in attention and agenda entrance are only a part of the policy process, those who study framing are interested in how particular frames or explanations for some phenomena come to dominate the debate. Cobb and Elder (1972) describe a connection between agenda setting, or inclusion in the list of issues that demand attention of a governmental entity, and issue expansion, or the number of people mobilized around an issue. As we know from the cannon in agenda setting literature, the government agenda is comprised of issues of concern to policymakers and is often derived from the public agenda (Baumgartner \& Jones 2005; Kingdon and Thurber 1994). Members of Congress are highly motivated by reelection (Mayhew 1974) and creating good public policy (Arnold 1990; Fenno 1973; Hall 1996). Baumgartner and Jones $(2002 ; 2005)$ note that one key to the policy process is the way that issues are defined and debated because issue definition will determine the groups that receive policy benefits.

Schneider and Ingram (1993), focus on the importance of social constructs for target populations, or the popular images of the person whose well-being and behavior are affected by public policy. The constructs become embedded in policy and are transferred through modes of socialization. Ultimately, those who have the power to frame an issue often determine whether it is considered a public or private concern (Schneider and Ingram 1993). This seems particularly applicable in the case of women's health policy as questions of motherhood, public and domestic spheres of work, and androcentric research practices helps 
to explain shifts in the policy image and low allocation of benefits provided to this population in early legislation.

\section{POLITICAL ENTREPRENEURSHIP}

Political entrepreneurship can encompass a variety of activities, (Schneider, Teske and Mintrom 1995; 2000; Miroff 2003), originate in multiple venues (Wawro 2000; Sheingate 2003), and lead to rapid policy change (Mintrom and Norman 2009). According to Sheingate (2003), "entrepreneurs are individuals whose creative acts have transformative effects on politics, policies, or institutions" (p. 185). This idea of political entrepreneurship is recognized across the discipline in various forms with relation to Congress, the executive, policy innovation, and collective action. Pioneering the use of the term, Kingdon (1984) distinguished that policy entrepreneurs "could be in or out of government, in elected or appointed positions, in interest groups or research organizations. But their defining characteristic, much as in the case of a business entrepreneur, is their willingness to invest their resources-time, energy, reputation, and in some cases money- in the hopes of a future return" (p. 122).

For Sheingate (2003), however, the general understanding of political entrepreneurship focuses more on the interactions between institutions than the rules that exist within them. Considering these complex relationships, policy innovations, and institutional changes can help us draw conclusions about the facets of the institutions that enable or prevent political entrepreneurship (Sheingate, 2003).

In addition to the institutional environment ripe for entrepreneurship is the shared qualities of political entrepreneurs. Schneider et al. (1995) note that entrepreneurs, both public 
and private actors, perform three general functions: discover unfulfilled needs, bear the "risk" whether it be emotional, personal, or financial, and the coordination of network of resources. Entrepreneurs share the ability to perceive opportunities for political and policy change, and ultimately, they are embedded in the system they are seeking to alter (Schneider et al. 1995; Woon 2008).

Sheingate (2003) describes the more general understanding of political entrepreneurship, and Scheinder et al. (1995) make the distinction between public and private entrepreneurs. Legislative entrepreneurship, on the other hand, "is a set of activities that a legislator engages in, which involves working to form coalitions of other members for the purpose of passing legislation" (Wawro 2000, p. 5). Legislative entrepreneurs, issue owners (Petroick 1996), policy advocates (Kingdon 1984), and coalition leaders (Arnold 1990) invest time, staff, and other resources to gain expertise in a policy area. Wawro's concept of the legislative entrepreneur, like Arnold's (1990) concept of the coalition leader, outlines the process by which policymakers "design policy proposals and selective strategies for enacting them" (5). In Congress, this is characterized by four key activities: acquiring information, bill drafting, coalition building, and pushing legislation (Price 1989; Wawro 2000; Binder, Lee, Mansbridge, \& Martin 2016).

It is important to note that entrepreneurship in legislatures is a unique example of political entrepreneurship because lawmakers have the advantage of resources and access to the policymaking process, but they are burdened by the pressures of reelection. As a result, members sometimes seek to mobilize support through entrepreneurial activity on issues that are particularly important to their constituents (Price 1989). Similarly, the increased attention 
that members obtain through legislative entrepreneurship may enable them to attract voters who might not otherwise support them (Wawro 2000). The scarcity of time and agenda space often means that no single issue can dominate the public agenda indefinitely and further indicates that the policy choices members of congress make are telling (Kingdon 1984; Baumgartner \& Jones; 1993).

Members of Congress build their portfolio by capitalizing on opportunities afforded by committee assignments, institutional context, and shifts in attention (Miler 2017). A member's choice of bill sponsorship is a strong indicator of which issues he or she wants to be associated with and the reputation he or she wants to acquire among colleagues (Schiller 1995). Bill sponsorship and the subsequent fate of the proposed legislation has been used as an indicator of legislative activity and success through the literature (Matthews 1960; Frantzich 1979; Wawro 2000 Anderson et al. 2003; Cox \& Terry 2008; Binder et. al 2016). However, these measures have evolved beyond the simplistic inspection of roll call votes and bill sponsorship. Similar to other comprehensive measures, Volden and Wiseman $(2012 ; 2014)$ have developed a metric of legislative effectiveness that they designate as a Legislative Effectiveness Score (LES). More succinctly, not only is a member's attachment to a proposed bill important, but also the subsequent legislative activity. Volden and Wiseman $(2012 ; 2014)$ track how successfully members move legislative agenda items through the major stages in the legislative process, telling any even greater part of the policy story.

\section{WOMEN AS POLICY ENTREPRENEURS}

The very first woman elected to Congress was Representative Jeanette Rankin (R-MO) who initially served from 1917 to 1919. She also served in the 77th Congress from 1941 to 1943 
and was a noted suffragist and women's rights advocate. The first woman to serve in the Senate Was Rebecca Latimer Felton (D-GA) in 1922; she was appointed and served for only one day. From these humble beginnings, it is hard to imagine the most heavily female Congress of all time as sworn into service on January 3, 2019 (CAWP). The past thirty years in Congress has seen the largest spike in-service of women in congress, and the largest gains have been among Democratic representatives and senators (Bump, The Washington Post, January 3, 2019). However, there have been some smaller spikes of Republican women as was the case in previous election cycles. And for all the progress that has been made, including increased racial, ethnic, and religious diversity, this historically female Congress is notably still more than $75 \%$ male (CAWP).

Although women are experiencing increased electoral success, the United States has yet to elect a woman president, and the percentage of women serving in Congress is about $20 \%$ of the 535 members (CAWP). However, in congressional behavior studies defining women's interests "as women" separate from their partisan ideology is complex. Past research shows that Democratic candidates, male or female, are more likely to support liberal policies that appeal to women (Dodson 1998; Swers 2002; Childs \& Krook 2009). Despite this complexity, the progression of current research demonstrates that women do have an impact on politics. Initially, this was characterized by how gender identification shapes representation (Pitken 1967; Swers 1998; 2001; Dolan 2008; Huddy, Cassese, and Lizotte 2008).

We know that political participation is determined in part by gender socialization, which shapes women's political interest, knowledge, and ambition (Paxton, Kunovich, and Hughes, 2007). In short, constituents are more likely to get involved when they see themselves in the 
political leaders in elected office (Mansbridge, 1999; Phillips, 1995). For women, this means that as the number of female officeholders increase, so does the legitimacy of the legislature as perceived by women (Schwindt-Bayer and Mishler, 2005). As a result, women in elected office actively seek to represent the needs of women in their districts, as well as women in general. Vega and Firestone (1995) studied behavior in the form of roll call voting and bill introduction between 1981 and 1992. They find that in Congress women sponsor and cosponsor more feminist legislation and bills related to women's traditional role as caregiver than men. Often, women feel compelled to pursue feminist initiatives and legislation, as well as legislation traditionally coined as women's issues including education, health, and welfare (Angevine 2017).

As such, it is reasonable to assume that the characteristics of political parties are important to women. Democrats are generally more egalitarian and more likely to promote traditionally underrepresented groups such as women (Matland 1993). Women in the United States have been more successful achieving power in the Democratic Party than in the Republican Party. When women have the opportunity to frame debates, they tend to speak on behalf of marginalized constituencies more than men, as well as speak to their experiences in ways only women can, thus effectively expanding the debate (Cramer Walsh 2002).

Though Swers $(2013 ; 2016)$ reports some influence of gender as a predictor for women's issue bills, ideology remains a stronger predictor. However, a pattern does emerge among Republican women deviating from party lines and voting for women's issues more than their male Republican colleagues. In order to consider the combination of women's health care policy, issue attention, and legislative entrepreneurship, a discussion of legislative composition 
in regard to gender is essential. A critical facet of this literature is whether "who" holds office, descriptive representation, affects the types of policies passed, substantive representation (Pitkin 1967; Childs \& Krook 2009; Swers 2013).

Women may and may not be changing the culture of Congress. Conventional wisdom has long held that by increasing the number of women serving in Congress, the culture of bipartisanship will be encouraged. Gender expectations of female compromise perpetuate such notions. However, scholars find that the historic traditions of party loyalty are much more important in predicting the behavior of legislators (Lawless \& Theriault, 2016). Though the tendency of women to collaborate in professional environments is well documented in other fields, the role and pressures of party in Congress is too important to advancement, encouraging reelection, achieving desirable committee assignments, and more (Lawless, Therriault, \& Gunther 2018).

\section{INSTITUTIONAL DIMENSION}

Over the last half century, the role of the federal government has expanded to encompass more important policy decisions, and in turn, the practical demands on Congress have risen in number and intensity (Loomis and Schiller 2018). However, even before the policy explosion of the New Deal and the Great Society, there were many instances of intense, sophisticated, and frequently successful lobbying efforts by organized interests. For example, in the years immediately following World War I, the farm lobby, demonstrated its influence in terms of information and support (Polsby 2004). For dozens of legislators, who repaid the agricultural interest with increasing access to the process of lawmaking, the farm lobby would 
often work with farmers in legislator's home districts. The political and policy information that they provided gave members of Congress good reason to listen (Polsby 2004).

By the 1950s, however, committees served as the binding agent in cultivating close-knit relationships (Thurber 1991), also referred to as subsystems (Worsham 1998; Worsham and Stores 2012), or advocacy coalition frameworks (Sabatier and Jenkins-Smith 1999).

Congressional committees serve as anchors of policy subsystems and link key outside interests to particular agencies in bureaucracy (Workman 2015). For example, those involved with sugar interests worked with the appropriate agricultural committee and subcommittees in the House and Senate and US Department of Agriculture officials. This arrangement helped to maintain domestic sugar prices that were consistently higher than those in other markets around the world (Polsby 2004). However, by the 1960 s other various interests began to challenge the sugar subsystem. Consumer and environmental groups were chief among those interested. In 1974 , the sugar iron triangle broke apart and the subcommittee could not maintain control over price support policies (Polsby 2004).

While the power structures from the 1960 to 1980 s continued to evolve, so too did the political environment in Congress (Schiller and Loomis 2018). Bureaucracy consistently engaged with Congress in an effort to define policy problems (Baumgartner and Jones 1993; King 1997; Workman 2015). As such, both bureaucrats and organized interests permeated the policy process in varying degrees over time and across multiple dimensions (Workman 2015). Interest groups became politically active as more government policies prompted them to action. This period is marked by significant interest group proliferation was fueled by advances in technology and the civil rights movement among other reasons (Nownes and Neely 1996; 
Hrebenar and Scott 2015). The 1960s also saw an increase in new programs for targeted constituencies, such as women, the poor, and the elderly that changed the distribution of benefits. As a result, federal programs, budget deficits, and distributive politics have grown exceedingly (Schiller and Loomis 2018). Lawmakers seek to deliver concentrated benefits to their constituencies and the ceiling for government spending has become difficult to hold down.

Members of Congress favor a broad distribution of power within the chamber, as the committee system provides the membership disproportionate influence over jurisdiction specific policy and its agenda (Evans, 2013). This promotes the interest of individual members, but also increases the costs of collective action and the legislature's ability to compete with other institutions, mainly the president (Godwin and Llderton 2014). It was not until President George H.W. Bush raised taxes and President Clinton did the same, that deficit spending was managed (Polsby 2004). Budget rules since then require that tax cuts, as well as increases in entitlement and other mandatory spending, must be offset by tax increases or cuts in mandatory spending. Thus, creating a system of winners and losers for each decision, referred to as PAYGO (Schiller and Loomis 2018).

This restriction has made it difficult for Congress to respond to new issues as they arise, especially defense spending. The costs of fighting the war on terror have been particularly strenuous (Schiller and Loomis 2018). What has now resulted is a hostile relationship and a decline in trust between Congress, the president, and the public. There is often a disconnect between public approval for individual members in their districts and Congress as an institution 
(Evans 2013). Similarly, the growing partisanship in Congress has resulted in partisan control of the agenda.

Given the continuing budgetary constraints in creating new programs and institutional reluctance to eliminate old ones, members of Congress have invited public distrust and cynicism (Evans 2013). According to Schiller and Loomis (2018), ironically, when Congress does "rise to the occasion and act as a decisive policymaking body the normally skeptical and cynical public often embraces legislative action" (p. 11). For example, there was a significant increase in popular support after the September 11, 2001 terrorist attacks. However, voters are often suspicious of policies proposed by the opposite party, which was true in the case of the Affordable Care Act (2010). The legislation was passed unanimously along party lines and Republicans are still threating to repeal the act.

Congress is a majority-rule institution organized by parties and committees and since the founding, these ideals have prevailed even through constitutional amendments and reorganization (Shepsle and Weingast 1995). Congress has a deliberately slow approach to policy making built into the institutional rules and traditions of its processes. Similarly, the U.S. federal system purposefully makes widespread national change more difficult than a more centralized system. The features of our constitutionally prescribed separation of power are designed to prevent government from acting without carefully considering the outcomes and benefits of policy change (Robertson and Judd 1989). The contemporary congressional legislative process still appears broken and largely fragmented. As a result of huge deficits and extreme partisan polarization, the House and Senate typically fail to enact appropriations bills before the deadline. The agenda setting power of the committee is the right to halt or support 
proposals to change the status quo, or what Aldrich (1994) refers to as structure-induced equilibria (p 179). As such, committees are granted the power to kill legislation in their policy jurisdiction. Committees and subcommittees are organized by the majority party and help to shape the overall congressional agenda.

The political context of the institution is not only shaped by the preferences of individual members but also through the group characteristics of its membership. For example, in 1992 when a record number of women were elected to Congress. This period was marked by an expectation for attention to women's issues and a strong feminist agenda. Then just a few short year later in 1994, Republicans took control of Congress for the first time in forty years. These shifts in group characteristics are indicative of a group dynamic that alters the political environment and the policy context. While the institutional constraints (and sometime freedoms) of Congress help to shape the agenda, so does the makeup of induvial membership

\section{CONCLUSION}

Now having considered the literature of agenda setting, entrepreneurship, and the impact of gender in Congress, I will explore how the policy women's health care might be applied as a test case. The research builds on the work of Baumgartner and Jones' $(2005 ; 2013)$ The Policy Agendas Project, contributing a broader picture of health policy by including women's health care. In the following chapter I connect the literatures of issue attention, legislative entrepreneurship, and gender in Congress to map the health policy agenda and determine how attention to women's health care is altered. 


\section{CHAPTER 3: Mapping the Agenda}

Women's health care was initially defined in the literature and understood by policy makers as a part of social welfare policy (Gordon 1990). As individual leaders and as group participants, women were influential in organizing and nationalizing movements for public health, and in the late nineteenth and early twentieth centuries women who supported the general welfare movement also advocated specifically for women's welfare (Sapirio 1990). Before WWII, most bills introduced in Congress either ignored women as a class or focused on a narrow margin of their concerns. Government first established women's traditional activities as guardians of health and morals through their roles as wife and mother (Mink 1990).

Post WWII, however, the definition of women's health care has expanded to include health concerns for women beyond motherhood. The National Academy on Women's Health Medical Education defines women's health to include the screening, diagnosis, and management of conditions that are unique in women, more common in women, and more serious in women (Charney 2000). I purposely use this broad definition of women's health in order to capture the various facets of women's health policy across multiple measures. Cobb and Elder (1972) contend that issue expansion requires broad definition and Baumgartner and Jones agree that policy image is key in understanding punctuations in attention (1993). Attention shifts as particular actors focus on narrow dimensions of the policy and attention is altered.

This chapter focuses on how the issue of women's health gained space on the agenda. First, I map the health agenda using data available through The Policy Agendas Project, which allows me to illustrate how health care in general fits into the overall policy landscape. As 
women's health care was first defined through policy related to infants and children, I will then discuss The Policy Agendas Project data available for health specifically related to health care for infants and children. The final section of the chapter uses original research to track the entry of women's health on the health agenda.

The Policy Agendas Project is an archive of policymaking activity since 1946. Data is available across multiple subjects and is linked through a common policy topic coding system. For this study I use the available data for the United States including executive orders, New York Times index records, public laws, congressional bills, and congressional hearings. The Policy Agendas' data, however, does not distinguish women's health as a discrete subtopic. I supplement what is available in The Policy Agendas Project (https://www.comparativeagendas.net) to better understand the place of women's health care in relation to other health agenda items. Using "women's health issue" as a search term, I trace public attention through ProQuest Historical (https://www.proquest.com) digitized newspaper archives of the New York Times; map congressional attention by tracking bill introductions, committee hearings, and passed legislation through ProQuest Congressional (https://www.proquest.com) and Congress.gov; and track presidential attention using data available in The American Presidency Project (https://www.presidency.ucsb.edu).

\section{MAPPING THE HEALTH CARE AGENDA}

To begin, I am interested in what portion of the agenda is taken up by attention to health policy in general. I then map attention to infants and children health, a subset of health policy from the Policy Agendas' data. Finally, I supplement what is available in The Policy Agendas Project by developing a measure of attention to women's health care. 


\section{Public Attention}

As an indicator of public attention, I use data from the New York Times (NYT) index from The Policy Agendas Project to track mentions for health policy. ${ }^{1}$ Figure 3.1 indicates the number of mentions for news related to health policy generally. Attention to health is relatively stable from 1950 to the late 1960 s with upticks occurring in 1973, 1994, and the early 2000 s. The highest frequency of health mentions, 55, occurs in 2005 and the least, 9, in 1963. Attention to health policy mirrors the attention to all types of policy, which both generally increase over time and exhibit the same bumps in attention. For example, just as attention to health shows a dramatic increase in 1973 , so does attention to all policy issues. Though not an overwhelmingly dominant topic, health is still a policy consideration for the public ranging between $1.69 \%$ and $6.39 \%$ of all stories.

Figure 3. 1 Health New York Times Index

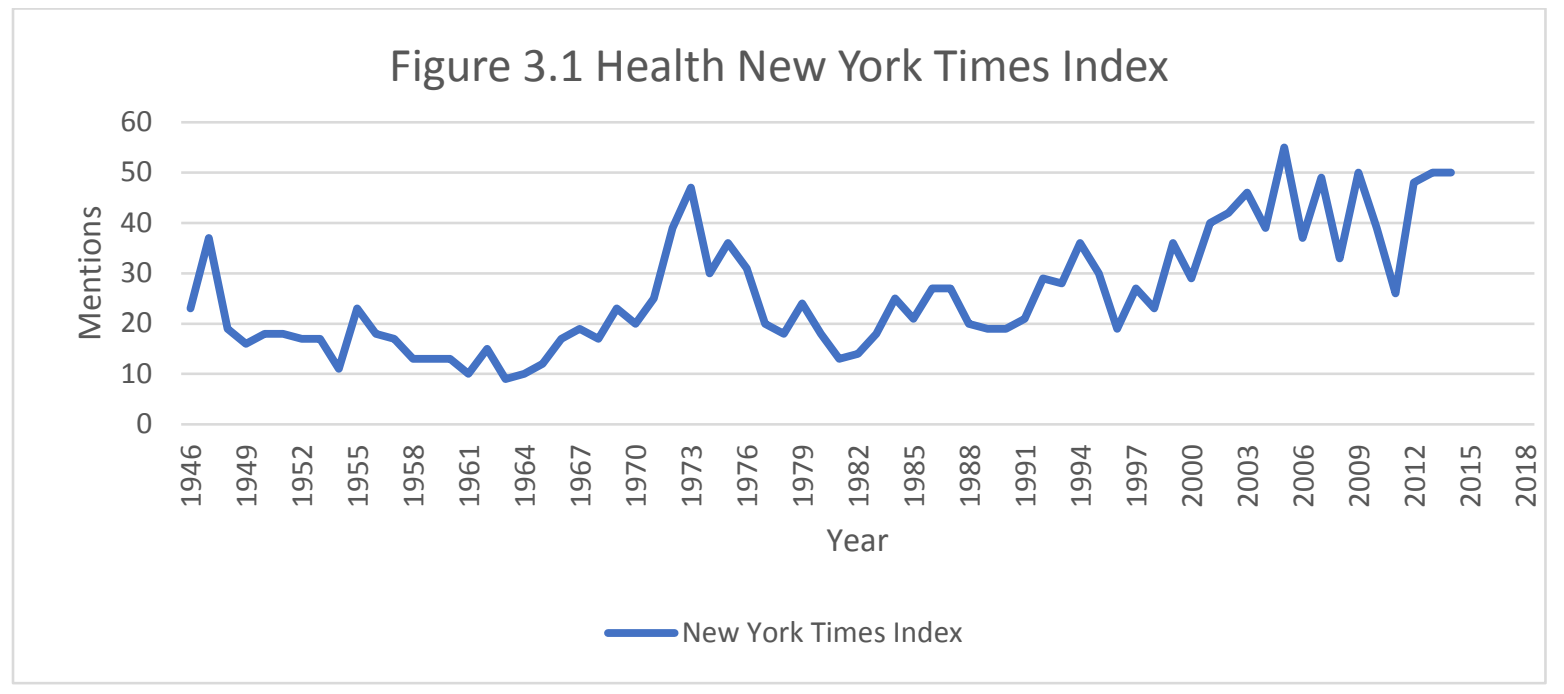

\footnotetext{
${ }^{1}$ The Policy Agendas Project dataset utilizes a systematic random sample of the New York Times Index. The sample includes the first entry on every odd-numbered page of the Index. Each entry is coded using the major topics identified across all datasets and includes other variables such as the length, date and location of the story and whether it addresses government actions. There are 54578 observations spanning the years 1946 to 2014.
} 


\section{Congressional Attention}

In order to get a feel for the place of health on the congressional agenda, I track bill introductions in the U.S. House of Representatives and Senate (Figure 3.2), using data coded through The Policy Agendas Project. The series peaks in the 1973 congressional session with bills introduced between both chambers representing roughly $7 \%$ of the 21,950 total bills introduced that year. Bill introductions for health policy follow a similar increasing and decreasing pattern that is observed for bill introductions for all topics, with one difference. There is a steady increase in such activity until 1965, when discussion of government sponsored health care was a regular topic on the agenda, culminating in the creation of Medicare and Medicaid in 1965 as amendments to the Social Security Act. The largest spike in the series occurs from 1967-1973, when the discussion of the rising costs of public health and the topic of abortion were particularly salient. The decline in attention in the 1975 congressional session is followed by a relatively stable continuation of the pattern through 1981 . However, the $104^{\text {th }}$ Congress (1995-1996) shows a more substantial decrease in the number of bills introduced after a slight bump in the 1989 congressional session. This period is followed by steady increase again with the largest peaks occurring in the 1999, 2007, and 2013 congressional sessions. House and Senate attention mirror one another with one exception. It appears there is a more dramatic rise in attention in the House between 1960-1979 than is the case in the Senate. As I consider other measures of attention and the agenda capacity for women's concerns, this will be an important issue. 
Figure 3. 2 Health Bill Introductions

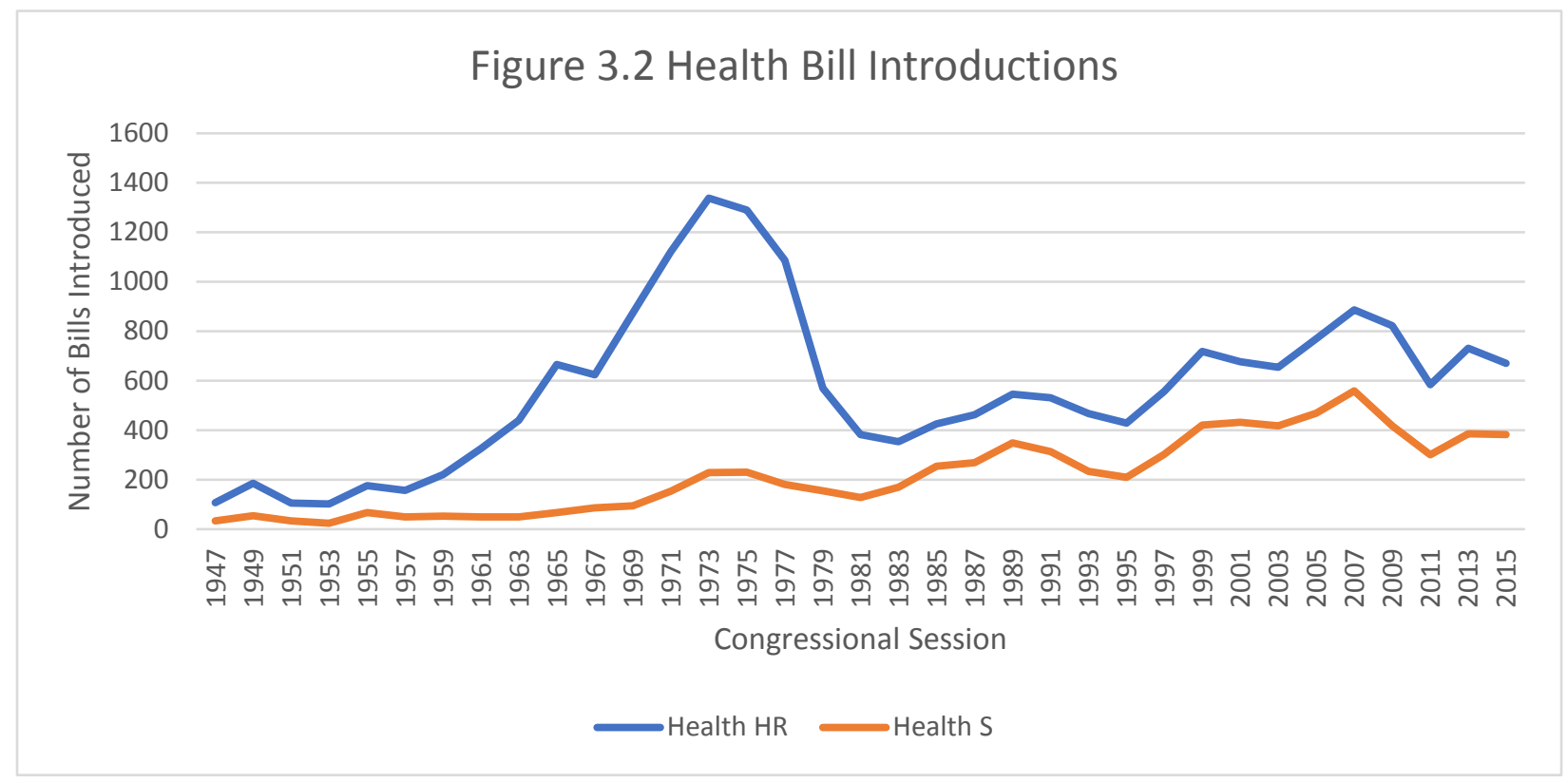

Bill introductions, however, only paint a portion of the activity on the congressional agenda. Congressional hearings fill out the portrait. Hearings have been used as an indicator of activity on the decision agenda (Cobb and Elder 1972; Kingdon 173; Walker 1977; Light 1982; Stores and Worsham 2012), as a measure of turf control (King 1997), and to get at formulation and adoption (Wilkerson et. al 2002). Using The Policy Agendas Project, I initially tracked all congressional hearing activity to get a feel for the variety of topics on the agenda and then focused on health related hearings to see how much agenda space was allotted to health concerns. The rise and fall in hearings mirror the pattern in legislative introductions. Figure 3.3 maps health policy hearings in relation to all hearings, while Figure 3.4 maps health hearings in each chamber as well as joint committee hearings. There are similar periods of increase and decline in all hearing activity and health hearing activity. Health-related hearings never exceed $10 \%$ of total hearings in a congressional session (Figure 3.3 ), ranging between $.86 \%$ and $9.6 \%$ of 
all hearings. Health hearing activity in both chambers picks up in the late 1970 s and continues to climb through the early 1990s with a sharp decline after 1993 (Figure 3.4). In terms of the level of attention, health as a subtopic is about in the middle of all the topics coded by the

\section{Agendas Project.}

Figure 3. 3 Hearings Health vs. All Topics

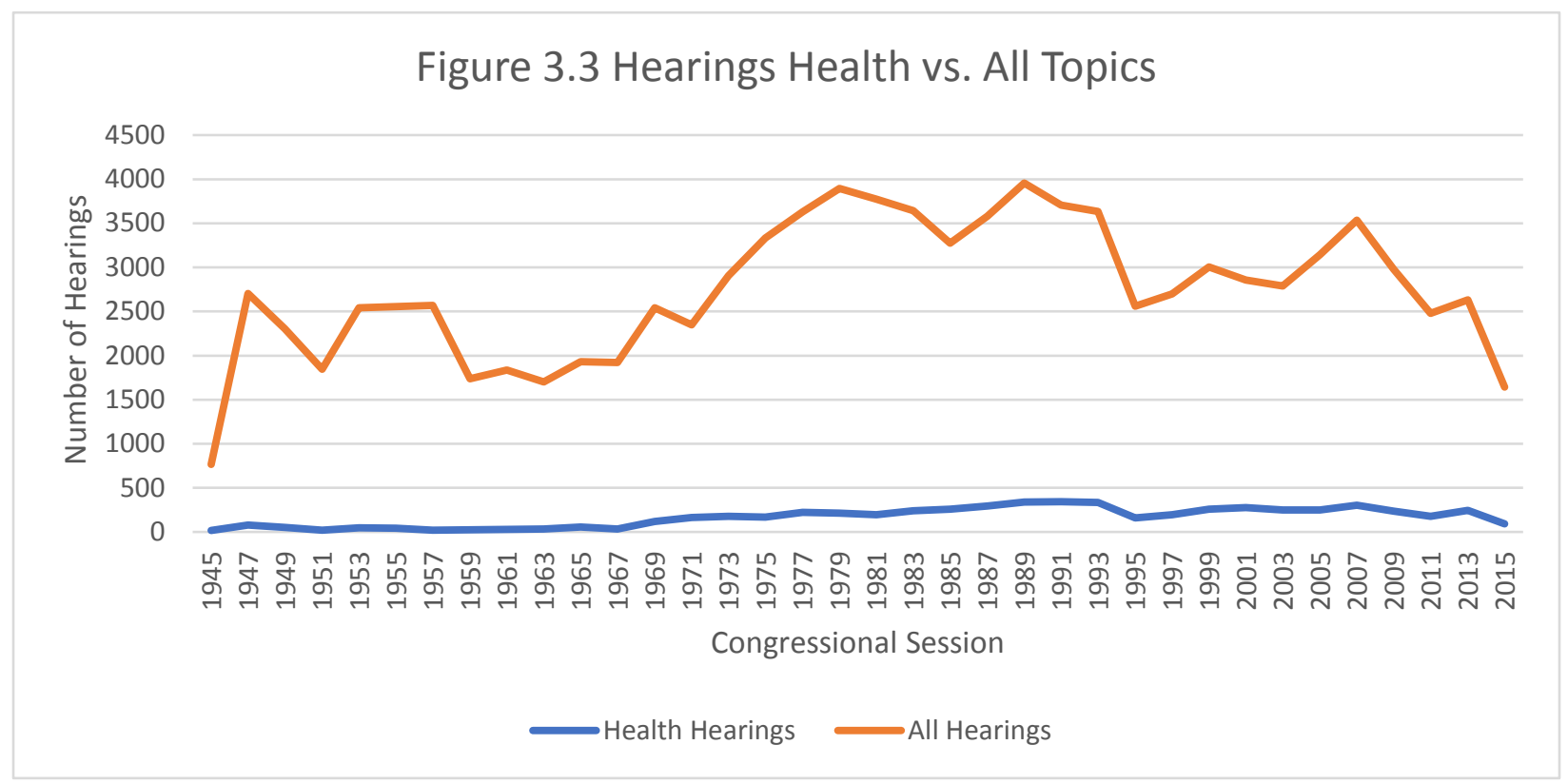

Figure 3. 4 Health Hearings

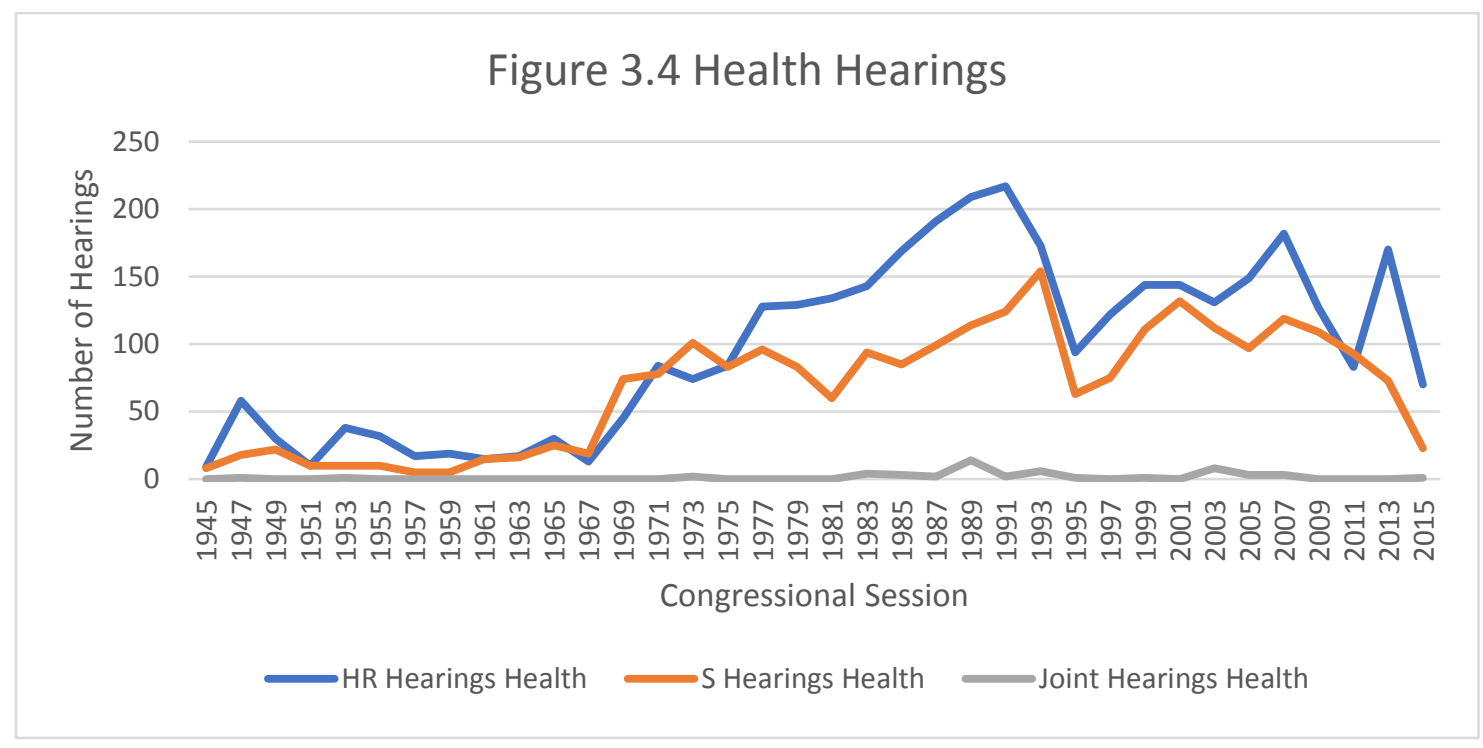


While bill introductions and hearings are indicators of congressional attention, legislation passed by Congress is perhaps the ultimate measure of attention. As was the case with bill introductions and hearing activity, I tracked both all legislation passed and health legislation passed (Figure 3.3 and Figure 3.4). Figure 3.5 indicates that the passage of legislation declines over time, leading some to conclude that it is getting harder to legislate (Binder and Lee 2013).

Figure 3. 5 All Topics Passed Legislation

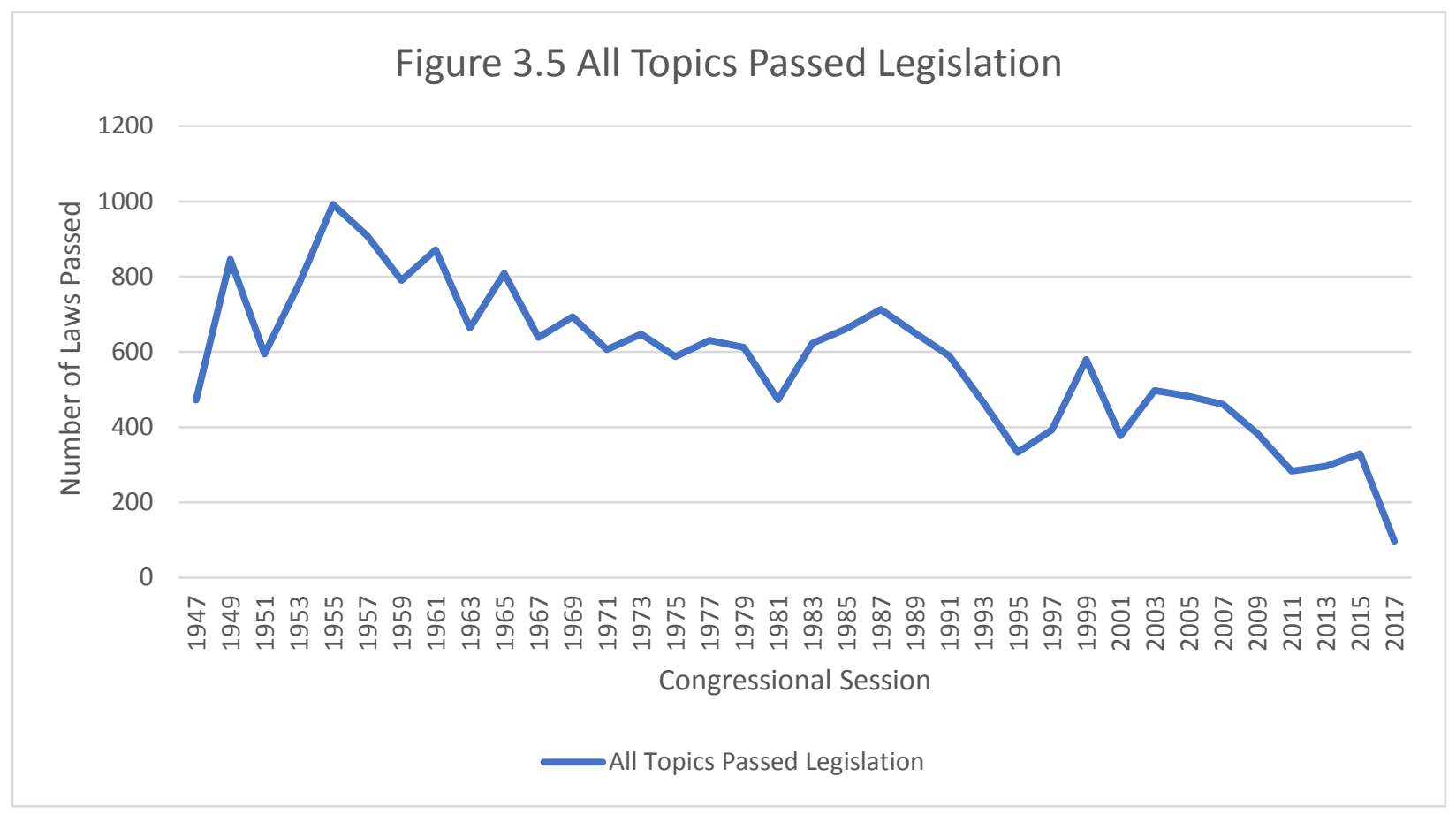

The passage of health policy legislation (Figure 3.6) does not seem to follow the pattern of overall decline. The series is fairly steady, punctuated by a flurry of activity between 1983 and 1991 when Congress grappled with the growing cost of health care. The drop-off in 2010, I would conjecture, is a result of the passage of the comprehensive health care reform bill, the Patient Protection and Affordable Care Act (2010). Overall, there is another period of increase from 2005-2009 and a small rise again in 2013. It should be noted that tracking the total 
number of bills passed obscures the importance of landmark legislation such as Medicare and Medicaid (1965) and the Affordable Care Act (2010).

Figure 3. 6 Passed Health Legislation

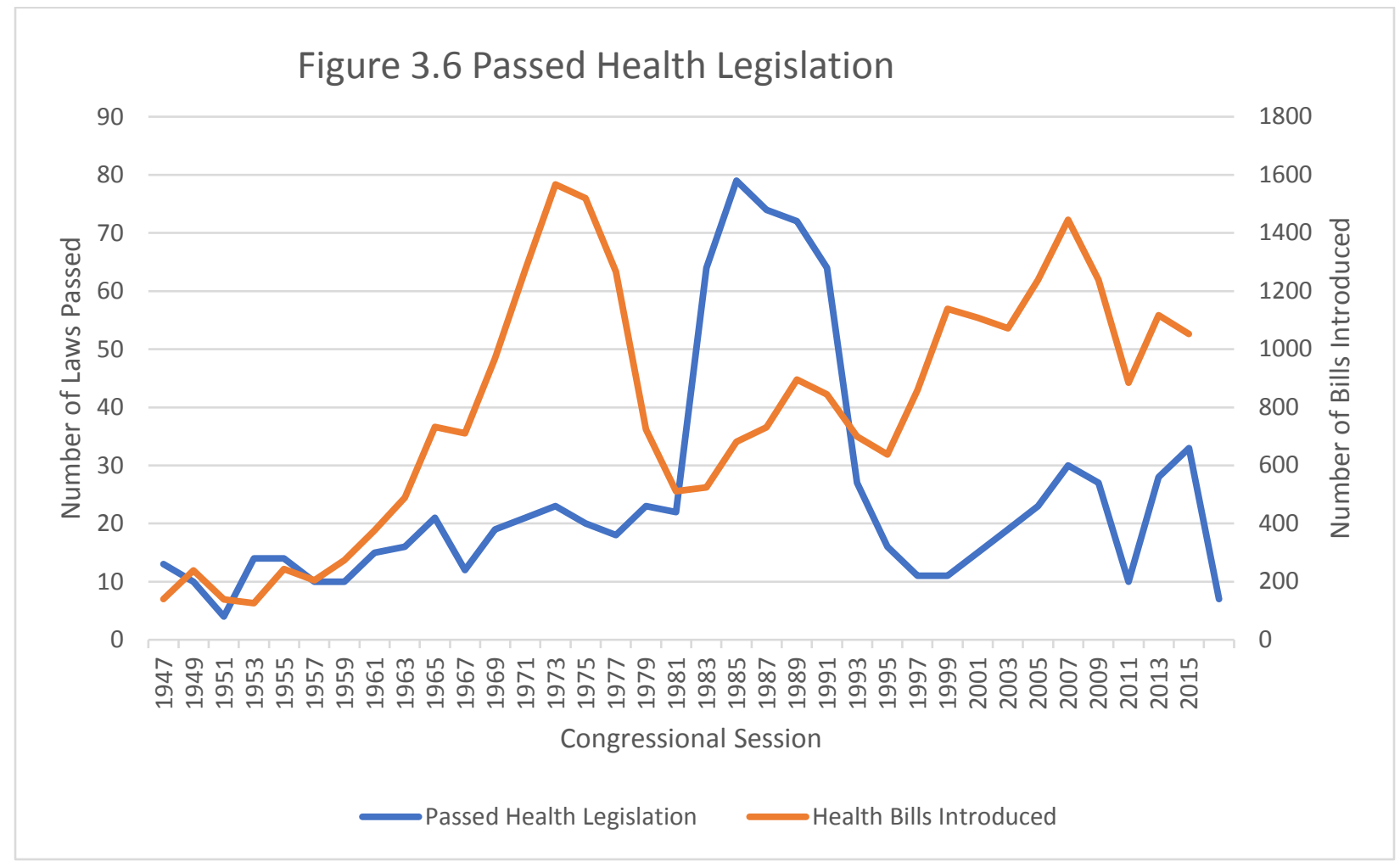

Presidential Attention

In addition to public and congressional attention, the president's ability to set the agenda, which varies by historical context and policy type, is a potential driver of health policy change (Light 1999; Skowronek 1982; Canes-Wrone 2006). In order to evaluate the presidential role in health care, I review executive orders, State of the Union (SOU) addresses, and public discussion on health issues from data collected using presidential papers available in The American Presidency Project (APP). The APP (https://www.presidency.ucsb.edu) is a database of public presidential documents and related key historical documents and advanced search 
tools maintained by John Woolley and Gerhard Peters through the University of California Santa Barbara. Documents are tagged with descriptive information employed to locate similar subjects or categories. I utilize the search subject term "health care." A review of 25 randomly selected results indicates that generally appropriate documents related to health care are returned.

Figure 3.7 traces the frequency of presidential mentions in public discussion, SOU addresses, and executive orders. For the purpose of this research, public discussion includes presidential mentions derived from interviews, news conferences, press briefings, inaugural and farewell addresses, other oral addresses (including Weekly and Saturday Addresses), and Fireside Chats.

Figure 3. 7 Presidential Mentions Health

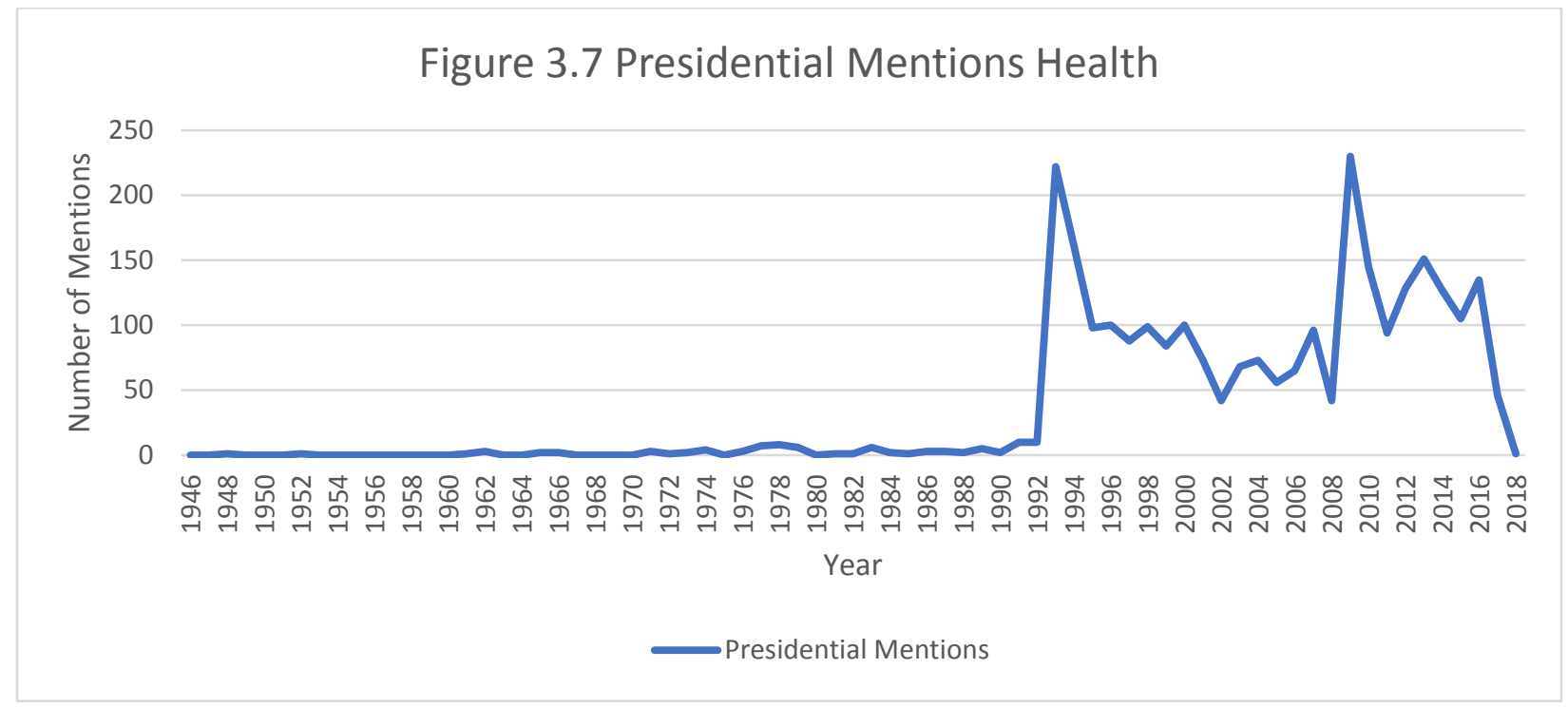

Presidential attention to health policy appears nearly non-existent but relatively stable until 1992. There is a major punctuation in 1992 followed by a sustained higher level of attention, which is subject to a second punctuation in 2008 . This period is followed by a return 
to the previously established equilibrium, which ends with a sharp drop-off in 2017. The punctuations are possibly related to the Clinton Health Care Plan (formally introduced Oct. 1993) and the passage of the Affordable Care Act (passed Mar. 2010). While public attention to health policy spiked in 1973, 1994, and the early 2000s (Figure 3.1), only the latter two spikes are associated with increased presidential attention.

\section{INFANTS AND CHILDREN}

As a first pass at mapping the agenda for women's health care, I begin by examining infants and children's policy. I use data for infants and children as a surrogate for women's health because a look at the policy history indicates that women's health was initially defined through childbirth and child care. I compare this data to data collected for all health policy coded in The Policy Agendas Project in order to better understand what portion of the health agenda is defined by topics concerning infants and children.

\section{Public Attention}

As a measure of public attention, I track the number of mentions for infants and children policy, using The New York Times index available through ProQuest Historical (https://www.proquest.com) cataloged from 1945-2015. There is not data available to track public attention for infants and children policy in the The Policy Agendas Project, so I have supplemented what is available with my own search.

ProQuest Historical Newspapers is a tool that allows researchers to search the collection of The New York Times index from 1851 to 2014. ProQuest advanced search tool retrieves documents containing all search terms, appearing in any field including document titles, 
authors, subjects, as well as the full text. Using the autocomplete feature, the advanced search tool provides suggestions from the subject index that are similar to my search. While this does not ensure that all results will align perfectly, some margin of error is expected.

I employed the following search terms as suggested in the advance search feature: infants and health, children health, children's health, child and health, and children health care. I limited results to only include: articles, features, general information pieces, front page or cover stories, editorials, and news. A review of 25 randomly selected documents across multiple time periods yields appropriate results concerning women's health.

Figure 3.8 illustrates the frequency of mentions and indicates that the greatest number of mentions occurs in 2001 and the least in 1958. The overall trend of the data indicates an increase over the time period studied. There are slight bumps in attention in 1966-1967, 1984, and 2001. In comparing this data to the data coded in The Policy Agendas Project for all health policy (Figure 3.1), I find substantial inconsistency. The Policy Agendas Project reports a total of 1,798 mentions for health policy for the total time period studied. A cursory search using ProQuest Historical (New York Times index) yields over two million results. I use "health" as a search term with the same document type filters (articles, features, general information pieces, front page or cover stories, editorials, and news). Given the refined coding system used in the Policy Agendas Project, this may simply be a limitation of the available data and a function of the specificity of results. However, this discrepancy is worth noting. 
Figure 3. 8 Infants and Children New York Times

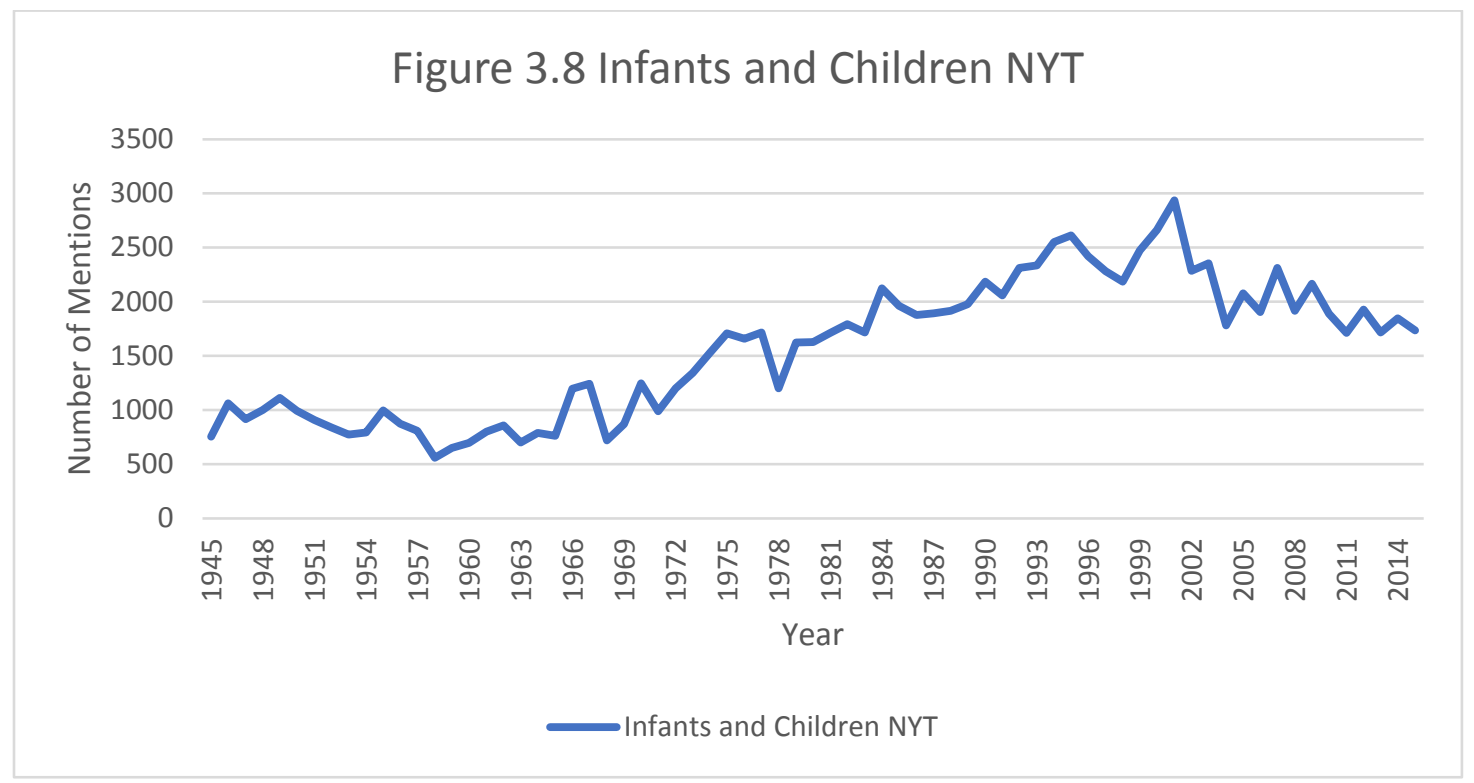

Congressional Attention

Figure 3.9 tracks the number of bills introduced in the House and Senate related to infants and children, using data available through The Policy Agendas Project (Health, subtopic Infants and Children). It appears that initially the House is more active and, not surprisingly, introduces more legislation (not surprising since there are more potential authors of legislation in the House). What is surprising is that the Senate actually matches the House levels during select periods. I am interested if a similar result is observed when tracking uniquely identified women's health legislation, as opposed to using infants and children as a substitute. Bill introductions in both chambers steadily increase over time, with a dramatic uptick in the mid1960 s in the House and again in the mid-1980s. The year with the greatest number of bill introductions for both chambers is the 2007 Congress, with 75 in the House and 66 in the Senate, totaling 141 out of 1,445, or roughly $10 \%$ of all bills introduced concerning health policy (Figure 3.2). 
Figure 3. 9 Bill Introductions Infants and Children

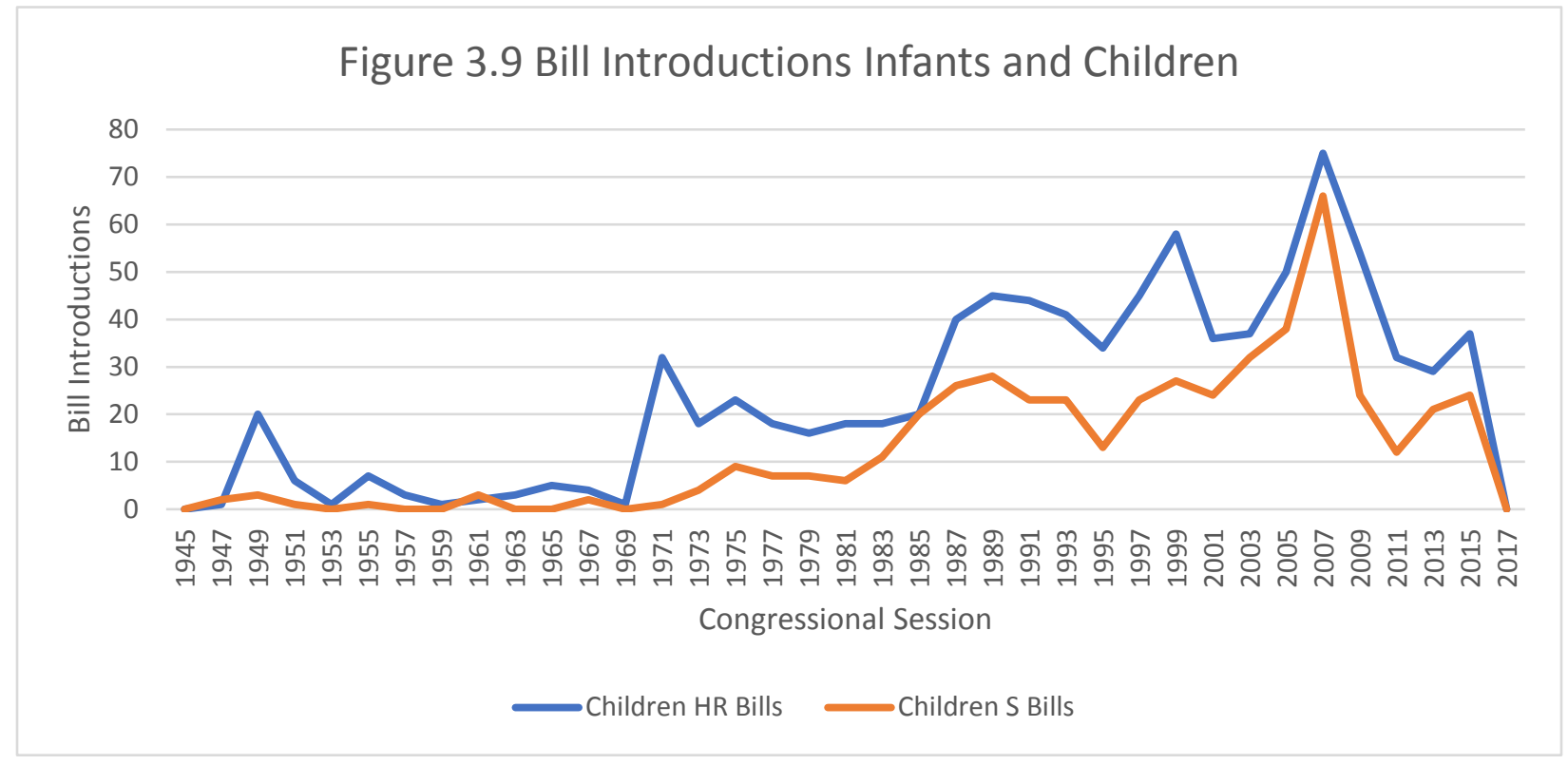

Also using data available through The Policy Agendas Project, I track congressional hearings in both the House and Senate using the health subtopic infants and children. The number of hearings concerning infants and children begins to increase after 1969 and experiences an uptick in 1973, 1987, 2001, and 2007 (Figure 3.10). The greatest number of hearings for all health policy topics occurs in the 1991 Congress, (343 hearings, Figure 3.4). Only 16 , or $4.7 \%$, of those hearings can be attributed to policy concerning infants and children. Hearings for infants and children policy, specifically, are most frequent in 1987 totaling 20 (Figure 3.8 ), or $6.8 \%$ of all health-related hearings. 
Figure 3. 10 Congressional Hearings Infants and Children

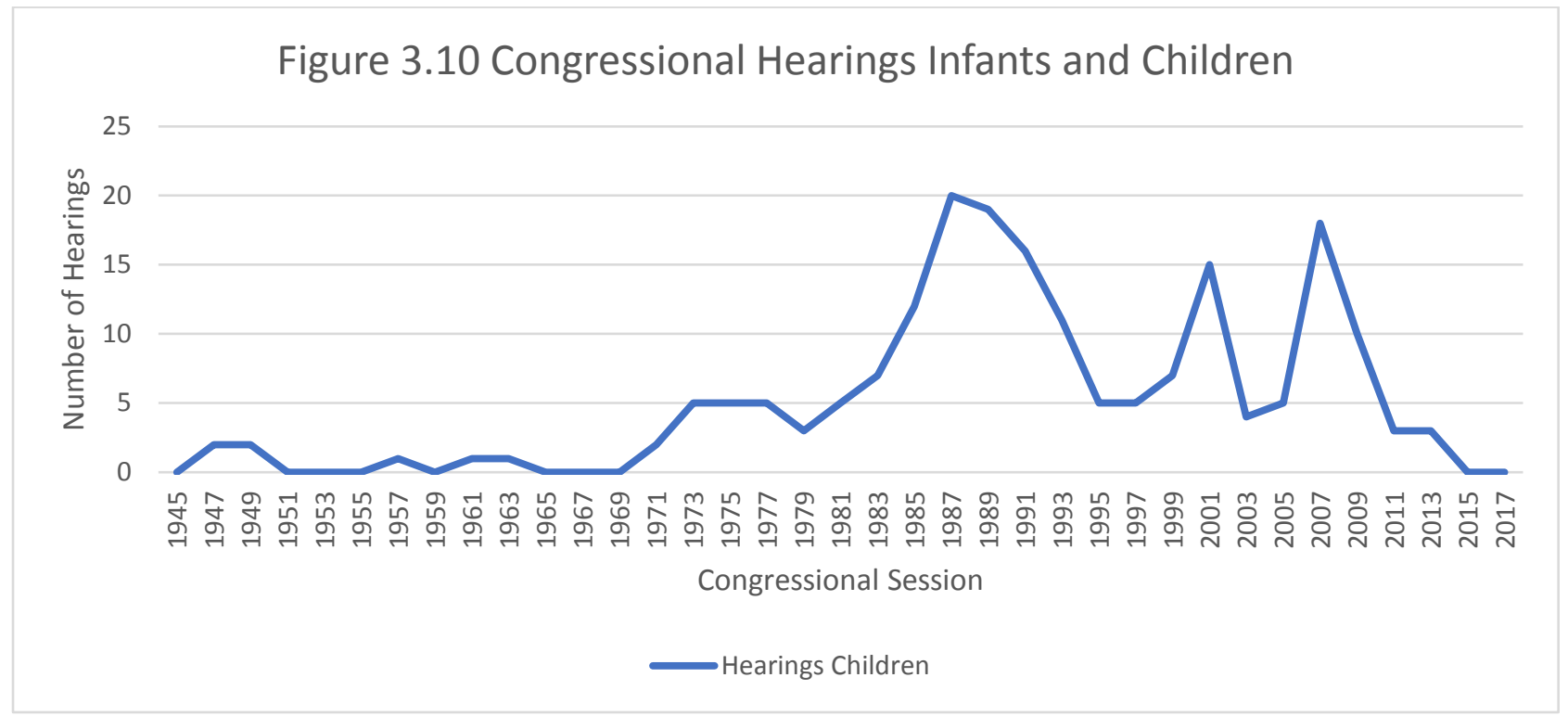

In addition to bill introductions and hearings, I map congressional attention using data collected in The Policy Agendas Project by examining passed legislation (Figure 3.11) for health policy concerning infants and children as compared to health policy generally. The greatest number of passed laws in health policy occurs in the 99th congressional session (1985-1986), totaling 79 (Figure 3.6). In that Congress, passed legislation specifically related to health for infants and children accounts for only five laws passed, or $6.3 \%$. We also see this number of laws passed concerning health of infants and children in the 2007 and 2013 Congresses. In each instance, it is clear that infant and children's health represent only a small portion of congressional attention to health policy. Measuring attention by the frequency of passed legislation demonstrates the limited agenda capacity (Tan and Weaver 2007) and competition among crowding policies (Baumgartner and Jones 2004), but it does not suggest that instances of passed legislation are not significant. 
In the 99th Congress for example, Congress passed the most health-related legislation, which included particularly salient measures for the health of infants and children and women by extension. On November 14, 1986, President Reagan signed into law a major package of health bills (S 1744 - PL 99-660). Congress cleared the bill, which included nine separate measures, just before the session adjourned. The final package was put together by Rep. Henry Waxman, D-Calif., chairman of the Energy and Commerce Subcommittee on Health and the Environment, and Orrin Hatch, R-Utah, chairman of the Senate Labor and Human Resources Committee, along with Rep. Edward Madigan, R-III., and Sen. Edward Kennedy, D-Mass., and the respective ranking minority members ("Congress Clears Omnibus Health Legislation" 1986). The bill included key provisions to establish the National Commission to Prevent Infant Mortality. This commission would be responsible for identifying and examining federal, state, local, and private resources which affect infant mortality; identifying health care barriers to reducing infant mortality; and promoting the health of childbearing women and their infants (S. 1744).

Also wrapped into an omnibus package was legislation strengthening federal standards for the testing and monitoring of infant formula ("Infant Formula Regulation" 1986). Both versions of the proposed bill toughened standards created by the 1980 Infant Formula Act (PL 96-359), which set minimum nutritional requirements for infant formulas. The approved measure was attached to omnibus drug legislation (HR 5484 - PL 99-570) signed into law October 27, 1986. Although Senator Orrin Hatch, R-Utah, expressed that the new regulatory burdens were unnecessary and would drive up the cost of formula, he admitted that it was 
"pretty hard not to vote for something that looks like motherhood and apple pie" ("Infant Formula Regulation" 1986).

Notably, health care for children hit a critical peak as the poverty rate for children reached a record high. In 1985, more than one out of every five children in the United States lived in a family whose income was below the poverty line (Rovner, 1986). Just before the 99th Congress adjourned, members approved a three-year reauthorization of five child nutrition programs that had been delayed in conference for the previous year. The act extended authorization through 1989 for five critical child nutrition programs, including the supplemental feeding program for needy pregnant women, infants and children (WIC) (S 2638 - PL 99-661).

Figure 3. 11 Passed Legislation Infants and Children

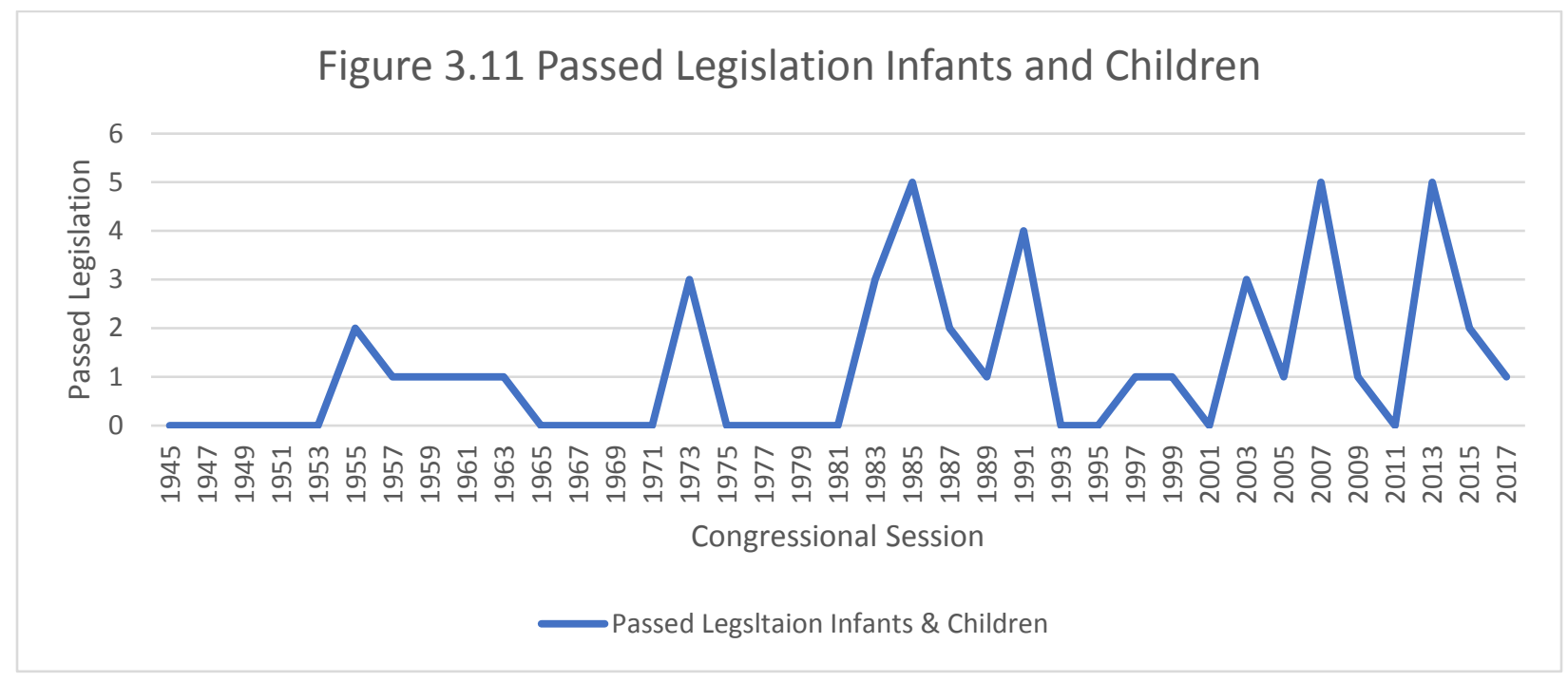

Presidential Attention

Finally, I map presidential attention to health policy for the subtopic infants and children by examining executive orders, using data available in The Policy Agendas Project. Illustrated in Figure 3.12, health policy appears in executive orders several times over the period studied, but 
health policy related to infants and children is only mentioned three times: 1997,2001 , and 2003. This indicates very little presidential action regarding health policy explicitly for infants and children. Potentially, this is a function of the limited data available for this subtopic in the Policy Agendas database and the specificity of coding. Infant and children's health may also be defined more broadly to include child labor and working conditions or as wards of the state.

Figure 3. 12 Executive Orders Infants and Children vs. All Health

Figure 3.12 Executive Orders Infants and Children vs. All Health

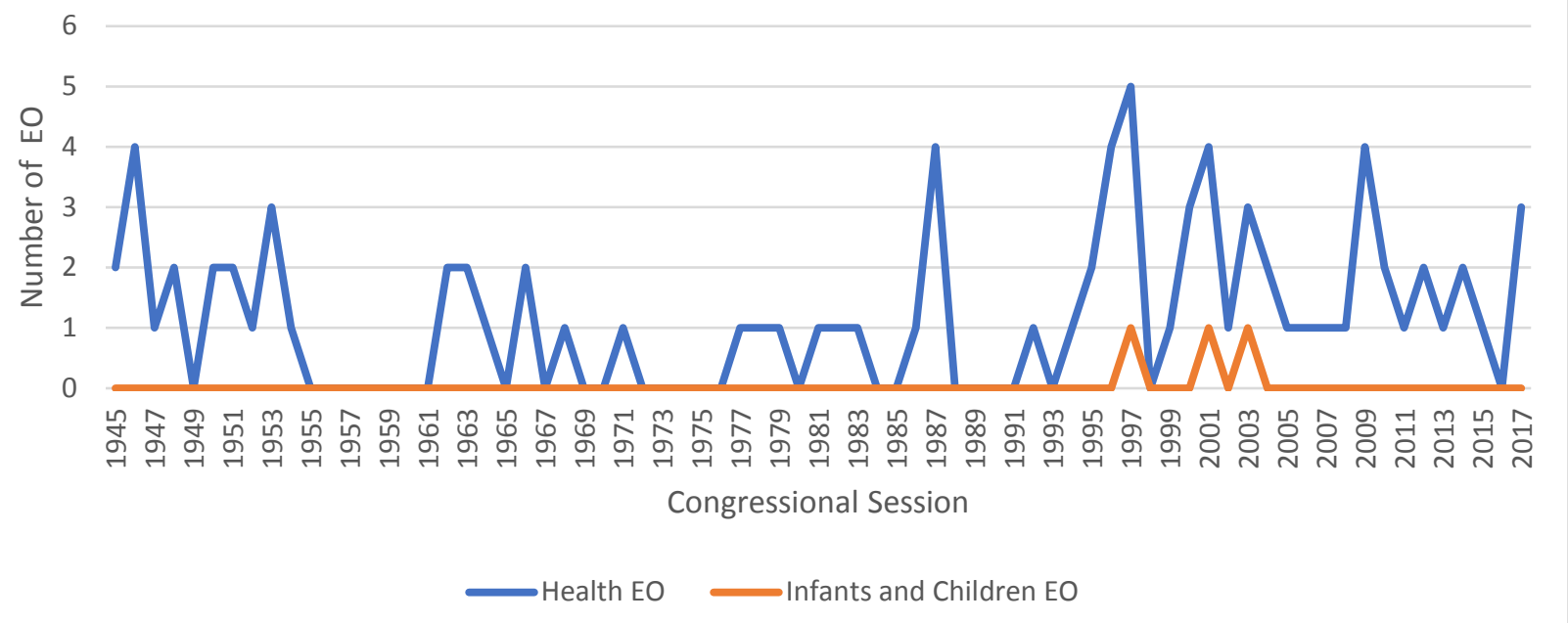

MAPPING WOMEN'S HEALTH POLICY

As a final step in mapping the health care agenda, I look specifically at attention to women's health care and what proportion of the total health agenda is dedicated to women's health. I add to the data available in The Policy Agenda's Project to further examine attention. As evidenced by the previous discussion of the health agenda and infants and children policy, the current tools for analysis are useful but limited. My research will help to expand understanding not only by focusing on attention to women's health in a more specific context but also evaluating the limitations of the current analytical tools available. 


\section{Public Attention}

To map public attention, I use data available through ProQuest Historical Newspapers (https://www.proquest.com) cataloging the New York Times index from 1945-2015. Again, I use the advanced search tool with suggested subject terms within my search. I employ the following search terms: women's health issue, asian women's health, black women's health, older women's health, rural women's health, global women's health, and women's heart health. I limited results to only include: articles, features, general information pieces, front page or cover stories, editorials, and news. I reviewed 25 randomly selected results and the documents are appropriate returns related to women's health. While the ProQuest tools are not perfect, its use is widely accepted among research and academic institutions. The databases are reliably constructed and maintained in regard to accuracy and time sensitivity and the conditions of my search can be replicated.

While public attention to health policy indicated by mentions in the New York Times experiences periods of increase and decline, there is a steady increase from the 1950 s to the early 1980s (Figure 3.13). Attention to women's health care experiences an uptick in 1984, 1995, and 2000. Comparing public attention observed for infants and children policy, it appears that both indicate an increase from the early 1960s to early 2000s followed by a period of decline. 
Figure 3. 13 New York Times Index Women's Health

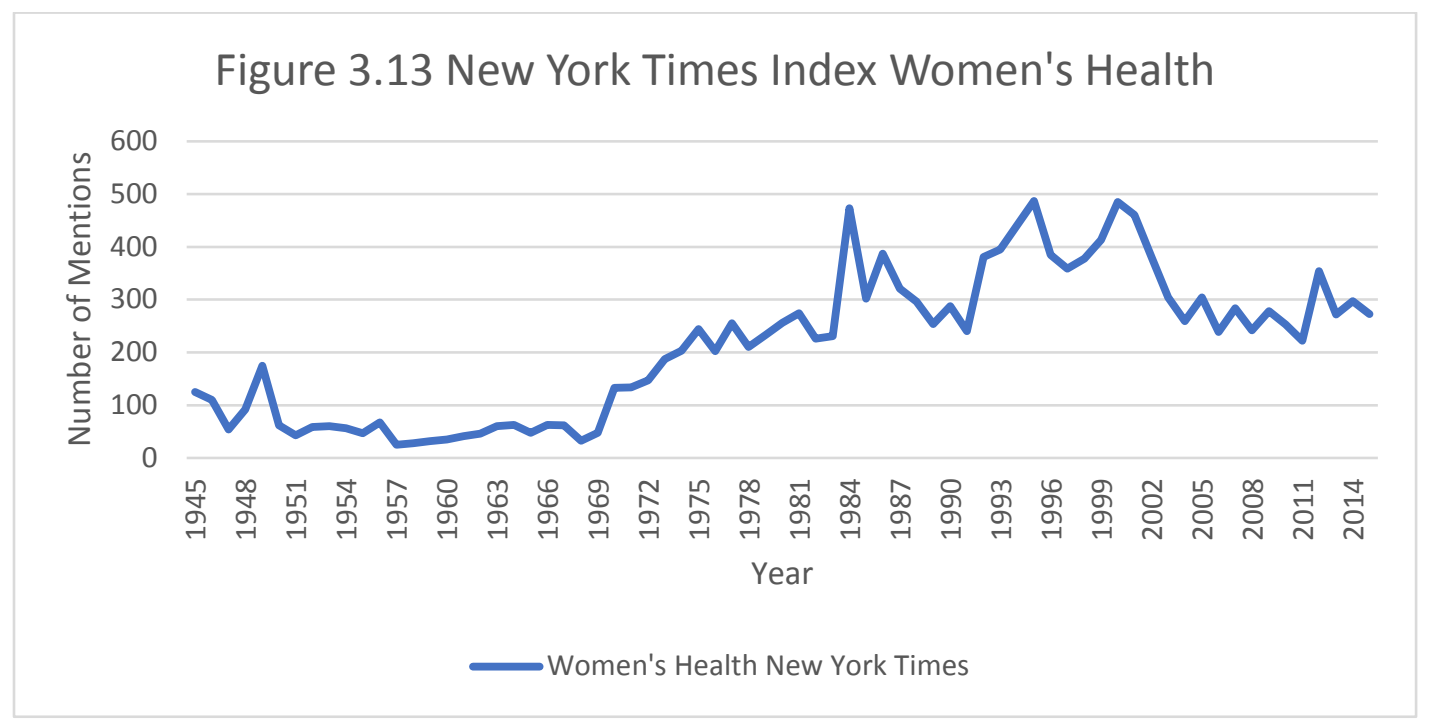

Congressional Attention

To examine attention to women's health as part of the overall health agenda, I compiled data utilizing the query tool available through Congress.gov. Congress.gov is maintained by the Library of Congress and is a reliable source for U.S. federal legislative information. The advanced search tool provides access to accurate, timely, and complete legislative information and allows the researcher to create custom search parameters. Combined data from the Office of the Clerk of the U.S. House of Representatives, the Office of the Secretary of the Senate, the Government Publishing Office, Congressional Budget Office, and the Congressional Research Service are included.

Using the advance search feature, I included data from 1945 to 2016 (the $93^{\text {rd }}$ to $114^{\text {th }}$ Congress) and limited my search with the legislative subject term "women's health." Legislative analysts from the Congressional Research Service (CRS) closely examine the content of each bill and resolution to assign Policy Area Terms and Legislative Subject Terms. Women's health has 
been identified as a discrete Legislative Subject Term, and bills may be assigned more than one term. Currently, there are over 1,000 terms in use (Congress.gov). I conduct a search for all legislation including introduced bills, resolutions, concurrent resolutions and joint resolutions.

In Figure 3.14, I examine introduced legislation concerning women's health in both the House and Senate. For all health legislation, The Policy Agenda's Project data indicates the largest number of bill introductions concerning health (Figure 3.2 House and Senate combined) occurs in 1973 , totaling 1,567 . This represents roughly $7 \%$ of the 21,950 bills introduced in that Congress. Women's health as a discrete subtopic, however, does not appear in bill introductions until 1975. The greatest number of bills introduced specifically aimed at women's health care occurs in the $114^{\text {th }}$ Congress beginning in 2015, with 137 bills originating in the House and 96 originating in the Senate. Women's health legislation introduced from 1973 to 2018 totals 2,391 bills (1,450 House and 941 Senate). Given the size and scope of the two chambers, the proportional activity in the Senate is notable. While many factors contribute to predicting the behavior of individual senators, activity on the chamber level is surprising.

Committee assignments and institutional position in the Senate come with certain advantages and disadvantages that a senator must incorporate into legislative and political strategy (Schiller 1995; Swers 2016). This result is likely part personal and part institutional. I discuss particular member's entrepreneurial activity in the Senate in chapter four.

Turning to competition in the overall health agenda, combined bill introductions in the House and Senate totals 233 , or $22 \%$ of the 1,053 total bills introduced concerning health policy generally (Figure 3.2). Introductions for women's health care policy follow a similar pattern of 
increasing and decreasing that is observed for bill introductions for all health policy and infants and children's health. The overall trend indicates an increase. This somewhat resembles the slight trend of increasing bill introductions for health policy concerning infants and children (Figure 3.9). Bill introductions related to infants and children also rose steadily in the early 2000s but peaked in 2005.

Considering the trends of public and congressional attention, it is apparent that bill introductions in Congress show more activity prior to the spike in public attention in 1995. However, the steady increase in bill introductions, particularly in the House, aligns with public attention in those years. Public attention and congressional attention do not necessarily perfectly align, but considering the institutional dynamics, this is not surprising. Preparing a bill for introduction in either chamber requires allocation of resources. In many ways Congress is a reactive institution, but it may be the case that members of Congress command public attention and not the reverse (Cobb and Elder 1983; Birkland 2017).

Figure 3. 14 Bill Introductions Women's Health

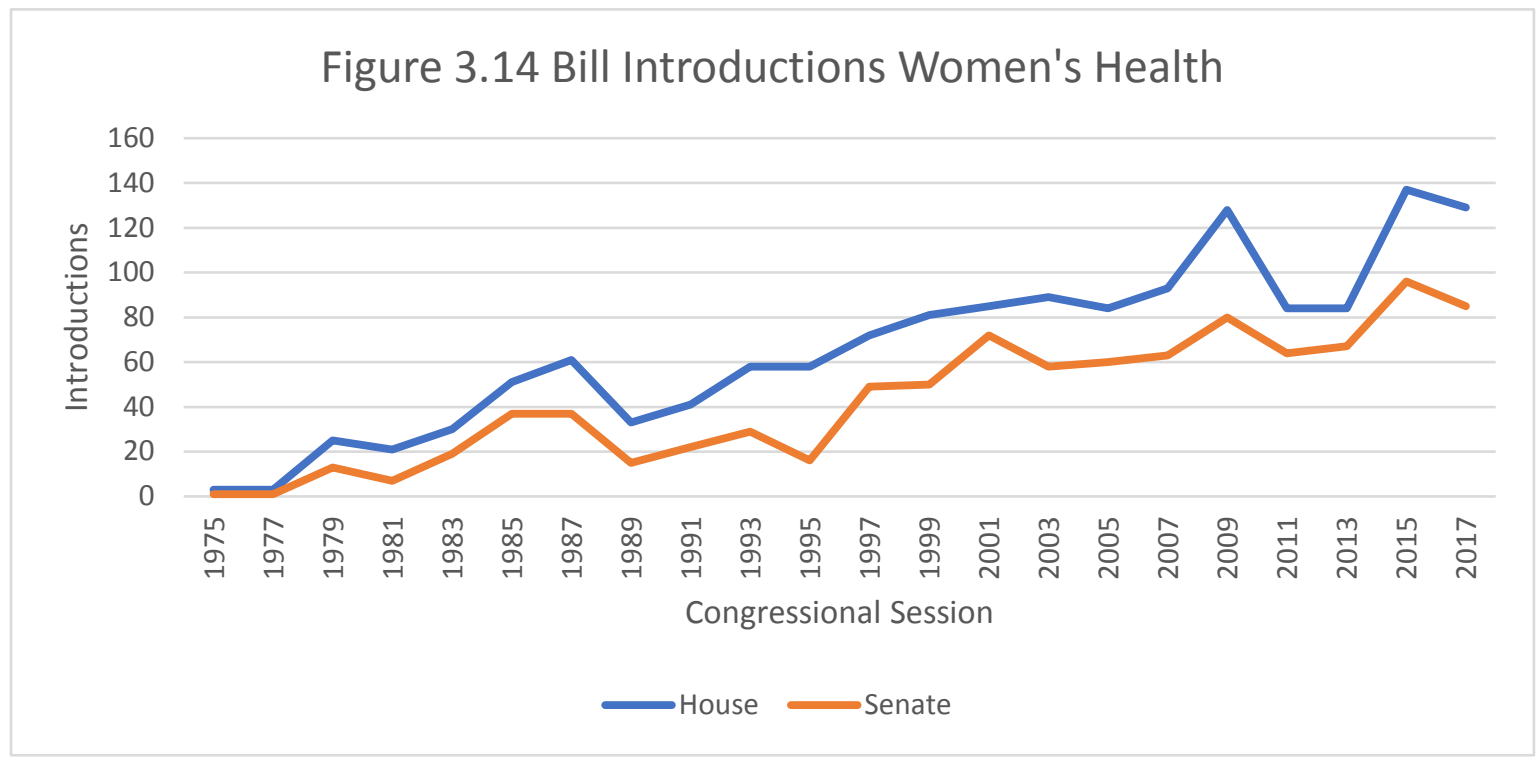




\section{Central Themes Women's Health Bills Introduced}

While tracking the frequency of bill introductions over time provides considerable insight into the capacity for Congressional attention, the actual substance and nature of the intention is equally important. Women's health legislation can be generally clustered into five categories. These include expansion of public health services through federal grant programs, child and maternal health, nationalizing health care, reproductive health, and cancer. Next, I carefully consider the nature of the bills introduced in these categories and provide a more substantive review of the legislation and the congressional context.

\section{Expanding Federal Grant Programs}

On November 19, 1945, Truman sent to Congress a five-point health program which included provisions for expansion of public health services and maternal and child health programs through larger federal grants to the states. In response, the Maternal and Child Welfare Bill of 1945 was introduced in the Senate (S 1318). The bill would have authorized over $\$ 100$ million a year in federal grants to the states to provide maternity and medical care for women and children under the Social Security Act. A number of other proposals were made but never gained traction ("Health Proposals in the $79^{\text {th }}$ Congress" 1945).

Four years later, The House Ways and Means Committee began a study of the entire Social Security program. Following a series of lengthy hearings, the committee reported HR 6000 August 22, 1949 ("Social Security Act Amendments" 1949). The bill proposed expansion of coverage and liberalized benefits, which included provisions for pregnant women and children. The House passed the measure without amendment by a 333-14 roll call vote, but the Senate did not act ("Social Security Act Amendments" 1949). 
For the next six electoral cycles (1950 forward), Congress elected to improve benefits under the Social Security Act. In 1965 Congress approved several major programs that had long been championed by the Democratic party, most notably in the case of medical care under Social Security. In the following years, Congress debated and a series of proposals continuing the general trend of expansion for federal grant programs. Then in 1979, three years after his campaign promise for comprehensive changes in health care, President Carter made a proposal for an all-inclusive health insurance plan, but it too turned out to be very limited. His plan, however, set the agenda for congressional debate on the issue (Wher and Donnelly 1980).

This debate continued in Congress through the late 1980s when the 100th Congress produced the most significant overhaul of the welfare system in fifty years. They officially passed the measure Sept. 30, 1988, when the House approved the conference report (H Rept 100-998) by a vote of 347-53 ("After Years of Debate, Welfare Reform Clears" 1988). The comprehensive bill specifically expanded provisions for women and children (prenatal and infant care), the elderly, and poor as part of Medicare and Medicaid. Senator Patrick Moynihan, who helped steer the bill's passage, commented, "We are redefining this 1935 program [AFDC] from a widow's pension to a program that will bring a generation of young American women back into the mainstream of American life." ("After Years of Debate, Welfare Reform Clears" 1988). Expansion and alteration of health grant programs impacting women and children continued through legislative authorization over the next thirty years until broad programmatic revisions occurred under the Patient Protection and Affordable Care Act (2010). 


\section{Child and Maternal Health}

Child and maternal health appear in introduced legislation in many forms post World War II. As federal grant programs ensuring health benefits for the needy and elderly began to unfold, President Lyndon Johnson made a very pointed request to Congress to fully fund his proposed health benefit package. In his "Health in America" message to Congress, President Johnson proposed expanded grant programs including health programs targeting expectant mothers ("Message to Congress: Johnson Asks Expanded Medical-Training Programs in "Health in America" Message" 1968). Johnson recommended a \$58 million increase in appropriations for the maternal and child health care programs, of which $\$ 25$ million of this increase would provide for maternity and infant care centers and clinics across the nation ("Message to Congress: Johnson Asks Expanded Medical-Training Programs in "Health in America" Message" 1968). The Child Health Act of 1968 didn't pass in Congress, but it did, however, raise awareness for the critical issues facing expectant mothers especially in rural America.

One such crucial issue reappearing in bill introductions is the rise and decline of infant mortality. President Kennedy, in an address to Congress, remarked, "Although infant mortality has decreased 75 percent since 1900, the decline has levelled off in the last ten years, and our rate is still higher than that, for example, of Sweden. Some states have an infant mortality rate double that of others" ("Message to Congress: Kennedy's Feb. 14 Message on Youth" 1964). As the civil unrest of the late 1960s took hold, the plight of the urban poor became a central issue in Congress and across the country. Much of the debate about the government's role in meeting social (especially health related) needs centered on the balance between spending for social programs and the need to finance the war in Vietnam ("Plight of Cities, Poor Americans 
Key Issues in 1968"1968). Again, President Johnson proposed an expanded child health program that could significantly reduce infant mortality by making health care more readily available to the poor. This proposal made no headway in Congress, likely in part because of the high cost that would be involved. Most of the health legislation enacted by Congress in 1968 expanded existing federal programs.

However, nearly twenty years later, on November 14, 1986, President Reagan signed into law a major package of health bills which created a national commission on infant mortality (S 1744). The commission's report generated several legislative proposals concerning the issue. In 1987, the House and Senate passed similar bills proposing federal programs aimed at reducing infant mortality. Members were unable to resolve differences before the end of the congressional session, but the issue was championed by several key players in health policy. Representative Henry Waxman (D-CA), chairman of the Subcommittee on Health for the House Energy and Commerce Committee, argued that "the United States had the highest rate of infant mortality among 20 industrialized nations" and "that studies had shown early prenatal care was a key factor in ensuring that babies were born healthy" ("Infant-Health Bills Pass" 1987).

Children and infant's health legislation was also often tied to nutrition. In 1972, as an amendment to the Child Nutrition Act of 1996, Congress authorized a pilot program to provide supplemental food assistance for pregnant and nursing women and for infants up to age four (“Congress Expands School Lunch Program" 1972). This developed into the program we know today as the Special Supplemental Nutrition Program for Women, Infants, and Children (WIC) 
(Gunderson 2013). In 1975 legislation established WIC as a permanent national health and nutrition program (PL 94-105).

In the early 1990s, maternal and children's health legislation focused on funding and reauthorization of key programs. In 1993, President Clinton signed into law the National Institutes of Health (NIH) Reauthorization (S 1, HR 4), which reauthorized selected programs at the NIH. The three-year, $\$ 6.2$ billion reauthorization included provisions codifying President Clinton's decision to permit federal funding of fetal tissue research. However, a major focus of the bill was an emphasis on health research involving women and minorities. The bill required increased participation of women in clinical studies, ordered the NIH to employ more women scientists, and increased funding for research on breast cancer, ovarian and cervical cancer, osteoporosis and reproductive health. Children's health also got more attention. One initiative focused on the search for more affordable, improved vaccines, including study into an HIV vaccine for women, infants and children ("National Institutes of Health (NIH) Bill Focuses on AIDS, Women's Health" 1993).

The road for women's and children's health, however, was not always an easy one, particularly in regard to the contentions State Children's Health Insurance Program (SCHIP). The program was established in 1997 (PL 105-33) to provide health care for low-income children whose parents could not afford private insurance but were not poor enough to qualify for Medicaid. The federal government provided grants while the states administered the program and matched a portion of the grant money, including provisions for pregnant women ("Democrats Unable to Overcome Bush Vetoes of Child Health Bills" 2007). 
Democratic leaders made expanding SCHIP a top priority in the 110th Congress (2007).

They argued that an additional 6 million uninsured children, beyond those already being served, were eligible for SCHIP or Medicaid but were not enrolled in either program. Lawmakers sent President Bush a version of the proposed Senate bill, but he quickly vetoed it. After an override attempt in the House failed, Democrats made a second attempt. They sent President Bush a revised bill that they hoped would garner some GOP support. When the President vetoed the second bill, Democrats elected to postpone a vote until 2008 ("Democrats Unable to Overcome Bush Vetoes of Child Health Bills" 2007). One of the first acts in the 111th Congress was to pass a significant expansion of the State Children's Health Insurance Program. President Obama signed the bill into law Feb 4, 2008 (HR 2 - PL 111-3).

\section{Nationalizing Health Care}

Women's health policy is not only present in legislation that expands and constricts individual programs. It is also part of more comprehensive health initiatives aimed at nationalizing care. As health programs grew post World War II, so did the cost of health care. With these rising costs came increased attention in Congress. The House Interstate and Foreign Commerce Committee opened hearings January 11, 1954, on the "cost of medical services" ("Health Hearings" 1954). Industrialist Henry J. Kaiser proposed private financing of a national health program in which, eventually, 30,000 doctors could care for 30 million Americans at low costs. Kaiser said an initial private outlay of $\$ 1$ billion could set up 1,000 health centers ("Health Hearings" 1954). Although this plan never came to fruition, Kaiser's proposal is particularly interesting, given the Kaiser Family Foundations continued support of health policy and research in the women's health field. 
Similarly, in the 1954 House Interstate and Foreign Commerce Committee hearings, Gerhard Hirschfeld, director of the Research Council for Economic Security, Chicago, described his organization's survey of prolonged illnesses. Hirschfeld found there were 37 prolonged illnesses (of more than four consecutive weeks) per 1,000 employees, with the rate higher among women than men ("Health Hearings" 1954). As health concerns for men and women grew among the medical and economic communities, it is evident that Congress was listening.

The role of the federal government in providing health benefits was a major congressional issue during the entire postwar period. Opponents of a national health insurance tied to Social Security have tried to limit the government's role. Labor interests supported a national health insurance program, while the American Medical Association feared socialized medicine ("Senate Kills Social Security Health Care Plan" 1962). The creation of programs targeted at large portions of the population have been stepping stones in this process. Haeder and Weimar (2015) argue that the American grant system used to expand access to health care has been "a long series of incremental, trial-and-error adjustments to new circumstances" ( $p$. 747). While the National Public Health Service Act of 1944 and its amendments provide for a wide range of programs, a broad federal health care plan was widely debated. Though often couched in other terms, Congress considered this idea in various forms. The 1971 Amendments to Title III Public Health Service Act of 1944 (PL 78-410) directed the Health, Education, and Welfare (HEW) Secretary to undertake a systematic analysis of national health care plans. Though the idea of national health care surfaced repeatedly, nationalized health care was most succinctly addressed in the Clinton Health Reform (1993) proposal. 
The scope of President Bill Clinton's health reform proposal and the decision to appoint First Lady Hilary Clinton to spearhead the effort, coupled with Congress' response, marked a critical and volatile period in the history of health policy legislation. Although Congress did not actively address President Clinton's proposal until he introduced legislation at the end of the congressional session, the issue was not far from public and congressional debate. President Clinton formally submitted the health care reform bill October 27, 1993 (1994 "Health-Care Debate Takes Off" 1994). Immediately following the bill's introduction, several alternative proposals emerged.

A viable health reform bill as the President envisioned never emerged. While the literature is divided as to a single issue that prevented the success of the Clinton health reform plan (Rushefsky and Patel 2016), it opened the door to a series of smaller health (and women's health) concerns to emerge on the congressional agenda. Similarly, it opened the door for comprehensive legislation to be considered under the Obama administration (Rushefsky and Patel 2016).

Passage of the Patient Protection and Affordable Care Act (ACA) (2010) was a purely partisan effort. Over a period that stretched nearly six months, five committees (three in the House and two in the Senate) considered and approved versions of the bill ("Landmark Health Care Overhaul: A Long, Acrimonious Journey" 2009). Citing issues of a public option, individual mandate, employer mandate, abortion funding, and tax expenditures, the bill remained in committee and with competing versions. In an unusual move, President Obama appeared before a joint session of Congress to renew his appeal for a health care overhaul ("Landmark Health Care Overhaul: A Long, Acrimonious Journey" 2009). Ultimately, Congress passed the 
Senate version of the bill in order to avoid a lengthy debate process. The ACA was not only the broadest expansion of health care coverage since the creation of Medicare in 1965 but also represented a victory for women's health preventative medicine. Although some gains were made for women's health coverage, research, and access, one key part of the debate focused solely on abortion coverage. In order to win key democratic votes, the law restated the existing statute that prevents the use of federal funds to cover abortions except in the case of rape, incest, and endangers the woman's life ("Landmark Health Care Overhaul: A Long, Acrimonious Journey" 2009).

\section{Reproductive Health}

The issue of abortion has separated itself from women's health legislation in many respects. Though first understood in terms of the health and well-being of mothers, abortion has also come to be framed as a civil rights issue, a states' rights issue, religious rights, or question of sex and gender policy among many other things (Rebouché 2016). Abortion, nevertheless, fits into a faction of women's health policy related to reproductive health.

Nearly a decade before the landmark Roe v. Wade (1973) decision, Congress, for the first time, turned its attention to the controversial issue of birth control. Acknowledging growing public concern for population problems, hearings by the Senate Government Operations' Subcommittee on Foreign Aid Expenditures were intended to gather information about and focus attention on the subject of birth control. The hearings were specifically related to legislation introduced in the Senate by Subcommittee Chairman Ernest Gruening (D- AK). The bill (S 1676) proposed establishment of Offices for Population Problems in the Department of 
State and the Department of Health, Education and Welfare to collect and disseminate information on family planning and population growth.

Although the Roman Catholic Church also expressed concern that world population would outpace food production, its position in opposition to artificial birth control methods did not change. At the Senate hearings the spokesman for the U.S. Catholic hierarchy condemned all government support of birth control programs. Though pressure from the Church remained an important political force, President Kennedy, the first Catholic U.S. President, said in 1963 that government-sponsored studies in reproductive biology were "important" and information on the subject should "be made available to the world so that everyone can make their own judgment..." ("Population Control: Increased Federal Concern" 1970).

Before 1965, however, the Federal Government participated in birth control programs only on an indirect basis. State and local governments, through their health departments and hospitals, participated in the birth control education and practice significantly before the federal government. Many made a practice of referring patients to local clinics of the Planned Parenthood Federation of America ("Population Control: Increased Federal Concern" 1970). The Office of Economic Opportunity (OEO), as part of its "war on poverty" campaign, indicated attention early in 1965 to provide funds for local birth control projects if recommended by local organizations and approved by general community consensus ("Population Control: Increased Federal Concern 1970). Funds were used for information campaigns, mobile clinics, and medical supplies (including contraceptives). OEO policy stipulated that projects must assist married women only; include information on all types of birth control, consistent with a person's 
conscience and religious feelings; and provide services on a strictly voluntary and unconditional basis.

The Health, Education, and Welfare (HEW) Department (Children's Bureau) also participated in support of local birth control services through grants to state and city hospitals and clinics. These family planning services generally operated as part of maternal and child care programs funded under Title V of the Social Security Act (“Govt Programs in 1967” 1967). As support among vital service providing programs began to increase, the political nature of birth control legislation began to shift. In a 1965 congressional hearing, Katherine Oettinger, head of the Children's Bureau commented "that birth control services should be available to all parents as a matter of right" ("Senate Holds Hearings on Birth Control" 1965). Senator Joseph D. Tydings (D-MD) also noted, "the only way for Congress to ensure that substantial additional funds would be spent on family planning was to earmark them because family planning lacked the necessary bureaucratic champions to safeguard its funds" ("Senate Holds Hearings on Birth Control" 1965).

Just a few short years later, President Nixon urged Congress to adopt "the provision of adequate family planning services within the next five years to all those who want them but cannot afford them." In response, Congress approved \$218 million for family planning services in the 1971 budget, 2.2 million of which was budgeted for an estimated five million low-income women who needed and wanted birth control information but did not have access to family planning services. The rest was to go to research and international population activities (“Population Control: Increased Federal Concern" 1970). Senate bill 2108, introduced by Senator Tydings (D-MD.), consolidated the family planning programs of the Department of HEW 
into a single National Center for Population and Family Planning. The bill authorized a five-year program, beginning in 1971, for the use of grants for family planning services and population research. Elimination of unwanted births, championed by the Nixon administration as a national goal, would alleviate problems for all economic classes, especially the poor (“Population Control: Increased Federal Concern” 1970).

Congressional attention to reproductive health, and reproductive rights by extension, turned almost exclusively to abortion by 1974 . The politically volatile issue of abortion surfaced in Congress in several areas in 1974. The Supreme Court ruled on January 22, 1973, that states could not interfere with the decision of a woman and her doctor to terminate a pregnancy by abortion during its first three months (Roe v. Wade 1973). The decision led to the introduction of several constitutional amendments guaranteeing the right to life for unborn children. The Senate Judiciary Constitutional Amendments Subcommittee held intermittent hearings on the amendments in 1974 but took no further action ("Hearings Air Abortion Controversy" 1974).

Notably, in 1976 the Senate voted 47-40 against action to start debate on a proposed constitutional amendment (S J Res 178) to guarantee unborn children the right to life (“Abortion Amendment" 1976). It was the first time either house of Congress had given even procedural consideration on the floor to proposed anti-abortion amendments to the Constitution since the Supreme Court struck down restrictions on abortion in early 1973.

However, abortion became involved in debate over the 1977 Health, Education, and Welfare Appropriations Bill. In question was whether to permit the use of Medicaid funds for abortions for low-income women. Debate on this topic was an issue in Congress for over half 
the year. Passage of a $\$ 60-$ billion appropriations bill for the Departments of Labor and HEW was held up until Congress negotiated the conditions under which federally funded abortions would be allowed. After months of debate and roll-call votes, Congress finally agreed on a provision that would permit Medicaid abortions when the mother's life was endangered or when two doctors certified that severe and long-lasting physical health damage would result from continued pregnancy (“Health, Education, Welfare 1977” 1977). The compromise also permitted "medical procedures" for victims of rape or incest, if the offense were reported promptly to police or a public health agency (“Health, Education, Welfare 1977" 1977).

In this respect, abortion was understood in terms of funding, but in the 1984 State of the Union address, President Reagan called on Americans to "come together in a spirit of understanding and helping" and find "positive solutions to the tragedy of abortion" ("Federal Abortion Alternatives Cut by Reagan" 1984). For those who viewed abortion as health concern or even a civil right, this was a major shift in the policy image (Stone 1989). When he took office in 1981, President Reagan sought cuts in the government's three main programs related to family planning, reproductive health, and assistance for pregnant women ("Federal Abortion Alternatives Cut by Reagan" 1984). Congress balked at President Reagan's proposed cuts in two of the three programs that provided alternatives to abortion. In 1981, however, Reagan was successful in cutting by almost one fourth the money available for the government's most significant family planning program, Title X of the Public Health Service Act of 1970.

One proponent of legalized abortion was Representative Henry Waxman, (D-CA) chairman of the House Energy and Commerce Subcommittee on Health and the Environment. Waxman continued to support legislation that promoted safe practices in regard to women's 
health, Medicaid funding, and protections for the poor ("Federal Abortion Alternatives Cut by Reagan" 1984).

In 1990, congressional support for abortion rights was gaining traction even in light of the 1989 Supreme Court decision (Webster v. Reproductive Health Services) which gave states broader authority to restrict abortions. Family planning advocates were optimistic that 1990 would be the year they could break the stalemate that had prevented Title $X$ from being reauthorized since its last renewal expired in 1985 (Rebouché 2016). However, Senate bill 110 to reauthorize Title $X$ was pulled from the Senate floor by its sponsor, Edward Kennedy (D-MA), after supporters failed to rally enough votes (Rubin and Zuckman 1993).

Abortion remained as part of the women's health agenda through the 1990s with presidents George W. Bush, Bill Clinton, and George H.W. Bush facing off with Congress. President Clinton, in a message to Congress vetoing bill HR 1833 that would have banned an abortion procedure, commented

"the bill does not allow women to protect themselves from serious threats to their health. By refusing to permit women, in reliance on their doctors' best medical judgment, to use this procedure when their lives are threatened or when their health is put in serious jeopardy, the Congress has fashioned a bill that is consistent neither with the Constitution nor with sound public policy." ("Presidential Veto Message: Threat to Previous Women's Health Cited in Abortion Veto" 1995).

In 2002, abortion opponents in the House succeeded in passing several bills aimed at restricting the availability of abortion, but only one measure survived the Senate. The one bill that became law (HR 2175, PL 1072-07) protected infants who are born alive at any point, even if the birth occurs during an attempted abortion (House Acts to Limit Abortion" 2002). The abortion debate, however, seemed to take a backseat during most of the following Bush 
administration. As the War on Terror waged on, Congressional priorities (especially in regard to health) seemed to focus in other directions. That is not to say that abortion does not remain a salient congressional issue. Issues of abortion funding resurface again prominently during the debate over passage of the Affordable Care Act (2010) in 2008 and 2009.

\section{Cancer in Women}

Breast cancer, the leading form of cancer in women (CDC 2019), dominated medical news in 1974 after President Ford's wife, Betty, underwent surgery for removal of a malignant tumor. Ironically, Mrs. Ford's operation coincided with the publication of three new studies on breast cancer by the National Cancer Institute. Based on a two-year national survey, one of the studies tentatively concluded that the traditional kind of surgery ("radical" mastectomy) performed on Mrs. Ford may be no more effective than a "simple" mastectomy ("Health Policy 1974: Overview" 1974). Those working on the study stressed that the findings were preliminary but predicted that they would hold up after long-term, follow-up results. A second report in 1974 by the Cancer Institute Task Force indicated that early screening might save 22 more lives among every 100 women who develop breast cancer ("Health Policy 1974: Overview" 1974). These findings and unfortunate circumstances lead to a new dimension of attention as to the nature of cancer legislation in Congress.

A decade later, Congress passed legislation (HR 3979 -PL 98-474) in spite of the tobacco lobby, requiring new warnings for cigarette packages and advertisements which identified risk of cancer and harm to unborn children ("New Cigarette Labels" 1984). Congress was cautiously favorable toward legislation that proposed funding to support cancer research in women's health. However, by the early 1990s legislation to authorize certain programs at the National 
Institutes of Health (NIH) was passed by both houses, but only after the bill (S 2857) was stripped of all controversial provisions ("Stripped-Down NIH Authorization Passed "1990).

The provisions to overturn an NIH ban on certain types of fetal research were removed. Both the House and Senate versions included measures to authorize new research centers to study infertility and contraception, but the Bush administration and other critics objected on grounds that they might encourage abortions ("Stripped-Down NIH Authorization Passed "1990). Also removed were provisions intended to eliminate sex and race discrimination in $\mathrm{NIH}$ funded research studies and to provide new research attention to women's health concerns. This was particularly devastating to those who championed these issues.

These provisions were added at Senator Barbara Mikulski's (D- MD) insistence. They were among the nearly twenty initiatives included in the Senate version of the Women's Health Equity Act. Representatives Patricia Schroeder (D- CO) and Olympia Snowe (R-ME), co-chairs of the Congressional Caucus for Women's Issues, introduced the House version of the Women's Health Equity package (HR 5397). Senator Mikulski commented, “NIH has let us down and we're asking for a new prescription," noting that in 1987 less than $14 \%$ of the NIH's research funds were spent on women's health projects ("Stripped-Down NIH Authorization Passed "1990). While reproductive issues dominated committee debate over the NIH bill, more than half of the original legislation was aimed at research into women's health and women's cancer research overall.

In 1991, legislation to expand federal disease prevention and health promotion was approved by both chambers late in the session, but it did not clear before the session adjourned. Provisions in the bill called for the creation of a federal Office of Adolescent Health 
and authorized programs to screen for prostate cancer and an $\$ 80$ million program to prevent diseases that caused infertility in women (Disability, Alzheimer's Programs Considered in 1991"). However, the 1993 National Institutes of Health Reauthorization (S 1, HR 4) saw a three-year, $\$ 6.2$ billion reauthorization. The measure authorized $\$ 3.2$ billion in 1994 for the National Cancer Institute, including $\$ 2.7$ billion for the cancer institute in general; \$325 million was specifically marked for breast cancer research and $\$ 75$ million for research on other reproductive cancers (“National Institutes of Health (NIH) Bill Focuses on AIDS, Women's Health" 1994). The enactment of this bill reauthorizing the National Institutes of Health (NIH) marked another in a string of victories for advocates of increased spending for breast cancer research.

In the same year, Congress cleared a bill (HR 2202) reauthorizing several programs at the Centers for Disease Control (CDC), including \$150 million for early detection of women's reproductive and breast cancers. HR 2202 also included provisions to allow the Department of Health and Human Services to issue temporary quality standards for mammography. In many ways, women's health policy saw advancement through congressional appropriation of funds and recognition in the law.

While these categories represent important topics, which reappear in introduced legislation, many other more specific concerns relating to access to health care, affordability of health care and prescription drugs, and medical training are included. I provide a continued policy history in chapter five, outlining the important role of outside actors as well. 


\section{Presidential Attention}

To further consider the dynamics of women's health care, I map presidential attention based on all presidential mentions, using data available through The American Presidency Project (https://www.presidency.ucsb.edu). Again, I review executive orders, State of the Union (SOU) addresses, and public discussion on women's health issues from data collected using presidential papers with the search term: women's health. ${ }^{2}$

Figure 3.15 traces the frequency of presidential mentions in public discussion, SOU addresses, and executive orders. For the purpose of this research, public discussion includes presidential mentions derived from interviews, news conferences, press briefings, inaugural and farewell addresses, other oral addresses (including Weekly and Saturday Addresses), and Fireside Chats. Presidential attention to women's health is relatively stable from 1945-1991. This is followed by a period of increase from 1993 to 2016. It appears that presidential attention to women's health has only been particularly relevant over the past twenty-five years.

Figure 3. 15 All Presidential Mentions Women's Health

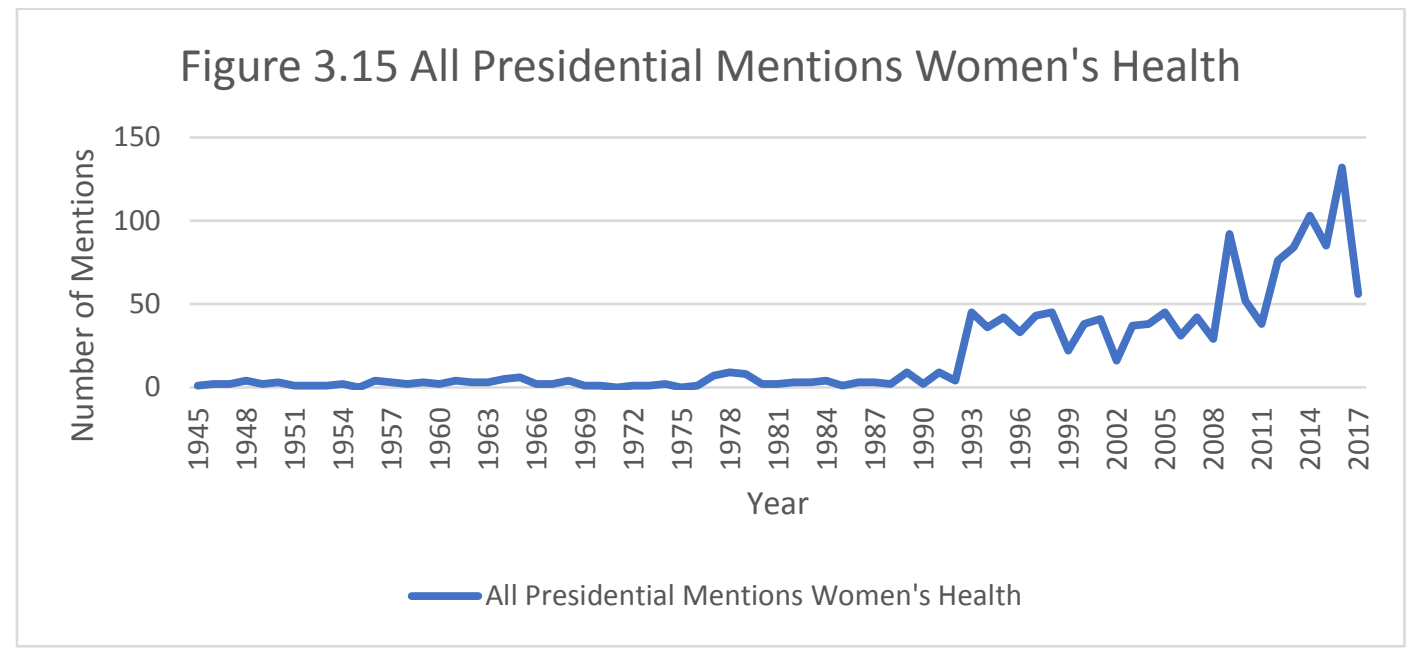

\footnotetext{
${ }^{2}$ Refer to the discussion of the American Presidency Project database advanced search methodology on pages 42.
} 


\section{Congressional Attention: Hearings}

Next, I track attention as evidenced by congressional hearings. I report data collected through ProQuest Congressional (https://www.proquest.com ), using the subject search term "womens health." Also, in the umbrella of searchable database through ProQuest Congressional, offers a database of searchable abstracts and indexing for congressional publications including the Hearings Digital Collection. This database is a primary source collection of reports with documents available from 1824 to 2010 . Using the advanced search feature, the ProQuest autocomplete tool prompted me to search using the term "womens health" as it is referenced in the data as such (note the omission of an apostrophe). I reviewed record of published hearings, which are the official record of committee hearings proceedings. A random sample of 25 records indicated the returned results were germane to women's health. Results include spellings with and without an apostrophe.

Attention marked by congressional hearings for women's health care is demonstrated in Figure 3.16. There are not instances of congressional hearings related to women's health policy before 1981, and it appears that the most active period occurs in the 1989 and 1991 Congresses. As women's health was originally defined by maternal roles or through infants and children, women as a stand-alone group were not recognized in dedicated legislation until 1975 (see Figure 3.12). It seems likely that committees may not consider women's health until several years following its initial discussion in Congress. In the late 1980s, advocates fought to increase the representation of women in clinical studies of diseases, disorders, and drug treatments utilizing federal funding. To address the exclusion of women from clinical research, the National Institutes of Health (NIH) Office of Research on Women's Health was established in 
1990. This aligns well with the increased number of congressional hearings during this period.

Similarly, hearings related to infants and children policy also experience an uptick during this period. Attention throughout the early 2000 s is relatively stable and attention in the House and Senate seem to follow the same pattern.

Figure 3. 16 Women's Health Hearings

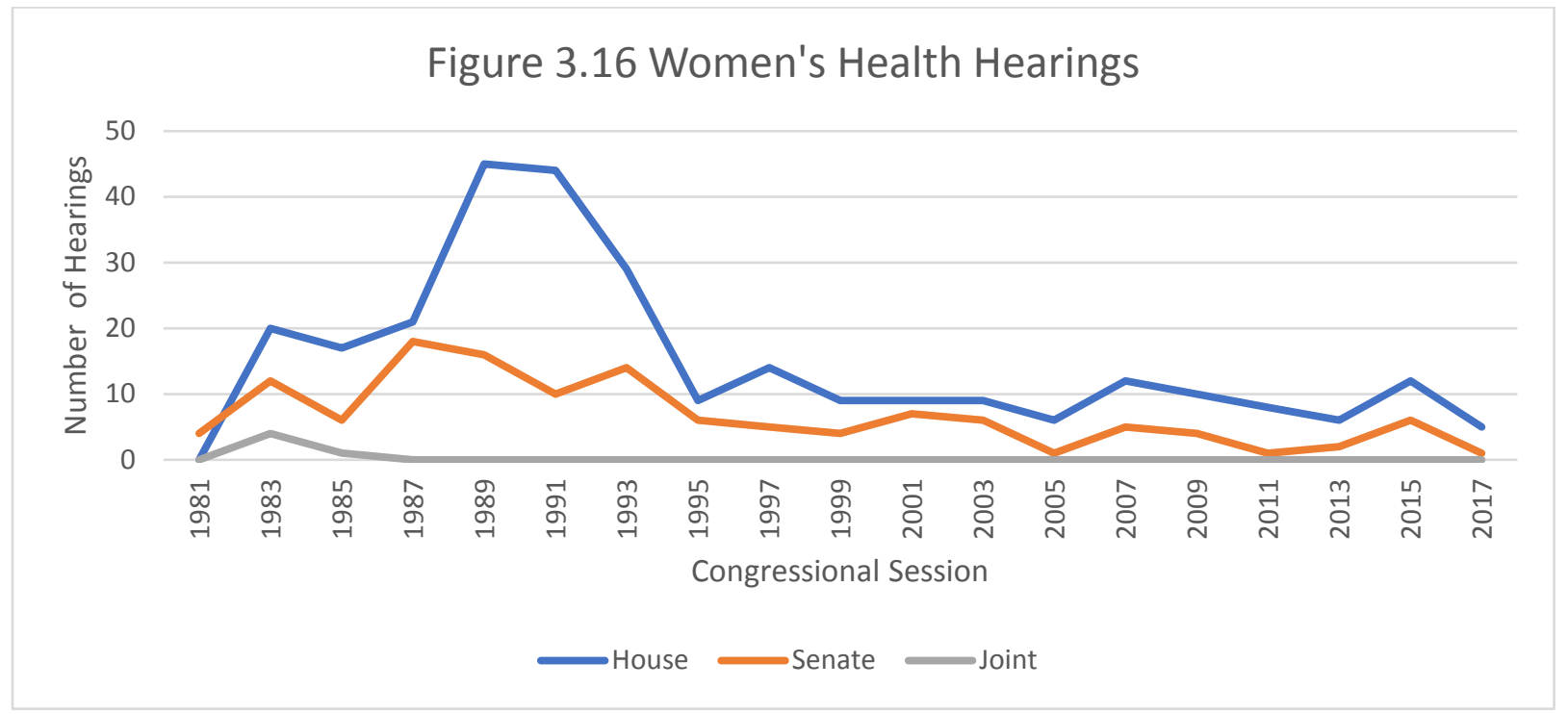

In order to determine how women's health fits into the overall context of health policy, I compare the frequency of women's health hearings to the total number of hearings for health policy generally. Figure 3.17 provides a closer look at the trend of congressional hearings for health policy (including all subtopics), separated by chamber. There appears to be a steady increase from the late 1960s until 1993 and a slight rise occurring again in 2007. Again, the House is generally more active, but surprisingly a relatively higher frequency of hearings occurs in the Senate in 1993, which is when the Clinton Care Plan was introduced. The greatest number of congressional hearings concerning all health policy occurs in 1991 (341) and women's health accounts for about $15.8 \%$. While women's health care is not overwhelmingly 
dominant among all health-related topics vying for space on the agenda, attention does indicate interest among Congress and political elites.

Figure 3. 17 Health Hearings

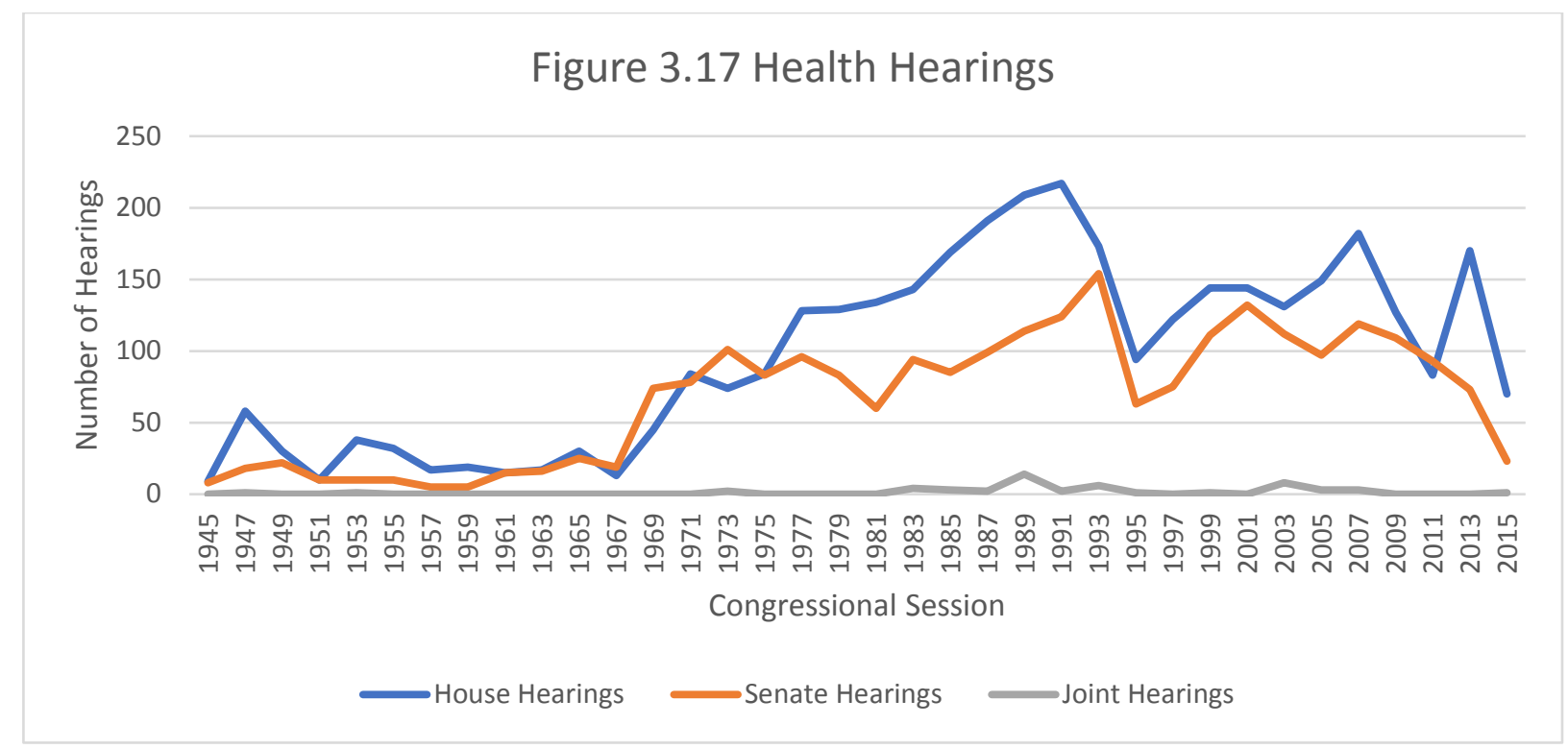

Following the leaders?

Considering these trends, it is interesting to note the connections (and in some cases lack of connection) to other avenues of attention. Beginning with public attention (Figure 3.11), it appears that there is no relationship between The New York Times mentions of women's health and the number of bill introductions per Congress (Figure 3.16). A Pearson correlation coefficient was computed to assess the relationship $(r=-0.04)$. Bill introductions experience a steady increase from the late 1970s until a peak in 2009, and this is followed by a decline until 2013. This may simply be a function of limitations in data collection or represent a lag time between shifts in attention on the public and congressional attention (Birkland 2017).

There is a slight increase in bill introductions in 1992, which aligns with the steady rise of congressional hearings until 1991 (Figure 3.16). However, I computed a Pearson correlation 
coefficient to assess the relationship between bill introductions and congressional hearings over the total time period studied, and there is a strong negative correlation $(r=-0.49)$. Congress and expert witnesses open a dialogue about women's health in the late 1980s to early 1990s but do not demonstrate spikes in attention again until 2007 and 2015 (Figure 3.16). This result is curious, as I expected the opposite to occur. There may be some issues of data coding in terms of the difference between the use of Legislative Subject Terms from Congress.gov and the suggested use of the term in ProQuest Congressional. However, it is not out of the question to conclude that a flurry of attention may occur when several bills are introduced, but that attention is not sustained through an entire session or at least in the amount of time to be considered during a committee hearing (Feinstein 2017).

Hearings, while an indicator of attention, are not a perfect measure of intensity. A measure of frequency of committee hearings does not account for intensity. That is to say, the length of the hearing, the number of witnesses, and the number of questions asked, or even the number of people attending. While most would agree that committee hearings are prime opportunities for members to demonstrate and develop policy expertise, participation among members varies (Taylor 2013). Given the increased partisanship of the last decade, Patashnik and Peck (2016) call into question the utility of committee hearings in the legislative process, calling the exercise symbolic.

Turning to the relationship between measure of public attention and congressional attention (or bill introductions and congressional hearings), there does not appear to be a relationship $(r=0.09)$. I also consider the relationship between public attention (NYT: Figure 3.11) and congressional hearings (Figure 3.14). I computed a Pearson correlation coefficient, 
indicating there appears to be a strong correlation between New York Times mentions $(r=0.49)$ and presidential attention (Figure 3.13), but in the case of presidential attention and bill introductions, there is a stronger correlation $(r=0.73)$. There is a negative correlation between presidential attention and congressional hearings $(r=-0.53)$. This is an interesting result as one might expect a positive relationship between shifts in presidential attention and bill introductions, the inverse relationship between presidential attention and congressional hearings is puzzling. Considering Marvel and McGrath's (2016) recent work, I would conjecture that lags in presidential attention open the door for greater bureaucratic oversight on the part of congressional committees in this area. Using these opportunities of seeming presidential indifference as an opportunity to shape policy. Marvel and McGrath (2016) findings support that levels of congressional oversight is primarily determined by political and policy motivations.

Congressional Attention: Legislation Passed

Finally, in order to gain greater insight to the outcomes of attention in women's health care, I also track passed legislation, using data derived from my legislative information search through Congress.gov. As with other measures, attention could be characterized by periods of increase followed by immediate periods of decline (Figure 3.18). There are slightly higher increases in 1993, 2009, and 2015.

Passed legislation for all health policy (Figure 3.6) generally follows the same pattern of increase and decrease that is observed for women's health, but it experiences a period of more sustained increase from 1983-1991. The greatest number of health laws passed occurs in 1985, totaling 79, and women's health care represents about $9 \%$ of those laws passed. 
Now, I consider the trajectory of attention marked by passed legislation but with a lens focused on a connection to other measures. There is no relationship between New York Times mentions and the frequency of passed legislation (Figures 3.13 and 3.18). A Pearson correlation coefficient was computed with a result of $r=0.07$. And the years with most legislation passed (1993, 2009, and 2015) do not align with peaks of increased public attention in 1984, 1995, and 2000. It seems plausible that there would be a significant lag time between any increased attention as a result of shifts in public attention, given the very truncated nature of the current legislative process. Volden, Wiseman, and Wittmer (2016) study trajectory of "women's issues" in Congress over a forty-year period. As expected, they find that only 2 percent of bills introduced concerning women's issues are passed and to only 1 percent of women's issue bills sponsored by women themselves are passed. They conclude that the committee process in particular has a negative impact.

Considering passed legislation and bill introductions, both experience an overall increase from the early 1980s. I calculate a Pearson correlation coefficient with a result of $r=$ 0.72. It seems reasonable to conclude that an increase in the number of bills sponsored also yields an increase in legislation passed. Congress appears to take the lead in elevating women's health policy in the late 1970 s and experiences periods of increased attention in the early 1990s and from approximately 2001-2015. Passed legislation for women's health policy also increased surrounding those periods (Figure 3.18). 
Figure 3. 18 Women's Passed Legislation

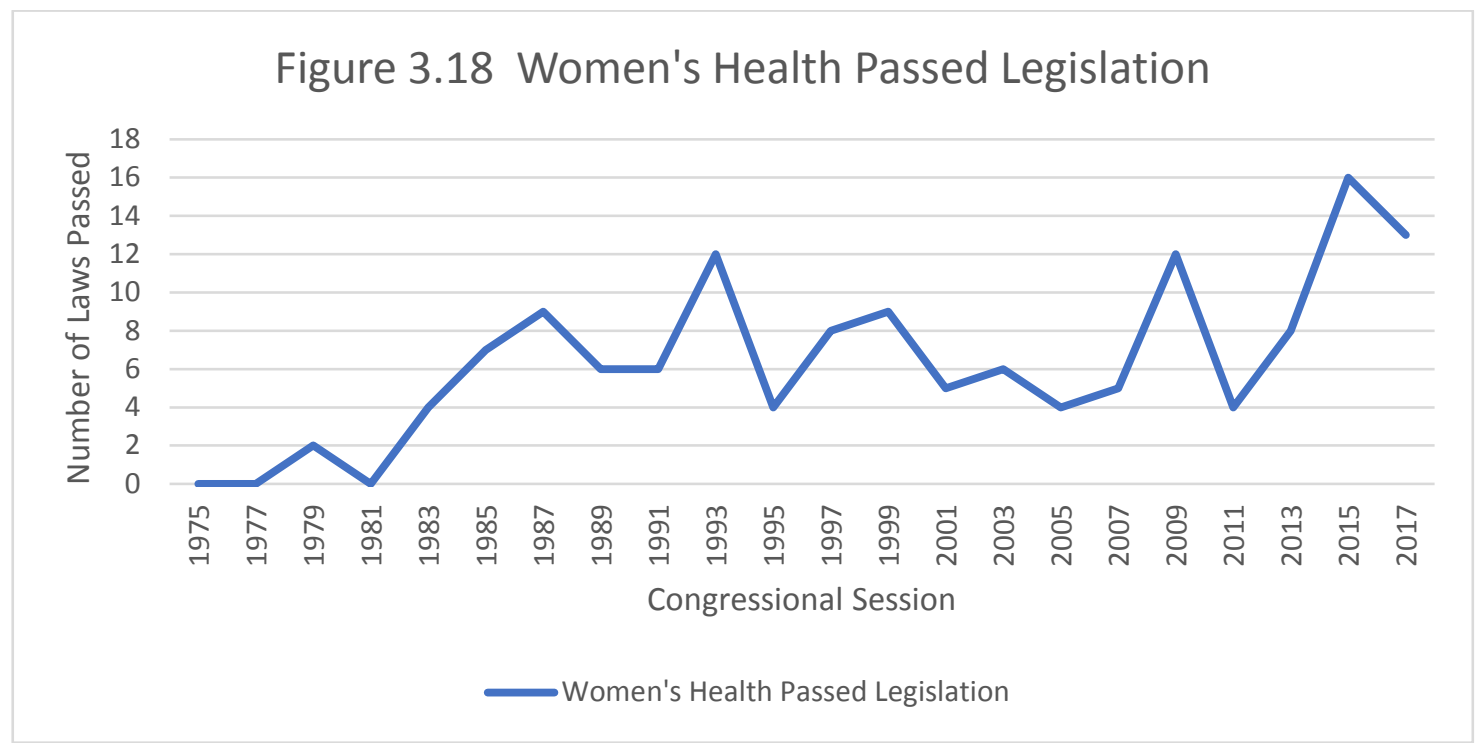

\section{AGENDA DYNAMICS}

The Policy Agendas Project provides some insight as to the dynamics of the health care agenda, but less information is currently available concerning attention to women's health. Data focused on infants and children in the Agendas Project, utilizing women as caregivers, demonstrates the dynamics of limited agenda space in this policy area. A look at women's health in its own right reveals a back and forth rotation where punctuations in attention bounce between Congress and the public. Baumgartner and Jones (2004) describe this occurrence as agenda crowding, or policy spillovers. When the public and Congress are focused on separate issues or even different facets of the same issue, the agenda becomes crowded and trade-offs in attention or policy activity are likely to occur.

Using the data collected to measure attention, it appears that $22 \%$ of all health bill introductions are women's health related, which is a little more than one in five. In regard to 
congressional hearings, women's health represents about $16 \%$ of all health hearings, and less than $10 \%$ of all health laws passed are directly related to women's health.

Similarly, public attention does not appear to coincide with congressional attention, as New York Times women's health mentions appear to have no relationship to the number of bills introduced, congressional hearings, or passed legislation. There is, however, a correlation between public attention and presidential attention. In the case of presidential attention and bill introductions, there is a stronger correlation. I found that when presidential attention increases so does the amount of legislation regarding women's health care. Interestingly, though, it appears as the number of bill introductions increases, the number of congressional hearings decreases. In the next chapter, I narrow my focus in examining attention and consider how committee and individual attention shapes the agenda.

The findings in this chapter used to map the agenda for women's health care provide a clearer picture of the limited space on the health care agenda and certainly lead to plausible conclusions as to the most favorable venue for expanding attention. 


\section{CHAPTER 4: Entrepreneurship in Women's Health}

Narrowing my focus on attention in women's health policy, I now concentrate on activity in Congress observed at the committee and individual levels. As I established in previous chapters, it seems appropriate to investigate attention paid by members of Congress, as authorizing legislation and the critical role of funding, are central tenets of the institution. Women's health policy is most certainly curated and altered in other venues, but for the purpose of my research, I will turn to attention in Congress. To further investigate attention in Congress, I focus on periods of increased activity and rapid change fueled by policymakers' behavior and their ability to shift attention. This phenomenon is described in the literature as entrepreneurship. Legislative entrepreneurs, issue owners (Petroick 1996), policy advocates (Kingdon 1989), and coalition leaders (Arnold, 1990) invest time, staff, and other resources to gain expertise in a policy area. Using this policy knowledge, entrepreneurs will draft or support legislation (Wilkerson et al. 2002) concerning issues in that area and use coalitions (Sabatier \& Jenkins Smith, 1999) to help guide their policy proposal through the legislative process. This chapter will focus on developing indicators of legislative entrepreneurship in the area of women's health care policy. Additionally, as some researchers have also focused on whether "who" holds office (descriptive representation) impacts the types of policies supported, I will also consider the gender composition of congressional committees and the chamber as a whole. (Pitkin 1967; Childs \& Krook 2009; Swers 2013).

Entrepreneurship can occur at the committee level as well as the individual level. In order to capture both dynamics, I will consider both the behavior of congressional committees and individual members. I analyze entrepreneurial activity in three stages. First, I consider bill 
sponsorship and legislative introductions. I am interested in which committees received referrals and are struggling for turf control in women's health (King 1997). Similarly, I track who is sponsoring women's health legislation and whether subsequent bills are referred to the committees on which they serve. Next, as a parallel to the legislative process, I track hearing activity. At the committee level, I am interested in which committees are holding the greatest number of hearings concerning women's health. Alternately, I also track which members are testifying in congressional hearings concerning women's health. Serving as a witness in congressional hearings signals that a member has considerable policy knowledge and has developed policy expertise (Wawro 2000; Mintrom 2009).

Finally, I am interested in entrepreneurial activity related to legislation passed. Which committees report out the most bills and how many bills are passed? Likewise, which members sponsor the most passed legislation, and is the number of cosponsors related to whether a bill passes? After considering these measures of entrepreneurship, I also study what role gender plays, if any. In subsystem politics we know that as the cast of characters changes, so do the policy dynamics (Baumgartner \& Jones 2002; King 1997; Worsham 1998). I am interested if the gender of top entrepreneurs matters and also how the gender makeup of the chamber shapes receptivity to making an issue of women's health.

\section{BILL INTRODUCTIONS}

\section{Committees}

As a first look at entrepreneurship in women's health, I track committee referrals in both the House and Senate. Using the advanced search function in Congress.gov, I limited my 
results with the Legislative Subject Term "women's health. ${ }^{3 "}$ I include data from all Congresses beginning with the $93^{\text {rd }}(1973)$ through the $115^{\text {th }}(2018)$. This returns 2,391 results for all introduced legislation with 1,450 originating in the House and 941 originating in the Senate. (I use the download results feature to further sort and divide the data). In the report of my findings, I exclude the House and Senate Committees on Appropriations, which is consistent with the literature and provides a clearer picture of actual entrepreneurship activity.

Figure 4.1 tracks bills referred to House committees between 1973 and 2018. Energy and Commerce receives the most referrals by far-some 1006-or forty-one percent of all legislation introduced. Ways and Means (395), Education and Labor (256), and Foreign Affairs (148) account for another thirty-three percent, with the remaining bills spread among a variety of committees. This is a fairly strong indicator of clearly defined turf in women's health policy, suggesting Commerce exercises near monopoly control over the consideration of women's health legislation.

Figure 4. 1 House Committees Bills Referred 1973-2018

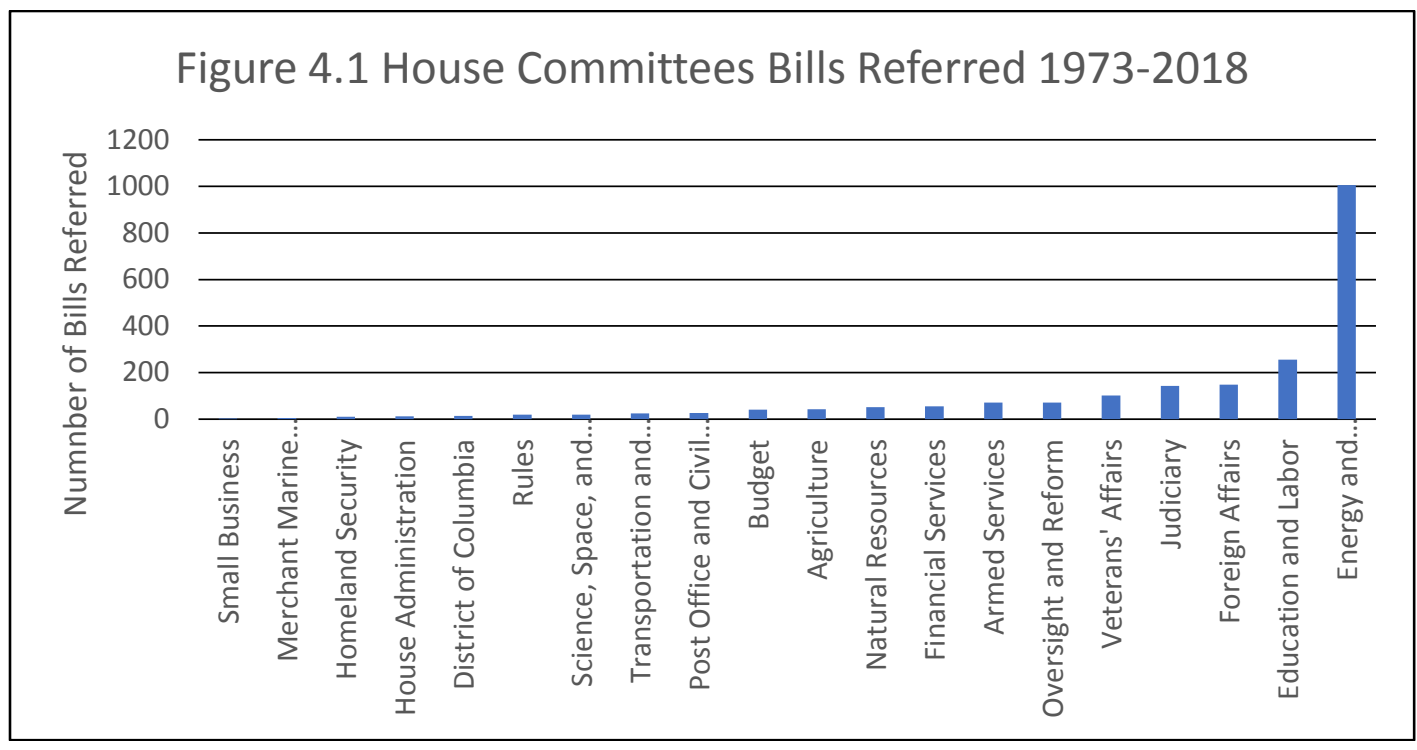

\footnotetext{
${ }^{3}$ A more detailed explanation of this search process is offered in chapter three pg.36
} 
Figure 4. 2 Senate Committees Bills Referred 1973-2018

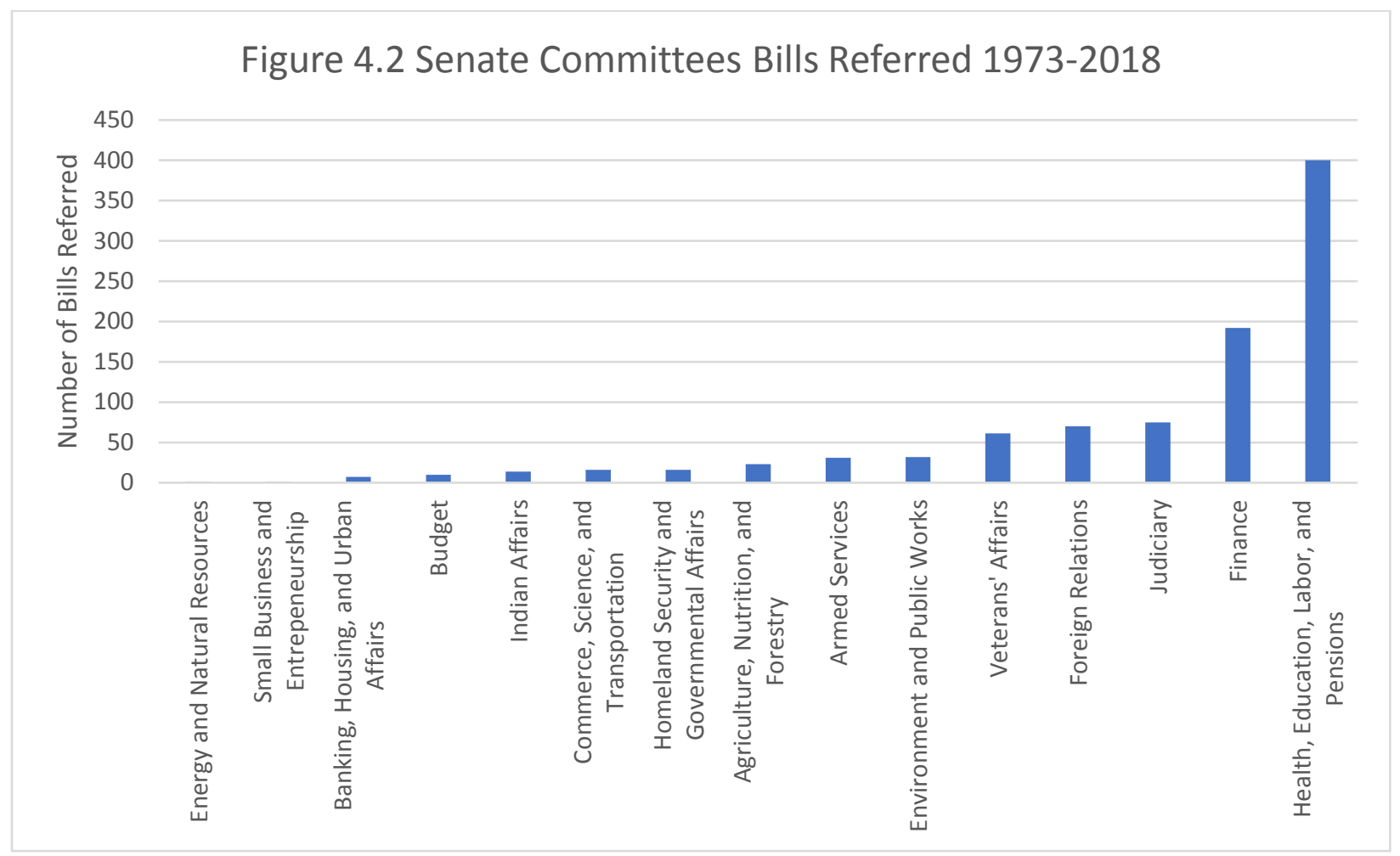

Figure 4.2 indicates similarly defined turf in the Senate, as the Committee on Health, Education, Labor and Pensions clearly receives the most bill referrals. With 400 bills referred from 1973-2018, Health, Education, Labor, and Pensions receives more than double of any other committee. The other major Senate player, Finance, received 192 referrals. After that, a cluster of committees including, Judiciary (75 bills), Foreign Affairs (70 bills) and Veterans' Affairs ( 61 bills) round out the most active players. Attention to health is reflected in the creation of subcommittees focused on health in Education and Labor, Energy and Commerce, Foreign Affairs, Veterans' Affairs and Ways and Means. 
Individual Members

Turning to individual bill sponsorship, Figure 4.3 identifies the members in the House who sponsored 10 or more health-related bills from 1973-2018. Table 4.1 incorporates the fraction of bills sponsored as compared to the total of women's health bills introduced. Representative Carolyn Maloney (D-NY) sponsors the most women's health bills at 45, which represents $3.05 \%$ of the total number of bills introduced in the House over the time studied. Maloney (45 bills), DeLauro (D- CT) (42 bills), and Waxman (D- CA) (39 bills) are grouped together as the greatest contributors. In the total group, 19 are Democrat and 3 are Republican. Representative Carolyn Maloney (D-NY) was elected to the One Hundred Third and to the thirteen succeeding Congresses. She has established herself as an advocate for women's and family issues, particularly in regard to women's health needs, reproductive freedom, and family planning. During her first term in office, Rep. Maloney helped to pass landmark legislation that provided coverage for annual mammograms for women under Medicare and she later worked on legislation to create Women's Health Offices in five federal agencies, which was part of the Affordable Care Act (2010) (“Carolyn Maloney” 2006). During this time she served as co-chair of the Women's Caucus.

Though not always finding legislative success, her work in introducing legislation and through committee service has helped to earn the reputation as a standout women's rights advocate. She introduced the Saving Women's Lives Act of 2002 to try to pressure the Bush Administration to release the $\$ 34$ million budgeted for the United Nations Population Fund (“Carolyn Maloney" 2006). Maloney has reintroduced legislation that would amend the 
Constitution and guarantee equal rights for women, and over 200 members have signed onto the Women's Equality Amendment (“Carolyn Maloney” 2006).

She hasn't been shy about her positions on controversial programs. During the floor debate in 1994 about the proposed act "Law Protects Abortion Clinic Access," Maloney said those who committed violent acts or physically obstructed women's access to abortion clinics had to be "deterred by the strongest means possible" and "the right to choose is meaningless without the access to choose" ("Carolyn Maloney" 2006). While other abortion rights initiatives remained dead-locked, Congress this bill criminalizing violence at abortion clinics (S 636 made it a federal crime to use force, or the threat of force, to intimidate abortion clinic workers or women seeking abortions).

In her 2008 book, Rumors of Our Progress Have Been Greatly Exaggerated: Why Women's Lives Aren't Getting Any Easier--And How We Can Make Real Progress For Ourselves and Our Daughters, Maloney writes, " based on some indicators, one might think that women have never been better off," but "there are many areas in which women's rights are being eroded and women's vital needs are not being met" (Maloney 2008, p. 7). It is interesting that much of her reputation is not based on large-scale legislative wins, but rather on her tenacity and ability to persevere and continue to rally support for the causes she champions.

Arriving in Congress just two years earlier, Representative Rosa DeLauro (D- CT) boasts a similar record related to women's health advocacy. Representative DeLauro was elected to the One Hundred Second and to the fourteen succeeding Congresses ("Rosa DeLauro" 2006). She currently serves in the Democratic leadership as Co-Chair of the Democratic Steering and Policy Committee, and she is the Chair of the Labor, Health and Human Services, and Education 
Appropriations Subcommittee (“Rosa DeLauro" 2006). Rep. DeLauro has become known as a leader in fighting to improve and expand federal support for child nutrition and for modernizing the food safety system.

Notably, she worked to reauthorize Johanna's Law, which ensures that women and their health care providers have access to information about gynecologic cancer for earlier detection ("Rosa DeLauro" 2006). She also introduced legislation to ensure that women and their health care providers have access to all medically relevant information in order to make informed health care decisions. Specifically, she introduced the Breast Density and Mammography Reporting Act (2017), which ensures that women and their health care providers have access to the information about an individual's breast density ("Rosa DeLauro" 2006). Although the bill did not pass in its original form, she opened the debate for this important legislation, and she played a critical role in the measure's eventual cultivation. She also continues to advocate for passage of the Breast Cancer Patient Protection Act, a controversial bill that would ensure decisions about a woman's hospital stay are made by the woman and her health care provider, not an insurance company (“Rosa DeLauro” 2006).

She has been a staunch advocate for breast cancer research and funding since the early 1990s and supported Clinton health care reform in 1993 and 1994, championing preventative health care measures for women. She has worked independently as well as with other women in the House and Senate. When asked about the difference the presence of women has made in Congress, she observed "It's been remarkable. I mean historically remarkable," but "we are in an institution that runs by numbers. You have to have votes, and there's just not enough of us 
here, we need to have more people here, women have changed the agenda and focus which is what I think is critical" (Dittmar, Sanbonmatsu, and Carroll 2018).

Even considering the long legislative history of both Maloney and DeLauro, Representative Henry Waxman (D-CA) is certainly considered the elder statesman in health policy. First elected as a Democrat to the Ninety-fourth and to the nineteen succeeding Congresses, for over forty years Rep. Waxman played a leading role in the enactment of major health, consumer protection, environmental, and telecommunications policy (Waxman 2009). Although most would consider Waxman's attention focused on health policy more generally, Waxman took on Women's Health Initiative. These included the laws establishing standards for mammography, requiring the inclusion of women in clinical trials, and creating the Office of Research on Women's Health at NIH (Waxman 2009). Waxman was Chairman of the Health and Environment Subcommittee of the Energy and Commerce Committee from 1979 through 1994, which also aided in facilitating his role in the expansion of Medicaid in the 1980s and early 1990s.

Figure 4. 3 Bill Sponsorship House

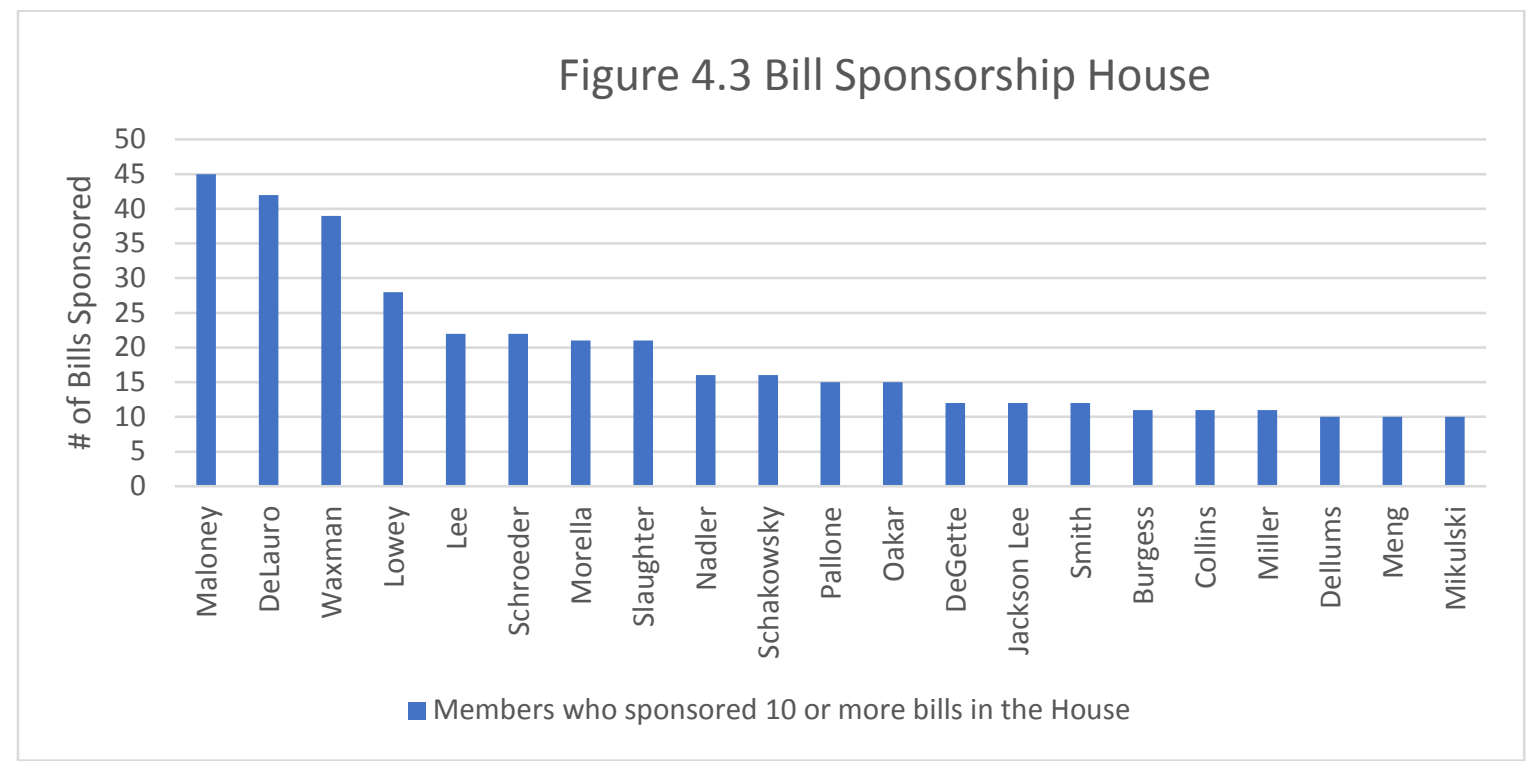


Table 4. 1 House Bill Sponsorship and \% Sponsored of Total Bills Introduced in House 4

\begin{tabular}{|l|c|c|c|c|}
\hline Member (House) & \# Sponsored & $\begin{array}{c}\% \\
\text { Sponsored }\end{array}$ & $\begin{array}{c}\text { \# of Terms } \\
\text { Served }\end{array}$ & $\begin{array}{c}\text { Average per } \\
\text { Term }\end{array}$ \\
\hline Rep. Maloney, Carolyn B. [D-NY] & 45 & $3.05 \%$ & 14 & 3.21 \\
\hline Rep. DeLauro, Rosa L. [D-CT] & 42 & $2.84 \%$ & 15 & 2.8 \\
\hline Rep. Waxman, Henry A. [D-CA] & 39 & $2.64 \%$ & 20 & 1.95 \\
\hline Rep. Lowey, Nita M. [D-NY] & 28 & $1.90 \%$ & 16 & 1.75 \\
\hline Rep. Lee, Barbara [D-CA] & 22 & $1.49 \%$ & 12 & 1.83 \\
\hline Rep. Schroeder, Patricia [D-CO] & 22 & $1.49 \%$ & 12 & 1.83 \\
\hline Rep. Morella, Constance A. [R-MD] & 21 & $1.42 \%$ & 8 & 2.63 \\
\hline Rep. Slaughter, Louise McIntosh [D-NY] & 21 & $1.42 \%$ & 16 & 1.31 \\
\hline Rep. Nadler, Jerrold [D-NY] & 16 & $1.08 \%$ & 15 & 1.07 \\
\hline Rep. Schakowsky, Janice D. [D-IL] & 16 & $1.08 \%$ & 11 & 1.45 \\
\hline Rep. Pallone, Frank, Jr. [D-NJ] & 15 & $1.02 \%$ & 8 & 1.88 \\
\hline Rep. Oakar, Mary Rose [D-OH] & 15 & $1.02 \%$ & 17 & 0.88 \\
\hline Rep. DeGette, Diana [D-CO] & 12 & $0.81 \%$ & 12 & 1 \\
\hline Rep. Jackson Lee, Sheila [D-TX] & 12 & $0.81 \%$ & 13 & 0.92 \\
\hline Rep. Smith, Christopher H. [R-NJ] & 12 & $0.81 \%$ & 20 & 0.6 \\
\hline Rep. Burgess, Michael C. [R-TX] & 11 & $0.74 \%$ & 9 & 1.22 \\
\hline Rep. Collins, Cardiss [D-IL] & 11 & $0.74 \%$ & 12 & 0.92 \\
\hline Rep. Miller, George [D-CA] & 11 & $0.74 \%$ & 20 & 0.55 \\
\hline Rep. Dellums, Ronald V. [D-CA] & 10 & $0.68 \%$ & 14 & 0.71 \\
\hline Rep. Meng, Grace [D-NY] & 10 & $0.68 \%$ & 4 & 2.5 \\
\hline Rep. Mikulski, Barbara A. [D-MD] & 10 & $0.68 \%$ & 5 & 2 \\
\hline
\end{tabular}

Figure 4.4 tracks those Senators who sponsored 10 or more bills between 1973 and

2018. Table 4.5 incorporates the fraction of bills sponsored as compared to the total of women's health bills introduced in the Senate. Senator Edward Kennedy (D-MA) and Senator Barbara Boxer (D-CA) sponsor the most legislation with 40 and 39 respectively. Senator Kennedy sponsors $4.19 \%$ of all women's health legislation introduced in the Senate and Senator Boxer sponsors $4.09 \%$. Senator Olympia Snowe (R-ME) follows closely with $3.25 \%$, and there is a steady and stable decline among other members' sponsorship.

\footnotetext{
${ }^{4}$ A complete listing of bills sponsored per member per term in the House is listed in the Appendix.
} 
Senator Edward Kennedy (D-MA) was elected in a special election on November 6, 1962, as a Democrat to fill the vacancy caused by the 1960 resignation of his brother, John Fitzgerald Kennedy. He served from November 7, 1962, until his death in August 2009 (Austin 2009). Many of his health legislative victories were fought and won in the Health, Education, Labor and Pensions Committee, where Kennedy had been both chairman or ranking Democratic member. Kennedy quickly capitalized on his assignment in 1971 as chairman of the health panel on what was then known as the Labor and Public Welfare Committee, pressing for a vast expansion in spending on medical research and advocating for universal health care (Austin 2009).

Using his family's name and personal success and losses to his advantage, Senator Kennedy was a powerful force in the Senate for health, and in turn women's health, legislation. But despite his record of promoting women's equality, Kennedy kept quiet during the debate over Clarence Thomas' nomination to the Supreme Court, leading most to believe that he was in no position politically, to take the lead against a nominee accused of sexual harassment. However, with the election of President Bill Clinton, Kennedy had a potential Democratic ally in the White House for the first time in decades. The first notable legislation Clinton signed into law was Kennedy's bill to require employers to provide their workers unpaid family and medical leave (Austin 2009).

Senator Kennedy endorsed Barack Obama for president in January 2008 but was diagnosed with a brain tumor the following May. Passage of the Affordable Care Act (2010) would become the last piece in his long legislative legacy. After his health condition began to take a toll, Kennedy's staff for the Health, Education, Labor, and Pensions (HELP) Committee held meetings and continued to make his support public. The committee members marked up 
the first version of the health reform bill that would be signed into law by President Obama and was the first committee in Congress to draft legislation to providing a patients' bill of rights. While this was a great victory for health care advocates, it was also an important step for advancing women's health care research and access.

Senator Barbara Boxer (D-CA) also amassed a lengthy legislative legacy, serving in Congress for 34 years (including 10 years in the House and 24 years in the Senate). She was a vocal advocate for families, children, consumers, and the environment ("Barbara Boxer" 2015). She retired from the Senate at the end of the 114th Congress (2015-2017). Senator Boxer was known for her understated, straightforward approach to the legislative process, which she described in one of her farewell interviews. "It's very easy," she said. "You introduce legislation that moves us forward. You fight bad legislation" ("Barbara Boxer" 2015).

As a member of the House, she was part of a bipartisan group of women members who marched on the Senate to demand extended hearings on the sexual-harassment charges against Supreme Court nominee Clarence Thomas in 1991. Among her women's health policy priorities was the protection for a woman's right to choose. In 2004, Senator Boxer sponsored S.2020, the Freedom of Choice Act (2004), which provided that every woman has the fundamental right to choose to: (1) bear a child; (2) terminate a pregnancy prior to fetal viability; or (3) terminate it after fetal viability when necessary to protect her life or her health. This bill was referred to the Senate Judiciary Committee, but no further action was taken. When asked why she is so passionate about women's reproductive health, Senator Boxer elaborated "It's not that women are better than men. We're not; we're equal to man, equally good and equally bad. But we bring with us a life story experience and you know when the men get out there on the floor and talk about the joys of childbirth, fine, but they never gave birth, and we know how joyful it is, but also how difficult it is and what you face 
when there is a problem with your pregnancy. So just there alone... we [Congresswomen] can authenticate the experience that women are having" (Dittmar, Sanbonmatsu, and Carroll 2018).

In a similar way, Senator Olympia Snowe championed the reproductive health of women and worked to bring Democrats and Republicans together on issues that benefitted both parties. Snowe was a member of the Congressional Caucus for Women's Issues for her entire career, chairing the caucus during the 98th Congress. Snowe's moderation and willingness to compromise won her bipartisan respect, and she used this strength as the GOP deputy whip in 1984 (Carey 2002).

Throughout her career, Senator Olympia Snowe supported women's health issues, including reproductive rights, allying with Democrats against a proposed GOP ban on "partial birth" abortion. She also joined her colleagues across the aisle to support a proposal to cover contraceptives under federal employees' health insurance plans (Carey 2002). In July 1999, after Democratic efforts to strengthen patients' rights were rejected, Snowe was able to pass a measure that gave women who underwent mastectomies the right to longer hospital stays as long as their doctor deemed it medically necessary. She sponsored the Senate version of the Breast Cancer Patient Protection Act (2006), which was mirrored by Representative Rosa DeLauro in the House (Carey 2002).

In 2008, Snowe successfully shepherded legislation that banned job and health insurance discrimination based on genetic testing. Having worked with Democratic Representative Louise Slaughter of New York for more than a decade on this issue, Snowe called the measure one of the "major satisfactions of my career" (Carey 2002). Snowe has not been afraid to make lasting partnerships or to break ranks with her party when necessary. She 
voted in favor of the Finance Committee's version of the Patient Protection and Affordable Care Act, becoming the only Republican senator to support the legislation at any level.

These members and others in the top tier of bill sponsorship not only demonstrate a willingness to support women's health issues, but also, long standing careers in which they have established policy expertise.

Figure 4. 4 Bill Sponsorship Senate

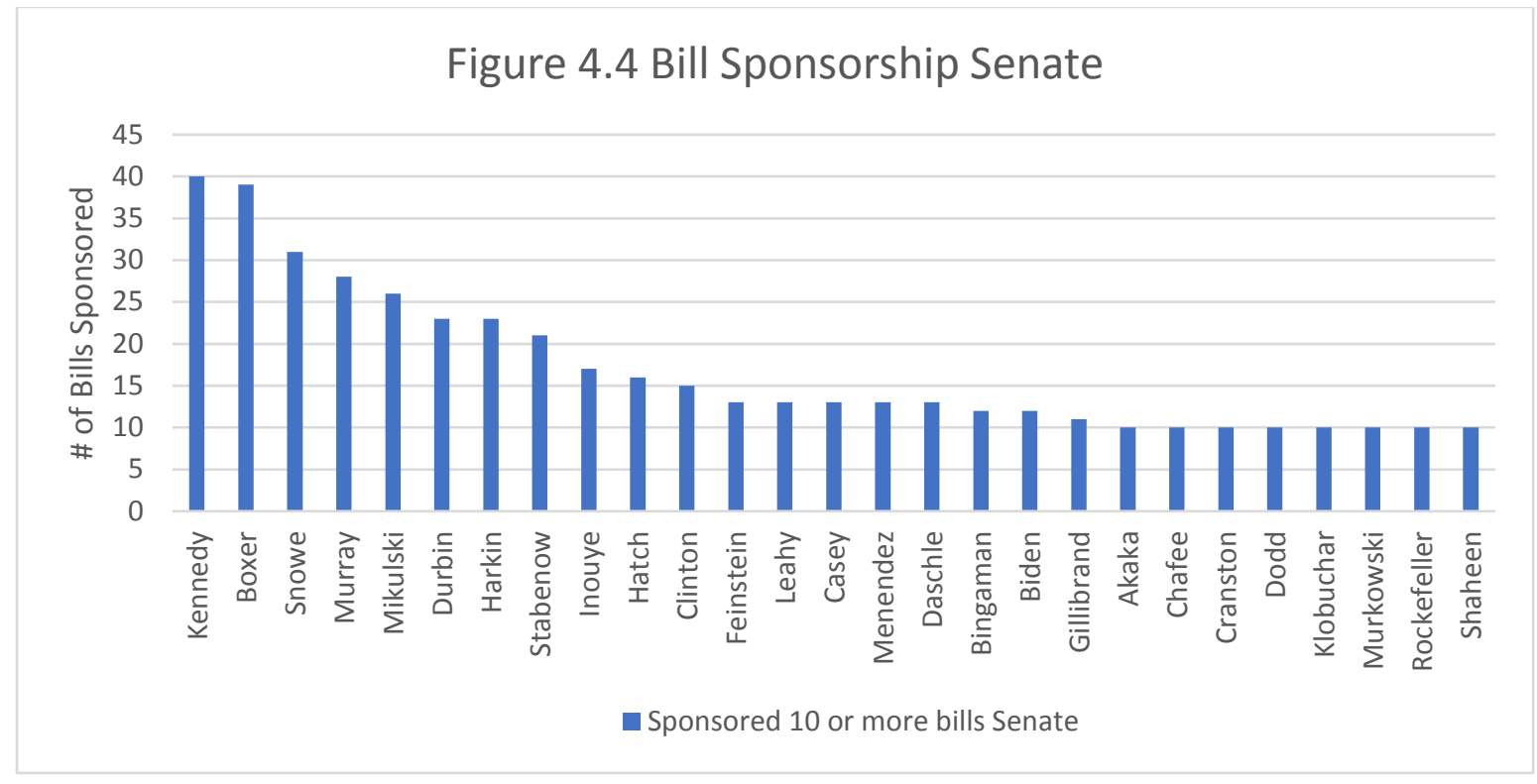

Table 4. 2 Senate Bill Sponsorship and \% Sponsored of Total Bills Introduced in Senate ${ }^{5}$

\begin{tabular}{|l|c|c|c|c|}
\hline Member (Senate) & \# Sponsored & \% Sponsored & $\begin{array}{c}\text { \# of Terms } \\
\text { Served }\end{array}$ & $\begin{array}{c}\text { Average Per } \\
\text { Term }\end{array}$ \\
\hline Sen. Kennedy, Edward M. [D-MA] & 40 & $4.19 \%$ & 9 & 4.44 \\
\hline Sen. Boxer, Barbara [D-CA] & 39 & $4.09 \%$ & 5 & 7.8 \\
\hline Sen. Snowe, Olympia J. [R-ME] & 31 & $3.25 \%$ & 3 & 10.33 \\
\hline Sen. Murray, Patty [D-WA] & 28 & $2.94 \%$ & 5 & 5.6 \\
\hline Sen. Mikulski, Barbara A. [D-MD] & 26 & $2.73 \%$ & 5 & 5.2 \\
\hline Sen. Durbin, Richard J. [D-IL] & 23 & $2.41 \%$ & 4 & 5.75 \\
\hline Sen. Harkin, Tom [D-IA] & 23 & $2.41 \%$ & 5 & 4.6 \\
\hline Sen. Stabenow, Debbie [D-MI] & 21 & $2.20 \%$ & 4 & 5.25 \\
\hline
\end{tabular}

\footnotetext{
${ }^{5}$ A complete listing of bills sponsored per member per term in the Senate is listed in the Appendix.
} 


\begin{tabular}{|l|c|c|c|c|}
\hline Sen. Inouye, Daniel K. [D-HI] & 17 & $1.78 \%$ & 9 & 1.89 \\
\hline Sen. Hatch, Orrin G. [R-UT] & 16 & $1.68 \%$ & 7 & 2.29 \\
\hline Sen. Clinton, Hillary Rodham [D-NY] & 15 & $1.57 \%$ & 2 & 7.5 \\
\hline Sen. Feinstein, Dianne [D-CA] & 13 & $1.36 \%$ & 3 & 4.33 \\
\hline Sen. Leahy, Patrick J. [D-VT] & 13 & $1.36 \%$ & 3 & 4.33 \\
\hline Sen. Casey, Robert P., Jr. [D-PA] & 13 & $1.36 \%$ & 6 & 2.17 \\
\hline Sen. Menendez, Robert [D-NJ] & 13 & $1.36 \%$ & 8 & 1.63 \\
\hline Sen. Daschle, Thomas A. [D-SD] & 13 & $1.36 \%$ & 3 & 4.33 \\
\hline Sen. Bingaman, Jeff [D-NM] & 12 & $1.26 \%$ & 7 & 1.71 \\
\hline Sen. Biden, Joseph R., Jr. [D-DE] & 12 & $1.26 \%$ & 5 & 2.4 \\
\hline Sen. Gillibrand, Kirsten E. [D-NY] & 11 & $1.15 \%$ & 3 & 3.67 \\
\hline Sen. Akaka, Daniel K. [D-HI] & 10 & $1.05 \%$ & 4 & 2.5 \\
\hline Sen. Chafee, John H. [R-RI] & 10 & $1.05 \%$ & 4 & 2.5 \\
\hline Sen. Cranston, Alan [D-CA] & 10 & $1.05 \%$ & 4 & 2.5 \\
\hline Sen. Dodd, Christopher J. [D-CT] & 10 & $1.05 \%$ & 5 & 2 \\
\hline Sen. Klobuchar, Amy [D-MN] & 10 & $1.05 \%$ & 3 & 3.33 \\
\hline Sen. Murkowski, Lisa [R-AK] & 10 & $1.05 \%$ & 4 & 2.5 \\
\hline Sen. Rockefeller, John D., IV [D-WV] & 10 & $1.05 \%$ & 5 & 2 \\
\hline Sen. Shaheen, Jeanne [D-NH] & $1.05 \%$ & 2 & 5 \\
\hline
\end{tabular}

In addition to the committees that monopolize bill referral, and thus control health turf, and the members that sponsor the most legislation, it is important to note how individuals and committees intersect. In Table 4.3, I track sponsors and their committee assignments, using member profiles available on ProQuest Congressional (www.proquest.com)l and the "people search" by last name available through History Art \& Archives of the United States House of Representatives (https://history.house.gov). Table 4.3 lists member committee assignments for the top tier of bill sponsors. Although this is not a perfect measure, it is an indicator of the connections between bill sponsorship/committee membership activity and committee turf. One would expect that members write legislation so that it is referred to committees on which they serve (King 1997; Wawro 2000; Wilkerson, Smith, \& Stramp 2015). 
Table 4. 3 Top Bill Sponsors (House) Committee Assignments

\begin{tabular}{|c|c|}
\hline Member (House) & Committees \\
\hline Rep. Maloney, Carolyn B. [D-NY] & Financial Services, Oversight and Reform \\
\hline Rep. DeLauro, Rosa L. [D-CT] & Homeland Security, Budget \\
\hline Rep. Waxman, Henry A. [D-CA] & Oversight and Reform, Energy and Commerce \\
\hline Rep. Lowey, Nita M. [D-NY] & Homeland Security \\
\hline Rep. Lee, Barbara [D-CA] & Science, Space, \& Tech, Budget, Financial Services, Foreign Affairs \\
\hline Rep. Schroeder, Patricia [D-CO] & Homeland Security, Judiciary \\
\hline Rep. Morella, Constance A. [R-MD] & Science, Space, \& Tech, Oversight and Reform \\
\hline Rep. Slaughter, Louise McIntosh [D-NY] & Homeland Security, Rules, Budget, Oversight and Reform \\
\hline Rep. Nadler, Jerrold [D-NY] & Trans \& Infrastructure, Judiciary \\
\hline Rep. Schakowsky, Janice D. [D-IL] & Budget, Financial Services, Oversight and Reform, Energy and Commerce \\
\hline Rep. Pallone, Frank, Jr. [D-NJ] & Natural Resources, Energy and Commerce \\
\hline Rep. Oakar, Mary Rose [D-OH] & House Administration, Post Office \& Civil Serv, Financial Services \\
\hline Rep. DeGette, Diana [D-CO] & Natural Resources, Energy and Commerce \\
\hline Rep. Jackson Lee, Sheila [D-TX] & Homeland Security, Science, Space, \& Tech, Budget, Judiciary, Foreign Affairs \\
\hline Rep. Smith, Christopher H. [R-NJ] & Veterans' Affairs, Foreign Affairs \\
\hline Rep. Burgess, Michael C. [R-TX] & $\begin{array}{l}\text { Rules, Science, Space, \& Tech, Trans \& Infrastructure, Oversight and Reform, Energy and } \\
\text { Commerce }\end{array}$ \\
\hline Rep. Collins, Cardiss [D-IL] & Oversight and Reform, Energy and Commerce \\
\hline Rep. Miller, George [D-CA] & Natural Resources, Education and Labor \\
\hline Rep. Dellums, Ronald V. [D-CA] & Homeland Security, District of Columbia, Post Office \& Civil Serv, Armed Services, Foreign Affairs \\
\hline Rep. Meng, Grace [D-NY] & Small Business, Foreign Affairs \\
\hline Rep. Mikulski, Barbara A. [D-MD] & Merch Marine \& Fish, Energy and Commerce \\
\hline
\end{tabular}

As expected, Energy and Commerce shows the most committee membership among top

bills sponsored, and notably, the other committees demonstrating the most entrepreneurial 
activity have higher membership (ex. Foreign Affairs). This is also true for the Senate (Table

4.4). The Committees on Heath, Education, Labor and Pensions and Judiciary have the highest membership (10) among top sponsors and demonstrate higher levels of entrepreneurship across each of the measures. This distribution of committee membership among top sponsors indicates that individual member entrepreneurship is related to committee level entrepreneurship.

Table 4. 4 Top Bill Sponsors (Senate) Committee Assignments

\begin{tabular}{|c|c|}
\hline Member (Senate) & Committee Assignment \\
\hline Sen. Kennedy, Edward M. [D-MA] & Armed Services, Judiciary, Health, Ed, Labor, \& Pen \\
\hline Sen. Bo1er, Barbara [D-CA] & Comm, Science, \& Trans, Envi \& Public Works, Foreign Relations \\
\hline Sen. Snowe, Olympia J. [R-ME] & Small Business \& Entr, Budget, Comm, Science, \& Trans, Armed Services, Foreign Relations \\
\hline Sen. Mikulski, Barbara A. [D-MD] & Health, Ed, Labor, \& Pen \\
\hline Sen. Durbin, Richard J. [D-IL] & Foreign Relations, Judiciary \\
\hline Sen. Inouye, Daniel K. [D-HI] & Indian Affairs, Comm, Science, \& Trans \\
\hline Sen. Hatch, Orrin G. [R-UT] & Energy \& Natl Resources, Indian Affairs, Judiciary, Finance, Health, Ed, Labor, \& Pen \\
\hline Sen. Clinton, Hillary Rodham [D-NY] & Budget, Agr, Nutrition, \& For, Envi \& Public Works, Health, Ed, Labor, \& Pen \\
\hline Sen. Feinstein, Dianne [D-CA] & Comm, Science, \& Trans, Judiciary \\
\hline Sen. Leahy, Patrick J. [D-VT] & Agr, Nutrition, \& For, Judiciary \\
\hline
\end{tabular}




\begin{tabular}{|l|l|} 
Sen. Biden, Joseph R., Jr. [D-DE] & Foreign Relations, Judiciary \\
\hline Sen. Gillibrand, Kirsten E. [D-NY] & Agr, Nutrition, \& For, Armed Services, Envi \& Public Works \\
\hline Sen. Akaka, Daniel K. [D-HI] & Energy \& Natl Resources, Banking, Housing, \& UF, Homeland Sec \& Gov Affairs, Armed Services \\
\hline Sen. Chafee, John H. [R-RI] & Envi \& Public Works, Finance \\
\hline Sen. Cranston, Alan [D-CA] & Homeland Sec \& Gov Affairs \\
\hline Sen. Dodd, Christopher J. [D-CT] & Banking, Housing, \& UF, Budget, Foreign Relations, Health, Ed, Labor, \& Pen \\
\hline Sen. Klobuchar, Amy [D-MN] & Comm, Science, \& Trans, Agr, Nutrition, \& For, Envi \& Public Works \\
\hline Sen. Murkowski, Lisa [R-AK] & Energy \& Natl Resources, Indian Affairs, Envi \&Publi Works, ForeignRelations, Health,Ed,Labor,\&Pen \\
\hline Sen. Rockefeller, John D., IV [D-WV] & Energy \& Natl Resources, Comm, Science, \& Trans, Foreign Relations, Finance \\
\hline Sen. Shaheen, Jeanne [D-NH] & Energy \& Natl Resources, Small Business \& Entr, Armed Services, Foreign Relations \\
\hline
\end{tabular}

\section{COMMITTEE HEARINGS}

As a second indicator of committee entrepreneurship, I track those committees that hold hearings focused on women's health issues. Using the advanced search feature of ProQuest Congressional, I search by witness and "womens health" as a subject term. I also consider sponsor's participation in hearings, looking for sponsors who also show up as witnesses at hearings. While legislators testifying at hearings is rare, when they do it is often a sign of their expertise and investment in an issue (Fenno 1973; Marvel and McGrath 2016). I use ProQuest Congressional (https://www.proquest.com) and the subject search term “womens health" to identify 414 hearings concerning women's health from 1945-2018.

\section{Committees}

Figure 4.5 (and Table 4.5) represent the total number of House committee hearings held from 1945-2018. The committee on Oversight and Reform was most active (34 hearings or 
$17 \%)$, during the period studied followed by Energy and Commerce (30 hearings), Veterans' Affairs ( 28 hearings), and Judiciary ( 28 hearings) which combined account for $43 \%$ percent of hearing activity. A variety of other committees makeup the remaining $26 \%$. Oversight and Reform holds the most hearings, yet the Committee on Energy and Commerce received far more bill referrals (Figure 4.1), 1006 as compared to 71.

Figure 4. 5 House Committee Hearings Women's Health

\section{House Committee Hearings Women's Health}

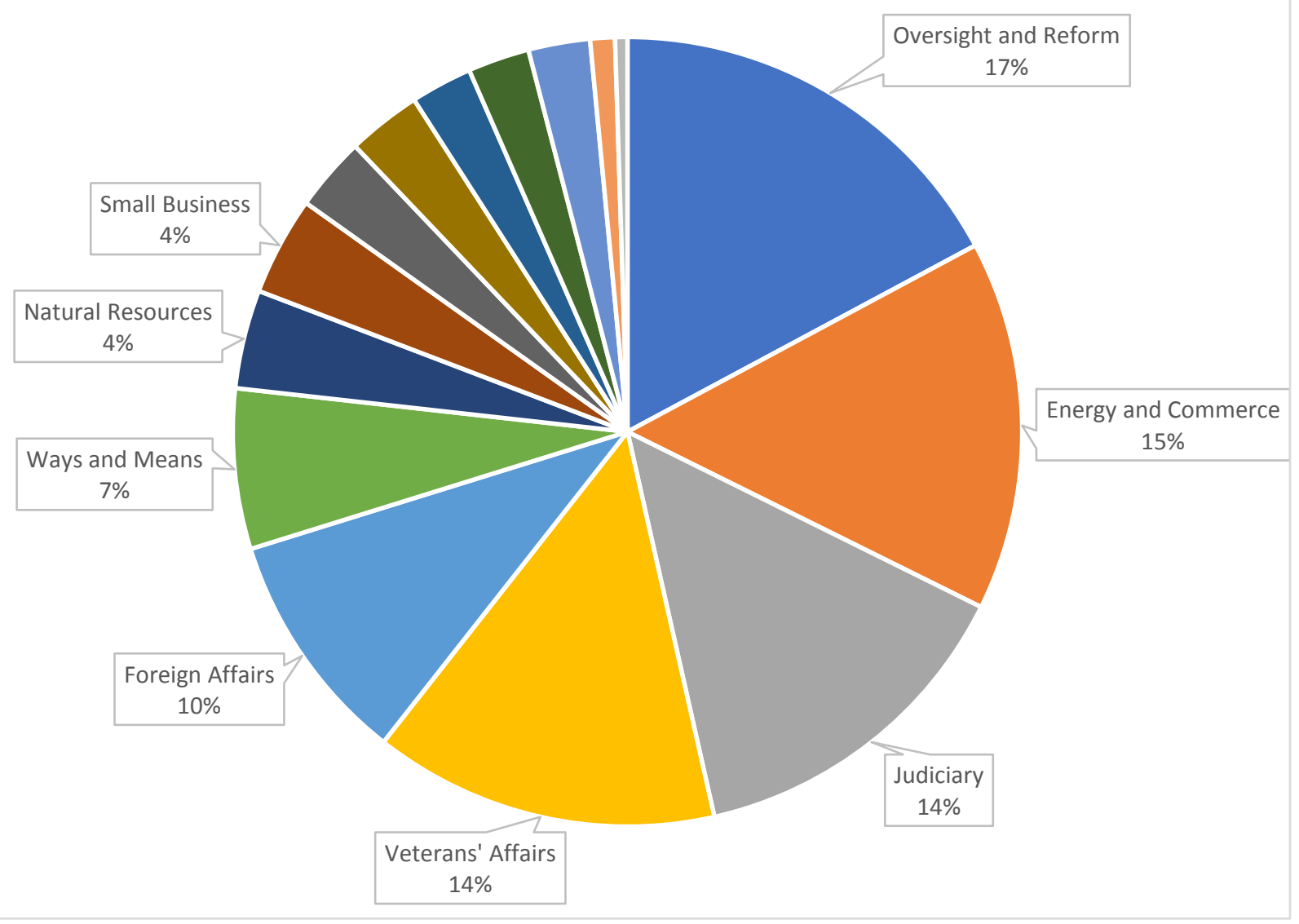


Table 4. 5 House Committee Hearings (Excluding Appropriations)

\begin{tabular}{|l|c|c|}
\hline House Committee Hearings & Total 198 & $\begin{array}{c}\text { \% of } \\
\text { Total }\end{array}$ \\
\hline Oversight and Reform & 34 & $17.17 \%$ \\
\hline Energy and Commerce & 30 & $15.15 \%$ \\
\hline Judiciary & 28 & $14.14 \%$ \\
\hline Veterans' Affairs & 28 & $14.14 \%$ \\
\hline Foreign Affairs & 19 & $9.60 \%$ \\
\hline Ways and Means & 13 & $6.57 \%$ \\
\hline Natural Resources & 8 & $4.04 \%$ \\
\hline Small Business & 8 & $4.04 \%$ \\
\hline Armed Service & 6 & $3.03 \%$ \\
\hline Transportation \& Infrastructure & 6 & $3.03 \%$ \\
\hline Agriculture & 5 & $2.53 \%$ \\
\hline Education and Labor & 5 & $2.53 \%$ \\
\hline Science, Space, and Technology & 5 & $2.53 \%$ \\
\hline Financial Services & 2 & $1.01 \%$ \\
\hline Budget & 1 & $0.51 \%$ \\
\hline
\end{tabular}

In the Senate (Figure 4.6 and Table 4.6), committee hearings closely match bill referrals.

The Committee on Health, Education, Labor, and Pensions holds the most hearings, 21, and Veterans' Affairs (16 hearings) is also an expected result. The Senate Special Committee on Aging held 11 hearings, which is interesting as specific bills are not referred to this committee.

The overall number of hearings are less in the Senate than the House, and this will be particularly notable as I also evaluate passed legislation. 
Figure 4. 6 Senate Committee Hearings Women's Health

\section{Senate Committee Hearings Women's Health}

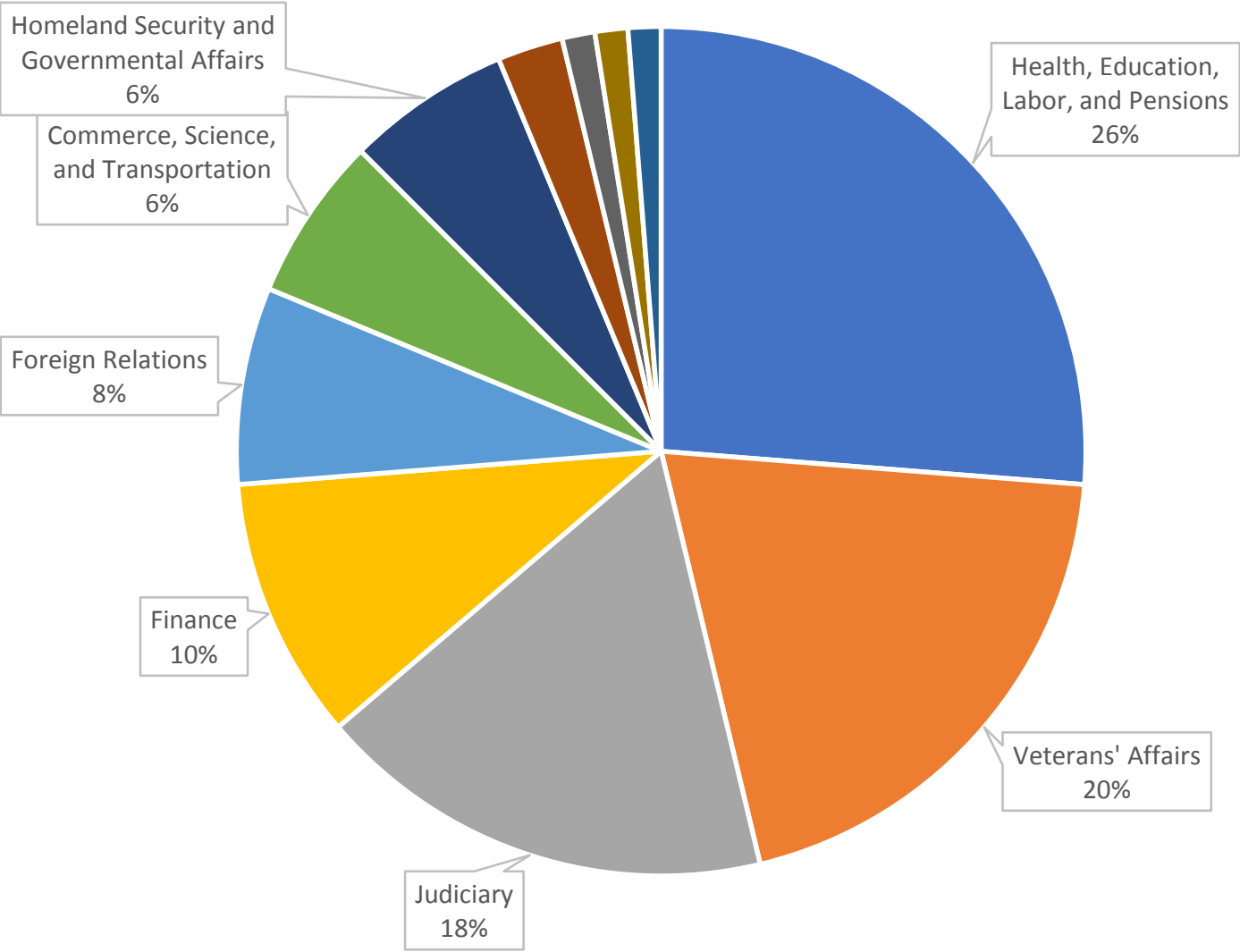

Table 4. 6 Senate Committee Hearings (Excluding Appropriations)

\begin{tabular}{|l|c|c|}
\hline Senate Committee Hearings & Total 80 & $\begin{array}{c}\% \text { of } \\
\text { Total }\end{array}$ \\
\hline Health, Education, Labor, and Pensions & 21 & $26.25 \%$ \\
\hline Veterans' Affairs & 16 & $20.00 \%$ \\
\hline Judiciary & 14 & $17.50 \%$ \\
\hline Finance & 8 & $10.00 \%$ \\
\hline Foreign Relations & 6 & $7.50 \%$ \\
\hline Commerce, Science, and Transportation & 5 & $6.25 \%$ \\
\hline Homeland Security and Governmental Affairs & 5 & $6.25 \%$ \\
\hline Armed Service & 2 & $2.50 \%$ \\
\hline Agriculture, Nutrition, and Forestry & 1 & $1.25 \%$ \\
\hline Budget & 1 & $1.25 \%$ \\
\hline Environment and Public Works & 1 & $1.25 \%$ \\
\hline
\end{tabular}


Individual Members

Table 4.7 lists the members who testified two or more times at hearings. Representative Patricia Schroeder (D-Co) testified 20 different times, which is significantly more than any other member in the House. She was also among the top sponsors with 22 bills, or $0.92 \%$ of all women's health bills.

Table 4. 7 House Hearing Testimony

\begin{tabular}{|l|c|}
\hline Member (House) & \# of Times Testified \\
\hline Schroeder & 20 \\
\hline Hyde & 4 \\
\hline Lowey & 4 \\
\hline Oakar & 4 \\
\hline DeLauro & 3 \\
\hline Morella & 3 \\
\hline Archrer & 2 \\
\hline Bilirakis & 2 \\
\hline Johnson & 2 \\
\hline Leland & 2 \\
\hline
\end{tabular}

Elected as a Democrat to the Ninety-third and to the eleven succeeding Congresses, Representative Pat Schroeder (D- CO) made many issues shared by middle-class Americans her top priority. She advocated for women's health care, child rearing, expansion of Social Security benefits, and gender equity in the workplace. She was known as a hard-working and straightshooting ally to her colleagues (Lowy 2003).

From her seat on the Armed Services Committee, she once told Pentagon officials that if they were women, they would always be pregnant because they never said "no" (Lowy 2003). When another asked how she could be a mother of two small children and a member of 
Congress at the same time. She replied, "I have a brain and a uterus and I use both" (Lowy 2003). She was a vocal pro-choice advocate and a supporter of the Equal Rights Amendment. In 1977, Schroeder co-founded the Congressional Women's Caucus, subsequently co-chairing it for 10 years. She helped pass the 1978 Pregnancy Discrimination Act, which mandated that employers could not dismiss women employees simply because they were pregnant or deny them disability and maternity benefits. Later she created and chaired the Select Committee on Children, Youth and Families (but it was dismantled in 1995).

In 1993, Schroeder garnered significant legislative success with the passage of the Family and Medical Leave Act and the National Institutes of Health Revitalization Act. For nearly a decade, she worked on and petitioned for the Family and Medical Leave Act, which in its final form provided job protection of up to 18 weeks of unpaid leave for the care of a newborn, sick child, or parent. (Lowy 2003).

She supported many facets of women's health policy and participated in committee hearings on health care reform, pregnancy- related services under Title X of the Social Security Act, NIH research and training programs for women's health research, discrimination in insurance practices, Global Human Rights Abuses and sexual assault against women, mammography benefits coverage and standards guidelines, and fetal-alcohol syndrome. One of her long-championed cases was veteran women's health.

In June 1993, alongside Representative Rosa DeLauro (D-CT), she testified before the Subcommittee on Oversight and Investigations of the Committee on Veterans' Affairs (House) in support of a bill (HR 2285) that she sponsored to alleviate deficiencies in women veteran's 
health care services (HRG-1993-VAH-0019). Although the committee helped to pass previous legislation expanding benefits for female veterans, Rep. Schroeder was determined to see quality programs established and maintained. Noting that the Inspector General's report indicated women's health care services at the VA are much worse than previously suspected. She explained to the committee, "It is not just the lack of coordinators, it trickles right out into all the services. Of the 166 facilities surveyed, 75 offered no on-site women's health care clinics, and that is really amazing" (HRG-1993-VAH-0019). She expressed her deep concern saying, "I was even appalled that some of those who said that they did have women's health clinics, when they pressed them, they found out they were every other week and maybe for four hours. So if you didn't know when that window was open, you were in real trouble" (HRG-1993VAH-0019).

The proposed bill provided for in-house, gender-specific services, reallocating staff in the Central Office to support women's health programs, developing quality indicators for gender-specific services, and training programs. Schroeder noted, "we just can't implement them fast enough." She also warned the committee,

"I am soon going to be also offering another piece of legislation that will provide women veterans a basic primary care and preventive care package and expand research on women's health at the VA. We need the tough quality standards for mammography, and we also need to look much more at research for women who have been in the military." The proposed bill garnered twelve cosponsors, including the committee chairman. The bill never made it out of the committee, but a Senate version of the bill, sponsored by Senator John D. Rockafeller (D- WV), passed in the Senate, but it was a similar bill (Veterans Health Programs Extension Act of 1994 HR 3313) that was finally signed into law later that year. 
Other members with active participation in committee hearing include Representative Mary Rose Oakar (D- OH), Representative Nita Lowey (D-NY), Representative Constance Morella (R-MD), and Representative Rosa DeLauro (D-CT). They also rank among top bill sponsors in the House, with Representative Nits Lowey sponsoring nearly $2 \%$ of all women's health legislation (Table 4.1).

Supporters of women's health legislation are not all necessarily Democrats or pro-choice advocates. This group certainly demonstrates that. During her tenure, Congresswoman Mary Rose Oakar (D- OH) was dedicated to improving the welfare of women. She was not shy about her position for women's rights, though she often came into conflict with national women's groups for her pro-life stance (Ruess 1992). Her position caused friction with powerful women's groups like the National Organization for Women (NOW), which served to undermine her potential as a leading public figure in feminist circles. Although frustrated with her inability to connect with leading women's organizations, Oakar developed a reputation as a liberal who worked on behalf of women's rights issues. Though mainly concerned with economic parity, she championed particular women's health causes. Representative Oakar encouraged her female colleagues on Capitol Hill to work for equality with men. "There are only 24 women in Congress," she declared. "It seems to me, beyond all other issues, we're obligated to correct inequities toward our own gender. No one else is going to do it" (Ruess 1992).

In a hearing before the Subcommittee on Health for the House Ways and Means Committee, Rep. Oakar gave an impassioned testimony alongside Senator Barbara Boxer in support of consideration for HR 3880. The bill included provisions concerning Medicare coverage of mammography screening for breast cancer, and was sponsored by the committee 
chair, Representative Pete Stark (D-CA) as well as the minority leader, Robert Michel (R-IL)

(Oakar was also a co-sponsor).

She began her statement by reminding the committee of the short-lived victory for breast cancer prevention under the Medicare Catastrophic Coverage Act (1988), but it was later repealed. She frankly stated "Mammography coverage saves money and most importantly it saves lives. One woman is diagnosed with breast cancer every 13 minutes in this country" (HRG-1990-WAM-0005). Her passion was evident as she closed her speech saying,

"I mean, I am outraged. If I sound a little bit on the outrageous side today, let me tell you, I have had it with this issue because I feel that if we don't do something about it in this Congress, and that is why I am delighted that you are having this hearing, and that you have this aspect in your legislation. Then I think we should be totally ashamed of ourselves"(HRG-1990-WAM-0005).

Although this bill never made it to the full chamber for consideration, coverage of screen mammography was included in HR.5835, Omnibus Budget Reconciliation Act of 1990, and signed into law almost one year later on November 5, 1990.

As the literature indicates, considering the frequency of committee hearings and the number of times a member testifies, this measure is still imperfect. Capturing the tenacity of members like Rep. Patricia Schroeder or passion of Rep. Mary Rose Oakar is impossible. Some hearings may last several days, while others last the entire session and the number of witnesses varies greatly. While testimony and committee hearings are good measures of entrepreneurship, it is clear that members establish their policy expertise in a variety of ways.

In the Senate (Table 4.8), Olympia Snowe (R-Ma) is the most active, testifying nine times. Senator Snowe also sponsors the third most legislation in the Senate $(1.3 \%$ of all women's health legislation). Barbara Boxer (D-Ca) testified at 5 hearings, and sponsors the 
second most bills, 39. Similarly, Richard Durbin (D-II) also testifies 5 times and sponsors 23 bills. Alan Cranston (D-Ca) is also quite active as a sponsor but only testifies twice. This is similar to the remainder of senators who testify more than once, none of whom sponsor more than 10 bills. Similar to the House, the senator who sponsors the most legislation, Senator Ted Kennedy, only testifies once.

Table 4. 8 Senate Hearing Testimony

\begin{tabular}{|l|c|}
\hline $\begin{array}{l}\text { Member } \\
\text { (Senate) }\end{array}$ & $\begin{array}{c}\text { \# of Times } \\
\text { Testified }\end{array}$ \\
\hline Snowe & 9 \\
\hline Boxer & 5 \\
\hline Durbin & 5 \\
\hline Chiles & 4 \\
\hline Bumpers & 2 \\
\hline Cranston & 2 \\
\hline Specter & 2 \\
\hline
\end{tabular}

\section{LEGISLATION PASSED}

Finally, I consider entrepreneurial activity as it relates to legislation passed. Using the advanced search function in Congress.gov, I limit my results with the legislative subject term "women's health." I include data from all Congresses beginning with the $93^{\text {rd }}(1973)$ through the $115^{\text {th }}$ (2018) and all legislative actions. Of the 2,391 results for introduced legislation, 140 became law with 90 originating in the House and 50 in the Senate. I use these results to track which committees report out the most bills and how many of passed laws come from each committee. Additionally, I track how many laws passed were sponsored by each member and the number of co-sponsors on each bill. I calculate whether bills with more co-sponsors (demonstrating coalition building, Wawro 2000) are more likely to pass. 


\section{Committees}

In the House, the Committee on Energy and Commerce is again the leading committee in legislative activity. Figure 4.7 indicates that the Committee on Energy and Commerce shows the most activity with regard to laws passed. From 1973-2018, Energy and Commerce passed almost three times as many bills as any other House committee, but only $4 \%$ of all women's health bills referred to the committee. Interestingly, the Committee on Small Business holds the highest percentage of laws passed at $75 \%$ (three out of four), and the no longer active Committee on Merchant Marines and Fisheries passed $40 \%$ of bills referred to it (two out of five). This is particularly interesting as the Merchant Marines was the first of the five military academies to admit women but unfortunately reports the highest rate of sexual assault and harassment of any other military school (Kennedy 1978; Rein 2016).

Figure 4. 7 Laws Passed House Committees 1973-2018

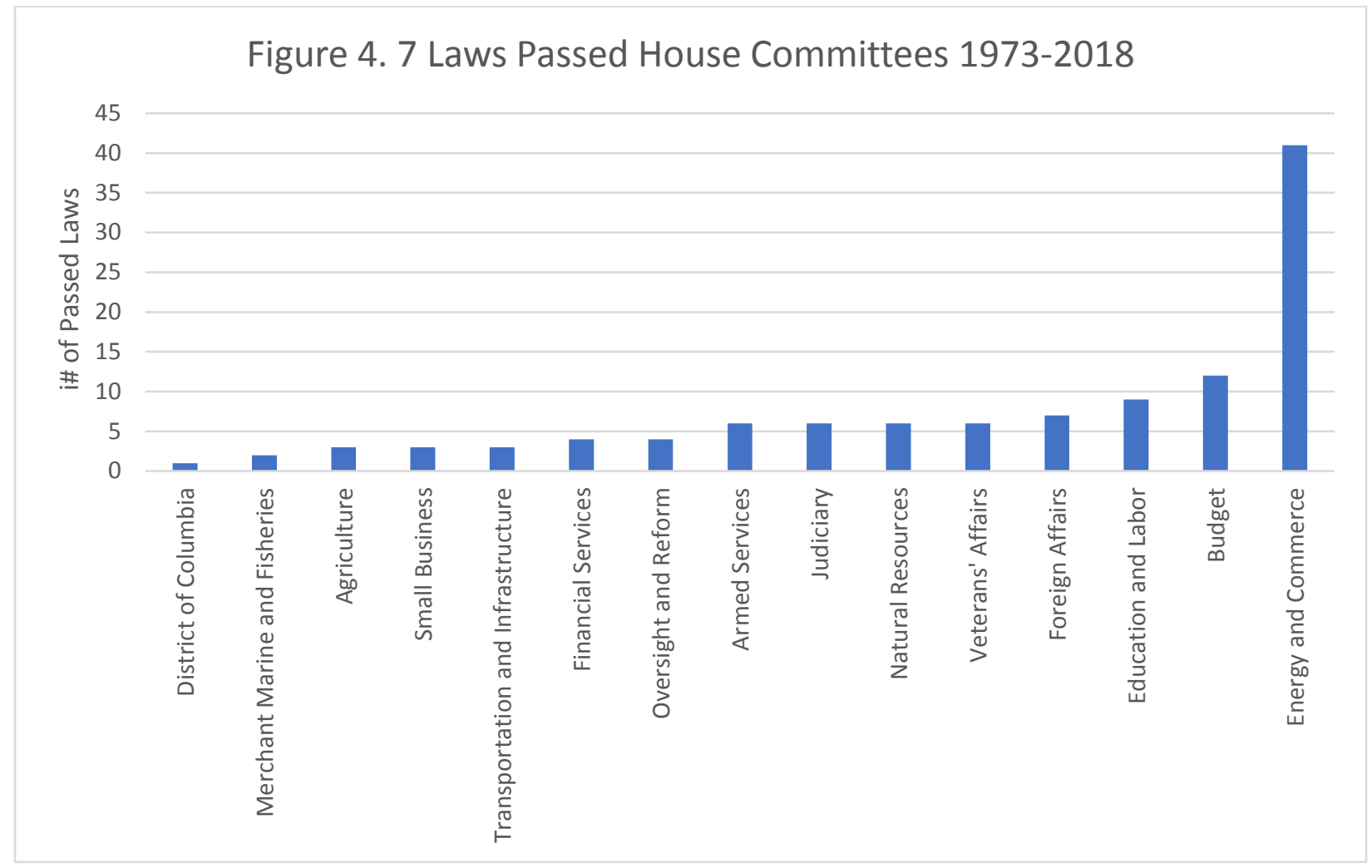


Table 4. 9 Laws Passed House Committees (Excluding Appropriations)

\begin{tabular}{|l|c|c|c|}
\hline House Committee & $\begin{array}{c}\text { Bills } \\
\text { Referred }\end{array}$ & $\begin{array}{c}\text { Laws } \\
\text { Passed }\end{array}$ & \% Passed \\
\hline Small Business & 4 & 3 & $75.00 \%$ \\
\hline Merchant Marine and Fisheries & 5 & 2 & $40.00 \%$ \\
\hline Budget & 41 & 12 & $29.30 \%$ \\
\hline Transportation and Infrastructure & 25 & 3 & $12.00 \%$ \\
\hline Natural Resources & 52 & 6 & $11.50 \%$ \\
\hline Armed Services & 71 & 6 & $8.50 \%$ \\
\hline Financial Services & 55 & 4 & $7.30 \%$ \\
\hline District of Columbia & 14 & 1 & $7.10 \%$ \\
\hline Agriculture & 43 & 3 & $7.00 \%$ \\
\hline Veterans' Affairs & 102 & 6 & $5.90 \%$ \\
\hline Oversight and Reform & 71 & 4 & $5.60 \%$ \\
\hline Foreign Affairs & 148 & 7 & $4.70 \%$ \\
\hline Judiciary & 142 & 6 & $4.20 \%$ \\
\hline Energy and Commerce & 1006 & 41 & $4.10 \%$ \\
\hline Ways and Means & 393 & 15 & $3.80 \%$ \\
\hline Education and Labor & 256 & 9 & $3.50 \%$ \\
\hline Homeland Security & 10 & 0 & $0.00 \%$ \\
\hline House Administration & 12 & 0 & $0.00 \%$ \\
\hline Post Office and Civil Services & 27 & 0 & $0.00 \%$ \\
\hline Rules & 20 & 0 & $0.00 \%$ \\
\hline Science, Space, and Technology & 20 & 0 & $0.00 \%$ \\
\hline
\end{tabular}

In the Senate, bills referred to the Committee on Health, Education, Labor, and Pensions also yields the most passed legislation (Figure 4.8). Health, Education, Labor, and Pensions receives more than double the amount of bills referred, and they also hold the greatest number of hearings. Foreign Relations (or Foreign Affairs) yields the second highest number of passed laws and falls in the top half of hearings held (Figure 4.6). There does not appear to be other instances of struggle for turf control concerning women's health in the Senate.

Figure 4. 8 Laws Passed Senate Committees 1973-2018 
Figure 4.8 Laws Passed Senate Committees 1973-2018

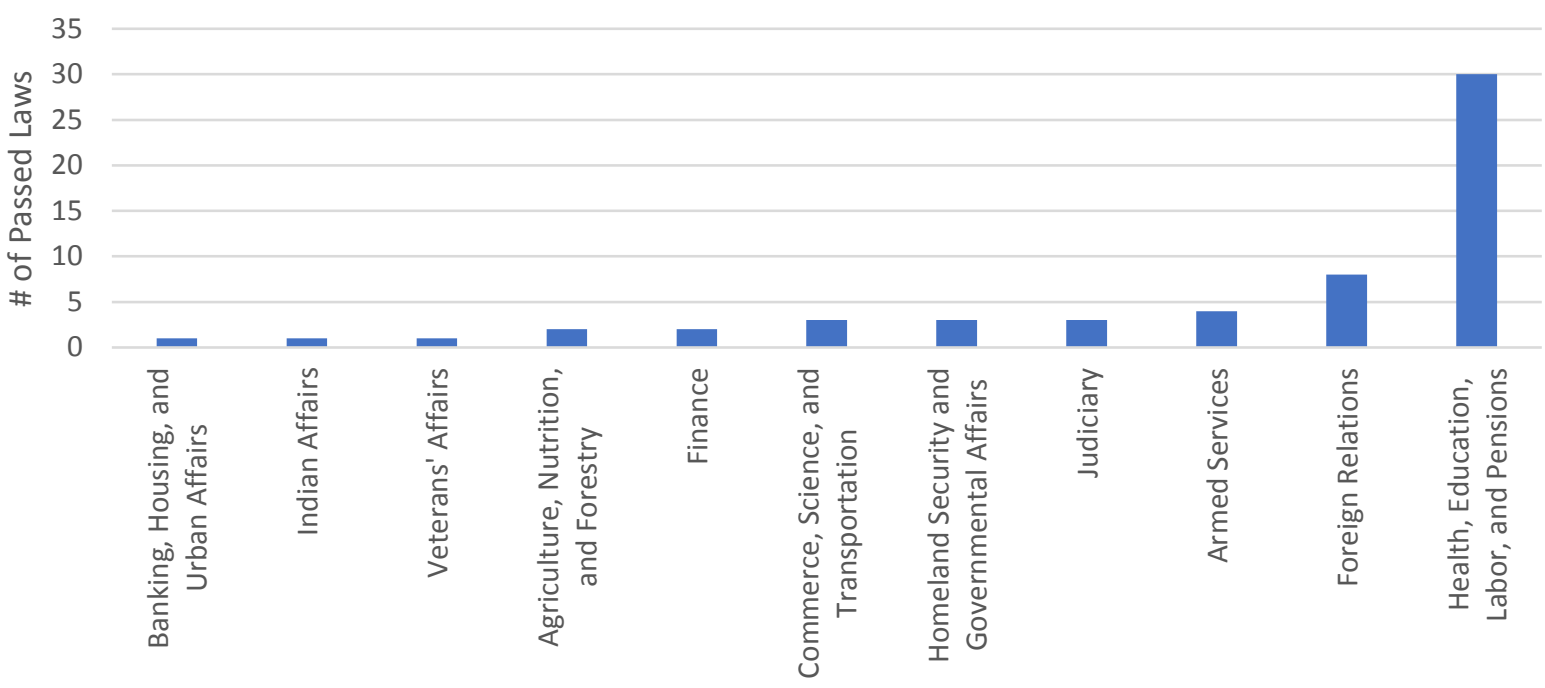

Table 4. 10 Laws Passed from Senate Committees (Excluding Appropriations)

\begin{tabular}{|l|c|c|c|}
\hline Senate Committee & $\begin{array}{c}\text { Bills } \\
\text { Referred }\end{array}$ & $\begin{array}{c}\text { Laws } \\
\text { Passed }\end{array}$ & $\begin{array}{c}\% \\
\text { Passed }\end{array}$ \\
\hline Commerce, Science, and Transportation & 16 & 3 & $18.80 \%$ \\
\hline $\begin{array}{l}\text { Homeland Security and Governmental } \\
\text { Affairs }\end{array}$ & 16 & 3 & $18.80 \%$ \\
\hline Banking, Housing, and Urban Affairs & 7 & 1 & $14.30 \%$ \\
\hline Armed Services & 31 & 4 & $12.90 \%$ \\
\hline Foreign Relations & 70 & 8 & $11.40 \%$ \\
\hline Agriculture, Nutrition, and Forestry & 23 & 2 & $8.70 \%$ \\
\hline Health, Education, Labor, and Pensions & 400 & 30 & $7.50 \%$ \\
\hline Indian Affairs & 14 & 1 & $7.10 \%$ \\
\hline Judiciary & 75 & 3 & $4.00 \%$ \\
\hline Veterans' Affairs & 61 & 1 & $1.60 \%$ \\
\hline Finance & 192 & 2 & $1.00 \%$ \\
\hline Budget & 10 & 0 & $0.00 \%$ \\
\hline Energy and Natural Resources & 1 & 0 & $0.00 \%$ \\
\hline Environment and Public Works & 32 & 0 & $0.00 \%$ \\
\hline Small Business and Entrepreneurship & 1 & 0 & $0.00 \%$ \\
\hline
\end{tabular}

Individual Members

Table 4.11 indicates the number of bills sponsored per member in the House, the number of bills sponsored that became law (the percentage of those that passed), and the 
percentage of total women's health bills introduced in both chambers. Twelve members sponsored more than one passed bill, including Representative Nita Lowey who also appears in the list of members who sponsor the most legislation, and testify multiple times. Among the top bill sponsors are Representative Henry Waxman, Representative Nita Lowey, and Representative Michael Burgess. As indicated by the percentage of bills passed calculation, sponsoring more bills does not necessarily yield a higher percentage passed.

Table 4. 11 Passed Legislation by Chamber per House Member (top tier)

\begin{tabular}{|l|c|c|c|c|}
\hline Member (House) & Sponsored & Passed & $\begin{array}{c}\% \\
\text { Passed }\end{array}$ & $\begin{array}{c}\% \text { of Total } \\
\text { WH Bills }\end{array}$ \\
\hline Rep. Montgomery, G. V. (Sonny) [D-MS] & 3 & 2 & $67 \%$ & $0.13 \%$ \\
\hline Rep. Obey, David R. [D-WI] & 3 & 2 & $67 \%$ & $0.13 \%$ \\
\hline Rep. Rowland, J. Roy [D-GA] & 3 & 2 & $67 \%$ & $0.13 \%$ \\
\hline Rep. Gray, William H., III [D-PA] & 4 & 2 & $50 \%$ & $0.17 \%$ \\
\hline Rep. Rostenkowski, Dan [D-IL] & 4 & 2 & $50 \%$ & $0.17 \%$ \\
\hline Rep. Dingell, John D. [D-MI] & 5 & 2 & $40 \%$ & $0.21 \%$ \\
\hline Rep. Rangel, Charles B. [D-NY] & 5 & 2 & $40 \%$ & $0.21 \%$ \\
\hline Rep. Panetta, Leon [D-CA] & 7 & 2 & $29 \%$ & $0.29 \%$ \\
\hline Rep. Porter, John Edward [R-IL] & 7 & 2 & $29 \%$ & $0.29 \%$ \\
\hline Rep. Burgess, Michael C. [R-TX] & 11 & 2 & $18 \%$ & $0.46 \%$ \\
\hline Rep. Lowey, Nita M. [D-NY] & 28 & 2 & $7 \%$ & $1.17 \%$ \\
\hline Rep. Waxman, Henry A. [D-CA] & 39 & 2 & $5 \%$ & $1.63 \%$ \\
\hline Rep. Bonamici, Suzanne [D-OR] & 3 & 1 & $33 \%$ & $0.13 \%$ \\
\hline Rep. Christensen, Donna M. [D-VI] & 3 & 1 & $33 \%$ & $0.13 \%$ \\
\hline Rep. Foley, Thomas S. [D-WA] & 3 & 1 & $33 \%$ & $0.13 \%$ \\
\hline Rep. Hawkins, Augustus F. [D-CA] & 3 & 1 & $33 \%$ & $0.13 \%$ \\
\hline Rep. Issa, Darrell E. [R-CA] & 3 & 1 & $33 \%$ & $0.13 \%$ \\
\hline Rep. Kasich, John R. [R-OH] & 3 & 1 & $33 \%$ & $0.13 \%$ \\
\hline Rep. McKeon, Howard P. "Buck" [R-CA] & 3 & 1 & $33 \%$ & $0.13 \%$ \\
\hline Rep. Myrick, Sue Wilkins [R-NC] & 3 & $33 \%$ & $0.13 \%$ \\
\hline Rep. Rogers, Harold [R-KY] & 3 & $33 \%$ & $0.13 \%$ \\
\hline Rep. Sires, Albio [D-NJ] & 3 & $33 \%$ & $0.13 \%$ \\
\hline Rep. Traficant, James A., Jr. [D-OH] & 3 & $25 \%$ & $0.17 \%$ \\
\hline Rep. Dent, Charles W. [R-PA] & 3 & & $0.13 \%$ \\
\hline
\end{tabular}




\begin{tabular}{|l|c|c|c|c|} 
Rep. Roybal-Allard, Lucille [D-CA] & 4 & 1 & $25 \%$ & $0.17 \%$ \\
\hline Rep. Berman, Howard L. [D-CA] & 5 & 1 & $20 \%$ & $0.21 \%$ \\
\hline Rep. Bilirakis, Michael [R-F] & 5 & 1 & $20 \%$ & $0.21 \%$ \\
\hline Rep. Dellums, Ronald V. [D-CA] & 5 & 1 & $20 \%$ & $0.21 \%$ \\
\hline Rep. Granger, Kay [R-TX] & 5 & 1 & $20 \%$ & $0.21 \%$ \\
\hline Rep. Stark, Fortney Pete [D-CA] & 6 & 1 & $17 \%$ & $0.25 \%$ \\
\hline Rep. Baldwin, Tammy [D-WI] & 7 & 1 & $14 \%$ & $0.29 \%$ \\
\hline Rep. Hyde, Henry J. [R-IL] & 7 & 1 & $14 \%$ & $0.29 \%$ \\
\hline Rep. Stearns, Cliff [R] & 7 & 1 & $14 \%$ & $0.29 \%$ \\
\hline Rep. Greenwood, James C. [R-PA] & 8 & 1 & $13 \%$ & $0.33 \%$ \\
\hline Rep. Dingell, John D. [D-MI] & 9 & 1 & $11 \%$ & $0.38 \%$ \\
\hline Rep. Maloney, Carolyn B. [D-NY] & 9 & 1 & $11 \%$ & $0.38 \%$ \\
\hline Rep. Pallone, Frank, Jr. [D-NJ] & 15 & 1 & $7 \%$ & $0.63 \%$ \\
\hline Rep. DeLauro, Rosa L. [D-CT] & 42 & 1 & $2 \%$ & $1.76 \%$ \\
\hline
\end{tabular}

In the Senate, the top tier of members with the most bills sponsored and passed into law is much more defined. A total of six senators sponsor bills that are passed into law with Senator Edward (Ted) Kennedy sponsoring seven passed laws. Senator Kennedy also sponsors the most women's health legislation in the Senate. Unlike the House, however, there is not a clear connection across all three measurements of entrepreneurship. Appearing in both top bill sponsorship and laws passed are Senator Patrick Leahy, Senator Diane Feinstein, and Senator Orrin Hatch. Senator Barbara Boxer appears in the top bill sponsors and testifies multiple times in congressional hearings, and Senator Olympia Snowe appears in the list of top sponsors and testifies the greatest number of times but does not get a bill passed. Although these measures of entrepreneurship are not definitive, they do provide an impression of the subsystem and the actors at play. 
Table 4. 12 Passed Legislation by Chamber per Senate Member (top tier)

\begin{tabular}{|c|c|c|c|c|}
\hline Member (Senate) & Sponsored & Passed & $\begin{array}{c}\% \\
\text { Passed }\end{array}$ & $\begin{array}{c}\% \text { of } \\
\text { Total } \\
\text { WH Bills }\end{array}$ \\
\hline Sen. Kennedy, Edward M. [D-MA] & 40 & 7 & $18 \%$ & $1.67 \%$ \\
\hline Sen. Alexander, Lamar [R-TN] & 9 & 3 & $33 \%$ & $0.38 \%$ \\
\hline Sen. Hatch, Orrin G. [R-UT] & 16 & 3 & $19 \%$ & $0.67 \%$ \\
\hline Sen. Jeffords, James M. [R-VT] & 4 & 2 & $50 \%$ & $0.17 \%$ \\
\hline Sen. Feinstein, Dianne [D-CA] & 13 & 2 & $15 \%$ & $0.54 \%$ \\
\hline Sen. Leahy, Patrick J. [D-VT] & 13 & 2 & $15 \%$ & $0.54 \%$ \\
\hline Sen. Goldwater, Barry [R-AZ] & 1 & 1 & $100 \%$ & $0.04 \%$ \\
\hline Sen. Hagel, Chuck [R-NE] & 1 & 1 & $100 \%$ & $0.04 \%$ \\
\hline Sen. Johnson, Ron [R-WI] & 1 & 1 & $100 \%$ & $0.04 \%$ \\
\hline Sen. Metzenbaum, Howard M. [D-OH] & 1 & 1 & $100 \%$ & $0.04 \%$ \\
\hline Sen. Sullivan, Dan [R-AK] & 1 & 1 & $100 \%$ & $0.04 \%$ \\
\hline Sen. Pell, Claiborne [D-RI] & 2 & 1 & $50 \%$ & $0.08 \%$ \\
\hline Sen. Rubio, Marco [R-FL] & 2 & 1 & $50 \%$ & $0.08 \%$ \\
\hline Sen. Isakson, Johnny [R-GA] & 3 & 1 & $33 \%$ & $0.13 \%$ \\
\hline Sen. Kassebaum, Nancy Landon [R-KS] & 3 & 1 & $33 \%$ & $0.13 \%$ \\
\hline Sen. Warner, John [R-VA] & 3 & 1 & $33 \%$ & $0.13 \%$ \\
\hline Sen. Hutchison, Kay Bailey [R-TX] & 4 & 1 & $25 \%$ & $0.17 \%$ \\
\hline Sen. McConnell, Mitch [R-KY] & 4 & 1 & $25 \%$ & $0.17 \%$ \\
\hline Sen. Nunn, Sam [D-GA] & 4 & 1 & $25 \%$ & $0.17 \%$ \\
\hline Sen. Santorum, Rick [R-PA] & 4 & 1 & $25 \%$ & $0.17 \%$ \\
\hline Sen. Dole, Robert J. [R-KS] & 5 & 1 & $20 \%$ & $0.21 \%$ \\
\hline Sen. Coons, Christopher A. [D-DE] & 6 & 1 & $17 \%$ & $0.25 \%$ \\
\hline Sen. Gregg, Judd [R-NH] & 6 & 1 & $17 \%$ & $0.25 \%$ \\
\hline Sen. Lincoln, Blanche L. [D-AR] & 6 & 1 & $17 \%$ & $0.25 \%$ \\
\hline Sen. Whitehouse, Sheldon [D-RI] & 6 & 1 & $17 \%$ & $0.25 \%$ \\
\hline Sen. Cornyn, John [R-TX] & 7 & 1 & $14 \%$ & $0.29 \%$ \\
\hline Sen. Frist, William H. [R-TN] & 7 & 1 & $14 \%$ & $0.29 \%$ \\
\hline Sen. Wicker, Roger F. [R-MS] & 7 & 1 & $14 \%$ & $0.29 \%$ \\
\hline Sen. Brown, Sherrod [D-OH] & 8 & 1 & $13 \%$ & $0.33 \%$ \\
\hline Sen. Levin, Carl [D-MI] & 8 & 1 & $13 \%$ & $0.33 \%$ \\
\hline Sen. Akaka, Daniel K. [D-HI] & 10 & 1 & $10 \%$ & $0.42 \%$ \\
\hline Sen. Bingaman, Jeff [D-NM] & 12 & 1 & $8 \%$ & $0.50 \%$ \\
\hline Sen. Casey, Robert P., Jr. [D-PA] & 13 & 1 & $8 \%$ & $0.54 \%$ \\
\hline Sen. Menendez, Robert [D-NJ] & 13 & 1 & $8 \%$ & $0.54 \%$ \\
\hline Sen. Inouye, Daniel K. [D-HI] & 17 & 1 & $6 \%$ & $0.71 \%$ \\
\hline
\end{tabular}




\begin{tabular}{|l|l|l|l|l|} 
Sen. Mikulski, Barbara A. [D-MD] & 26 & 1 & $4 \%$ & $1.09 \%$ \\
\hline Sen. Boxer, Barbara [D-CA] & 39 & 1 & $3 \%$ & $1.63 \%$ \\
\hline
\end{tabular}

\section{COSPONSORS}

In addition to bills sponsored and bills passed related to women's health, I track the total number of co-sponsors per bill. I am interested in whether the number of cosponsors is an indicator of whether a bill is more likely to pass or fail. I used a Chi Square test to determine if there is a relationship between the number of cosponsors and passed legislation. Considering the distribution of the data, I selected three levels of co-sponsorship (low, moderate, and high).

House

\begin{tabular}{cccc}
\hline Number of Cosponsors & Passed & Failed & \\
\hline 0 to 10 & 53 & 531 & 584 \\
11 to 50 & $(35.04)$ & $(548.9)$ & \\
& 19 & 420 & 439 \\
51 or higher & $(26.34)$ & $(412.7)$ & \\
& 17 & 317 & 334 \\
Total & $(20)$ & $(313.9)$ & \\
& 89 & 1268 & \\
$X^{2}=10.78 \mathrm{df}=2 \mathrm{p}=0.0046$ & &
\end{tabular}




\section{Senate}

\begin{tabular}{lccc}
\hline Number of Cosponsors & Passed & Failed & \\
\hline 0 to 10 & 24 & 561 & 585 \\
& $(35.1)$ & $(549.9)$ & \\
11 to 50 & 21 & 230 & 251 \\
& $(15.1)$ & $(235.9)$ & \\
51 or higher & 5 & 23 & 28 \\
& $(1.68)$ & $(26.3)$ & \\
\hline Total & 50 & 814 & 864
\end{tabular}

$X^{2}=13.59 \mathrm{df}=2 \mathrm{p}=0.0011$

Figure 4.9 Relative Percentage of House and Senate Bills to \# of Cosponsors

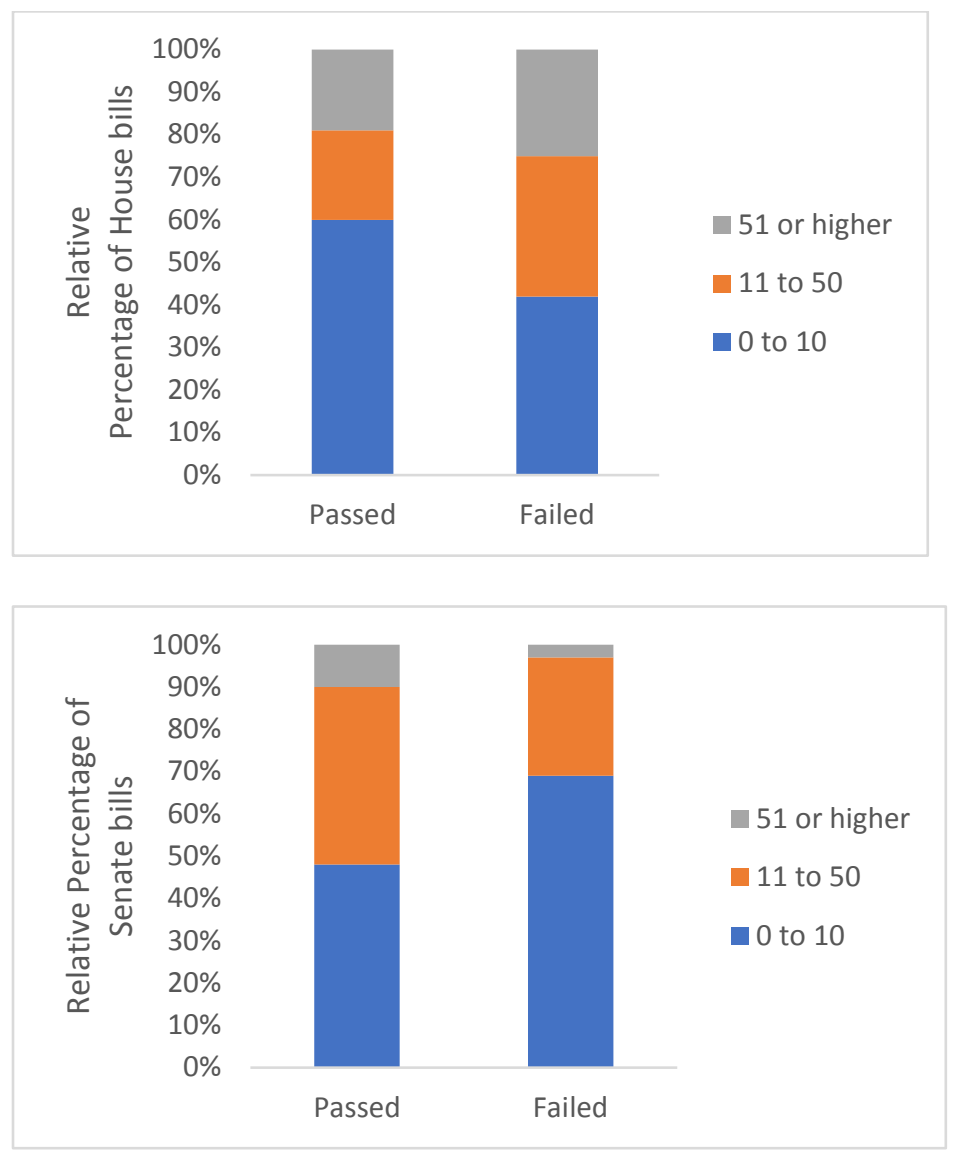


In this analysis, I consider whether there is a significant relationship between the pass or fail status and different levels of co-sponsoring (low, moderate, or high). The null hypothesis for this test is that there is no relationship, (that is, the number of cosponsors does not relate to the number of bills passed or failed). For both the Senate and House bills, the p-values are less than the significance level, thus we can reject the null hypothesis in favor of the alternative that there is a relationship. Although, as evidenced in Figure 4.9, it is easy to see the relationships are not the same in the House and the Senate.

Co-sponsorship, specifically, is notable as it is a signal of coalition building, bipartisan support, and general consensus (Hunt 2002). Wawro (2000) also attributes co-sponsorship to practices of coalition building and increased entrepreneurship activity. Interestingly, the relationship is stronger in the Senate than in the House. This result is particularly notable as the chamber-wide attention to women's health is generally greater in the Senate (discussed in chapter three).

Figure 4.10 depicts a broader look at the overall landscape, highlighting the percent of women's health bills introduced in comparison to the percent of women's health bills passed by Congressional session. As established in chapter three, the 1991 and 1993 Congresses were periods of important policy activity in women's health in Congress. Figure 4.10 provides a clearer look at the shifting dynamics over time and greater depth of context for political entrepreneurship exercised both by individual members and committees.

While the Clinton Health Care Reform (1993) did not succeed, this period saw many smaller and incremental changes in health care policy and in turn women's health care policy. Many Democrats used the opportunity to support the president's agenda, but the controversy 
surrounding several of the plan's features was too difficult to overcome. While aligning with the president was desirable, co-sponsorship with like-minded congressional members proved to be even more influential.

Previous studies using co-sponsorship as a measure of entrepreneurship, especially as a signal for coalition building, also consider the nature of co-sponsors (Wawro 2000, Fowler 2006). It seems likely that when congressional and party leadership sign on as a bill's cosponsor, this signals weighted support for the legislation. To assesses whether co-sponsorship by congressional and party leaders increases the likelihood of bills passed for women's health legislation, I reviewed the congressional session with most laws passed, the $114^{\text {th }}$ Congress (1995-1996). In order to determine if co-sponsorship by leadership in Congress (both majority and minority leadership) helped to elevate the status of a proposed bill, I reviewed each of the seventeen laws passed in 1995-1996 as a sample. Only one bill included congressional or party leaders as a co-sponsor. While, leadership typically helps to increase the likelihood that a bill will pass, it does not appear to be a very strong indicator in women's health policy.

Figure 4. 9 Women's Health Bills Introduced/Women's Health Bills Passed Into Law

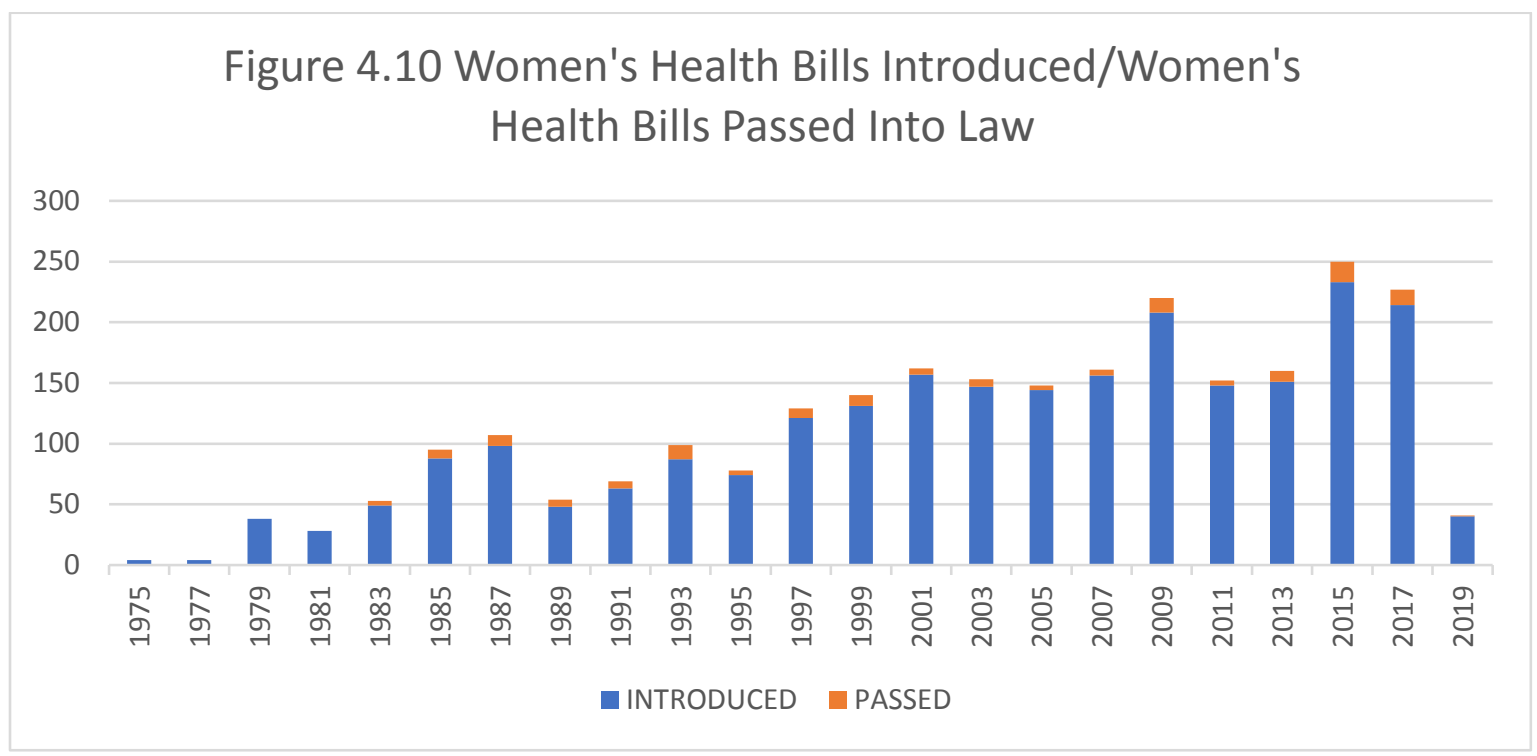




\section{GENDER}

To conclude, I am especially interested in the impact of gender in women's health entrepreneurship. As indicated in the literature, the effects of substantive representation are difficult to tease out in this type of study, but I attempt to provide a closer look at entrepreneurial activity with gender as a focusing lens. Although the impact of gender in legislative decision making is disputed, there is a perceived impact by the public and the members, as Senator Barbara Boxer (D-CA) comments that she and her female colleagues "carry with us the needs of women and their families" (Dittmar, Sanbonmatsu, and Carroll 2018). Tables 4.13 and 4.14 illustrate the gender distribution among the top members engaging in the most entrepreneurial activity. ${ }^{6}$

Table 4. 13 House Gender Distribution of Most Entrepreneurial Activity

\begin{tabular}{|l|c|c|c|c|c|c|}
\hline Gender & $\begin{array}{c}\text { Top Bill } \\
\text { Sponsors }\end{array}$ & Percentage & $\begin{array}{c}\text { Most Bills } \\
\text { Passed }\end{array}$ & Percentage & $\begin{array}{c}\text { Most } \\
\text { Testimony }\end{array}$ & Percentage \\
\hline Women & 13 & $62 \%$ & 9 & $24 \%$ & 6 & $60 \%$ \\
\hline Men & 8 & $38 \%$ & 29 & $76 \%$ & 4 & $40 \%$ \\
\hline
\end{tabular}

Table 4. 14 Senate Gender Distribution of Most Entrepreneurial Activity

\begin{tabular}{|l|c|c|c|c|c|c|}
\hline Gender & $\begin{array}{c}\text { Top Bill } \\
\text { Sponsors }\end{array}$ & Percentage & Bills Passed & Percentage & $\begin{array}{c}\text { Most } \\
\text { Testimony }\end{array}$ & Percentage \\
\hline Women & 11 & $41 \%$ & 6 & $16 \%$ & 5 & $71 \%$ \\
\hline Men & 16 & $59 \%$ & 31 & $84 \%$ & 2 & $29 \%$ \\
\hline
\end{tabular}

\footnotetext{
${ }^{6}$ Top-tier entrepreneurs have sponsored ten or more bills, testified two or more times, or sponsored one more bills that passed both houses.
} 
Especially among those engaging entrepreneurial activity in the House, it appears that women are generally more active. Similarly, in the Senate, women account for nearly half of the top bill sponsors and a greater proportion of those who pass the most bills. This, however, is not congruent with the overall proportion of women in each chamber through time. Using data collected through the Center for American Women and Politics (Rutgers), I report the percentage of women in each chamber and the total percentage of women in Congress from 1945-to current (Table 4.15).

Table 4. 15 Proportion of Women by Chamber and Total Congress

\begin{tabular}{|l|c|c|c|c|c|c|c|}
\hline \multicolumn{1}{|c|}{ Congress } & Years & $\mathbf{W}$ House & $\mathbf{\% W}$ & $\mathbf{W}$ Senate & $\mathbf{\%} \mathbf{W}$ & $\mathbf{W}$ Total & $\mathbf{\% ~ W}$ \\
\hline 79th & $1945-1947$ & 11 & $3 \%$ & 0 & $0 \%$ & 11 & $2 \%$ \\
\hline 80 th & $1947-1949$ & 7 & $2 \%$ & 1 & $1 \%$ & 8 & $1 \%$ \\
\hline 81 st & $1949-1951$ & 9 & $2 \%$ & 1 & $1 \%$ & 10 & $2 \%$ \\
\hline 82 nd & $1951-1953$ & 10 & $2 \%$ & 1 & $1 \%$ & 11 & $2 \%$ \\
\hline 83 rd & $1953-1955$ & 11 & $3 \%$ & 2 & $2 \%$ & 13 & $2 \%$ \\
\hline 84 th & $1955-1957$ & 16 & $4 \%$ & 1 & $1 \%$ & 17 & $3 \%$ \\
\hline 85 th & $1957-1959$ & 15 & $3 \%$ & 1 & $1 \%$ & 16 & $3 \%$ \\
\hline 86 th & $1959-1961$ & 17 & $4 \%$ & 2 & $2 \%$ & 19 & $4 \%$ \\
\hline 87 th & $1961-1963$ & 18 & $4 \%$ & 2 & $2 \%$ & 20 & $4 \%$ \\
\hline 88 th & $1963-1965$ & 12 & $3 \%$ & 2 & $2 \%$ & 14 & $3 \%$ \\
\hline 89 th & $1965-1967$ & 11 & $3 \%$ & 2 & $2 \%$ & 13 & $2 \%$ \\
\hline 90 th & $1967-1969$ & 11 & $3 \%$ & 1 & $1 \%$ & 12 & $2 \%$ \\
\hline 91 st & $1969-1971$ & 10 & $2 \%$ & 1 & $1 \%$ & 11 & $2 \%$ \\
\hline 92 nd & $1971-1973$ & 13 & $3 \%$ & 2 & $2 \%$ & 15 & $3 \%$ \\
\hline 93 rd & $1973-1975$ & 16 & $4 \%$ & 0 & $0 \%$ & 16 & $3 \%$ \\
\hline 94 th & $1975-1977$ & 19 & $4 \%$ & 0 & $0 \%$ & 19 & $4 \%$ \\
\hline 95 th & $1977-1979$ & 18 & $4 \%$ & 2 & $2 \%$ & 20 & $4 \%$ \\
\hline 96 th & $1979-1981$ & 16 & $4 \%$ & 1 & $1 \%$ & 17 & $3 \%$ \\
\hline 97 th & $1981-1983$ & 21 & $5 \%$ & 2 & $2 \%$ & 23 & $4 \%$ \\
\hline 99 th & $1985-1987$ & 23 & $5 \%$ & 2 & $2 \%$ & 25 & $5 \%$ \\
\hline 100 th & $1987-1989$ & 23 & $5 \%$ & 2 & $2 \%$ & 25 & $5 \%$ \\
\hline 101 st & $1989-1991$ & 29 & $7 \%$ & 2 & $2 \%$ & 31 & $6 \%$ \\
\hline 102 nd & $1991-1993$ & 28 & $6 \%$ & 4 & $4 \%$ & 32 & $6 \%$ \\
\hline 103 rd & $1993-1995$ & 47 & $11 \%$ & 7 & $7 \%$ & 54 & $10 \%$ \\
\hline 104 th & $1995-1997$ & 48 & $11 \%$ & 9 & $9 \%$ & 57 & $11 \%$ \\
\hline 105 th & $1997-1999$ & 54 & $12 \%$ & 9 & $9 \%$ & 63 & $12 \%$ \\
\hline 106 th & $1999-2001$ & 56 & $13 \%$ & 9 & $9 \%$ & 65 & $12 \%$ \\
\hline
\end{tabular}




\begin{tabular}{|l|l|l|l|l|l|l|l|}
107 th & $2001-2003$ & 59 & $14 \%$ & 13 & $13 \%$ & 73 & $14 \%$ \\
\hline 108 th & $2003-2005$ & 60 & $14 \%$ & 14 & $14 \%$ & 74 & $14 \%$ \\
\hline 109 th & $2005-2007$ & 68 & $16 \%$ & 14 & $14 \%$ & 82 & $15 \%$ \\
\hline 110 th & $2007-2009$ & 72 & $17 \%$ & 16 & $16 \%$ & 88 & $16 \%$ \\
\hline 111 th & $2009-2011$ & 73 & $17 \%$ & 17 & $17 \%$ & 90 & $17 \%$ \\
\hline 112 th & $2011-2013$ & 73 & $17 \%$ & 17 & $17 \%$ & 90 & $17 \%$ \\
\hline 113 th & $2013-2015$ & 80 & $18 \%$ & 20 & $20 \%$ & 100 & $19 \%$ \\
\hline 114 th & $2015-2017$ & 84 & $19 \%$ & 20 & $20 \%$ & 104 & $19 \%$ \\
\hline 115 th & $2017-2019$ & 87 & $20 \%$ & 23 & $23 \%$ & 110 & $21 \%$ \\
\hline 116 th & $2019-2021$ & 102 & $23 \%$ & 25 & $25 \%$ & 127 & $24 \%$ \\
\hline
\end{tabular}

As a first pass at evaluating the relationship between gender, political party, and bill sponsorship, I assess whether there is a difference in the rate of sponsorship between male and female members of either party. I consider the total number of women's health bills introduced over the time period studied. Table 4.16 demonstrates that female Democrats in the House are almost three times more likely to sponsor women's health legislation as male Republicans, and male Democrats are two times more likely to sponsor women's health legislation than their Republican counterparts. Similarly, Table 4.17 indicates that both female and male Democrats are two times more likely to sponsor women's health legislation than their Republican counterparts. While these percentages provide an overall account of congressional activity, future formal modeling by individual session would provide a more nuanced look at the data. Table 4. 16 House Gender Party Sponsorship

\begin{tabular}{|l|c|c|c|c|}
\hline & \multicolumn{2}{|c|}{ Democrat } & \multicolumn{2}{c|}{ Republican } \\
\hline Gender & Sponsored & Passed & Sponsored & Passed \\
\hline Female & 379 & 22 & 137 & 7 \\
\hline Male & 649 & 29 & 312 & 33 \\
\hline
\end{tabular}


Table 4. 17 Senate Gender Party Sponsorship

\begin{tabular}{|l|c|c|c|c|}
\hline & \multicolumn{2}{|c|}{ Democrat } & \multicolumn{2}{c|}{ Republican } \\
\hline Gender & Sponsored & Passed & Sponsored & Passed \\
\hline Female & 127 & 2 & 60 & 4 \\
\hline Male & 513 & 24 & 247 & 20 \\
\hline
\end{tabular}

\section{CONCLUSIONS}

This chapter illustrates the shifting dynamics of women's health policy in the U.S.

Congress and political entrepreneurship recognized through committee activity and the behavior of individual members. There is some struggle among committees in regard to turf, both in the House and Senate, yet each chamber demonstrates clearly dominant players. Individually, there are some patterns of entrepreneurship activity across the three dynamics studied. Specifically noting co-sponsorship, it does appear that a greater number of cosponsors increases the likelihood that a bill passes.

In consideration of gender, there is some discussion among congressional scholars as to whether "who" holds office, descriptive representation, affects the types of policies passed, substantive representation (Pitkin 1967; Childs \& Krook 2009; Swers 2013). While women's health policy is particularly complex, it does appear that women are more active among the top members demonstrating entrepreneurial activity. This is an area I would like to pursue in future research. 


\section{CHAPTER 5: Expert Attention}

Representative Rosa DeLauro (D-CT), a survivor of ovarian cancer, described her illness as a motivation for her to seek a committee assignment addressing health related issues. When she got to Congress, more than two twenty years ago, she joined with women members of both parties to fight for women to be included in clinical trials at the National Institutes of Health (NIH). She commented, "We thought we had settled that when I got here a while ago, and then to our chagrin, we find out that that's not the case and we are still, you know, dealing with this issue." Much of the battle over women's health policy has been based on the battle for inclusion in the discussion. Initially, women we largely excluded from health policy, barring their role as mothers, and then the discussion became dominated by challenges of reproductive rights. While reproductive health and reproductive rights are two sides of the same coin, the focus of policy is slightly different.

In this chapter I will provide further discussion about the nature of women's health policy in the context of expert communities and administrative agencies. Roger Cobb, Jeannie Keith-Ross and Marc Howard Ross (1976) describe agenda building as "the process by which demands of various groups in the population are translated into items vying for serious attention of public officials" (p. 126). The literature in agenda setting demonstrates that there are multiple venues by which political actors and the public become aware of policies. In this chapter, I investigate the dynamics of the medical establishment and women's health policy experts worked to carve out a niche for women's health in the health policy arena. 
Considering the outside initiative model (Cobb, Ross and Ross 1976; Kingdon and Thurber 1984; Rochertfort and Cobb, 1994) and Walker's (1977) evaluation of the expert and technical media, I open the story of women's health by tracking the attention of the medical establishment and academic and scholarly publications to women's health policy. This allows me to establish the identity of some of the key players in women's health policy and how they framed the issue. These include the Institute of Medicine, National Institutes of Health, Office

of the Surgeon General, Center for Disease Control, Department of Health and Human Services, and the Agency for Healthcare Research and Quality. Additionally, I track publications among the biomedical academic scholarly community, which would include important actors such as the American Medical Association. I track attention in the professional and expert community from 1945-2018.

Next, I look at how medical experts frame women's health as a separate concern, noting the initial focus of experts, the dialogue among experts, and how beliefs about women's health as a separate issue developed over time, taking care to note changes in policy core beliefs and programmatic emphasis (Sabatier and Jenkins-Smith 1999). Finally, I consider how expert attention relates to media, congressional, and presidential attention.

\section{MEDICAL ESTABLISHMENT}

In order to trace the influence of institutional actors within the medical establishment, I turn to professionalized media with the weight of expertise. I have identified five key organizations and government agencies that disseminate and contribute to the body of research in the medical community: The Health and Medicine Division (HMD/IOM), division of the National Academies of Sciences, Engineering, and Medicine, National Institute of Child 
Health and Human Development (National Institutes of Health- NIH), Office of the United States Surgeon General (USSG), Centers for Disease Control and Prevention (CDC), and The Agency for Healthcare Research and Quality (AHRQ).

The Health and Medicine Division (HMD) is a component of the National Academies of Sciences, Engineering, and Medicine (the National Academies). HMD previously was the Institute of Medicine (IOM). The National Academies are private, nonprofit institutions that provide independent, objective research and inform public policy related to science, technology, and medicine. The Health and Medicine Division (HMD), changed its name from the Institute of Medicine (IOM) in 2016 to better reflect a broader emphasis on health matters, rather than medicine explicitly. The fundamental charge of the HMD is to advise the nation on how to improve health based upon evidence driven practice. Though Congress may charge the HMD with a specific task or research initiative, the Academies are private, nonprofit institutions. The work of the HMD makes recommendations on a wide array of health issues, potentially influencing policy related to science, technology, and medicine. Publications by the $\mathrm{HMD} / \mathrm{IOM}$ are categorized by topic and I specifically focus on the women's health sub-section

Figure 5.1 illustrates HMD/IOM research and publication activity in regard to women's health by year. We begin to see publications from the HMD/IOM in 1988, with a dramatic increase in 1997, and in the period following there is a steady increase through 2017 . There is a punctuation in attention in 2003. 
Figure 5. $1 \mathrm{HMD} / \mathrm{IOM}$ Publications - Women's Health

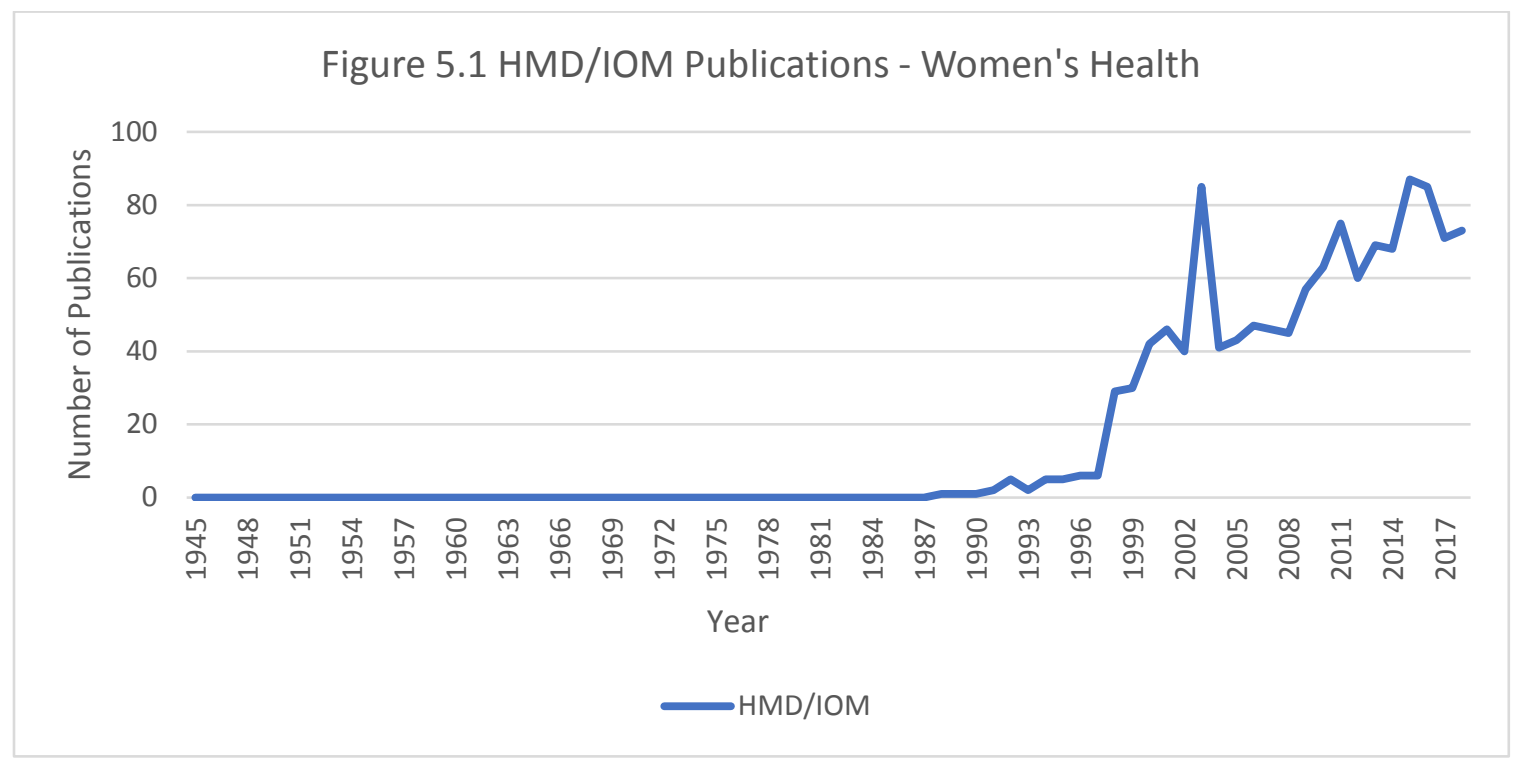

In the mid-1950s, as a division of the National Institute of Health (NIH), the National Institute of Child Health and Human Development (NICHD) was established. Fundamentally, the tasks of the Institute (NICHD) were to promote better understanding of infant and childhood development as well as to promote scholarship surrounding the issue of health through the life course. The NICHD established research arms within universities, developed facilities to train those working with individuals with developmental irregularities, and lead to the construction of a dozen, independent research centers across the country dedicated to research in these arenas.

The NICHD was formally renamed the Eunice Kennedy Shriver National Institute of Child Health and Human Development in 2007 to honor the tireless dedication of Shriver in her advocacy for those with intellectual and/or developmental delays and disabilities (Raju, Bock, and Alexander 2008). Due to Shriver's support, the medical community began to recognize that research and specialization in the areas of human development was needed and the study of 
aberrant development in the physical, intellectual, and emotional health of children was necessary. Both medical specialties, as well as the Institute generally, were influenced by Shriver's dedication. Today, the NICHD is tasked with enhancing the understanding of health during pregnancy as well as preconception. Further, the NICHD evaluates how growth and development should be considered throughout the life course, encourages better understanding of the reproductive health of men and women, and promotes rehabilitation medicine development to encourage an improved quality of life for those living with disabilities.

Research from the National Institutes of Health (NICH), specifically the National Institute of Child Health and Human Development (NICHD) (https://www.nichd.nih.gov), also provides regular contributions to science and medical care. According to the NICHD Annual Report (2019), their work has "yielded safe and effective vaccines for childhood infections, developed cutting-edge molecular imaging technologies, and provided new insights into the risks of certain environmental exposures among populations such as pregnant women, among other advances" (NICHD 2019). The NICHD generates regular public advisory research feature articles to explain NICHD research findings and public health issues to the public. These are searchable, using the NIH archive and the search term "women's health." Figure 5.2 illustrates NIH/NICHD research and publication activity in regard to women's health by year.

It appears that NIH attention to women's health in particular does not appear in the distribution until 1999. There is some activity from 1999 to 2006, but publications decrease again in 2008. However, there are more dramatic increases in 2011 and 2015. In June of 1990, The General Accounting Office (GAO) reports that women have been excluded from major federally funded clinical studies and that the NIH is not enforcing its policy of including women 
(Glazer, 1994). In response to the GAO report, the NIH establishes the Office of Research on Women's Health in 1990, and women's health publications increase shortly thereafter.

Women's health is an integral focus of the NICHD. The Institute attempts to address the comprehensive treatment of women's health and topically has focused upon fertility and infertility, maternal mortality, administration and menstrual problems, and pregnancy, among other topics (Raju, Bock, and Alexander 2008). The Women's Health office is dedicated to understanding sex differences and the unique health realities of women to best ensure good health and well-being.

The Office of Research on Women's Health (ORWH) was established in September 1990 within the NIH to focus upon women's health research. The historic deficit in research and the growing understanding of the critical need for research on the health differences of sex and gender led to the foundation of this office. The OWHR was the first United States Public Health Service office that was specifically dedicated to promoting women's health and evaluating sex differences in research. The specific charges ORWH include the following: (1) to strengthen, develop and increase research into diseases, disorders and conditions that are unique to, more prevalent among, or more serious than women or for which there are different risk factors for women then from there; (2) to ensure that women are appropriately represented in biomedical and behavioral research studies, especially clinical trials, that are supported by the NIH; and (3) to direct initiatives to increase the number of women in biomedical careers (Pinn 1994). 
Figure 5. 2 NIH Publications - Women's Health

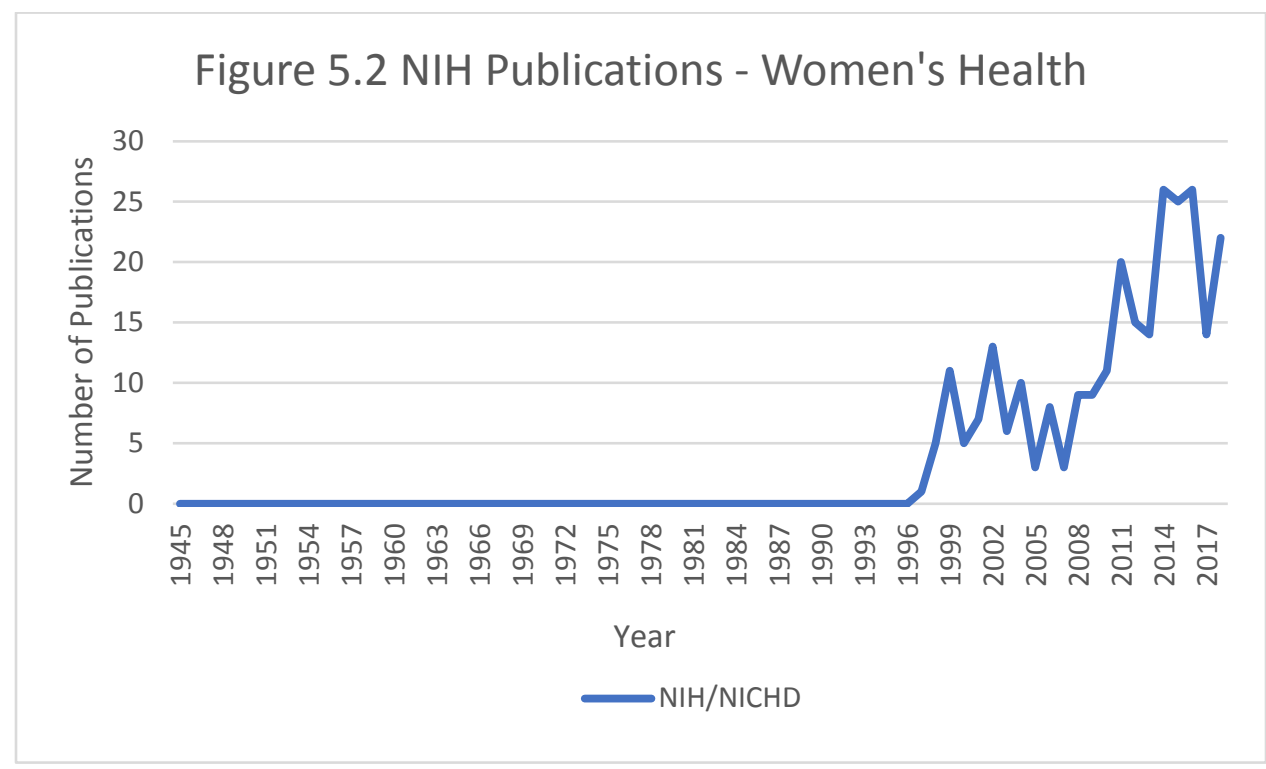

Next, I consider publications from the U.S. Surgeon General (USSG) available through the Surgeon General Collection at the National Library of Medicine. This index is searchable by year, and I used the search term "women's health" (https://www.surgeongeneral.gov). As part of its Profiles in Science project, the National Library of Medicine (NLM) has digitized reports and publications of the U.S Surgeon General (USSG) prior to 2000. The collection includes reports, proceedings, and background papers.

The Public Health Reports (PHR) have been published since 1878 and are the official public health journal of the US Surgeon General and the Public Health Service (PHS). The publications from the Surgeon General and the PHS generally, are relied on for the rigor and evidence-based approach. Said documents are often interdisciplinary in nature employing expertise from the scientific, medical, and public health worlds. The reports from the Surgeon General often have wide reaching impact on understanding, prevention, and practice of public health concerns. Such timely and critical public health emergencies as the HIV/AIDS epidemic, tobacco use, other 
addictions, mental health including suicide prevention, societal and domestic violence, food security, natural disasters, mental health among many others, have been recent topical emphases. This journal is published bimonthly and is peer reviewed.

Figure 5.3 illustrates USSG publications and reports in regard to women's health by year. Publications from the Office of the USSG peak earlier than the IOM and NIH, beginning in the mid-1960s. There are punctuations, however, in 1988 and 2001. The 1988 punctuation is particularly interesting as the "Alcoholic Beverage Labeling Act of 1988" (ABL requires that a health warning statement appear on the labels of alcohol beverages as a result of the Surgeon General Warning regarding consuming alcohol during pregnancy (women should not drink alcoholic beverages during pregnancy because of the risk of birth defect). The increase in 1966 coincides with the adoption of Medicare, and it is notable in 1990 that Dr. Antonia Novello was elected as the first female Surgeon General (Biography, National Library of Medicine 2015).

Figure 5. 3 USSG Publications- Women's Health

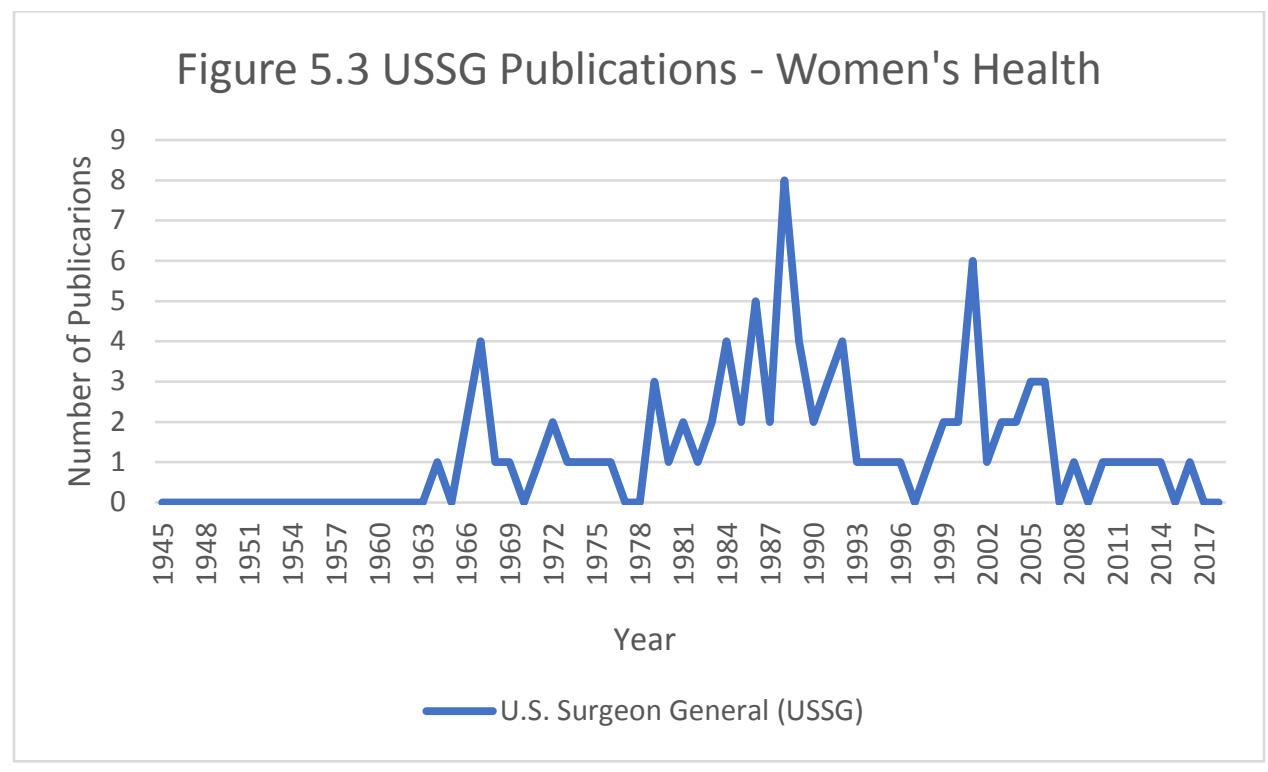


The United States Public Health Service (PHS) is a division of the Department of Health and Human Services and is dedicated to issues of the public health. First known as the Marine Hospital Service (1798), the Public Health Service was renamed in 1912. The position of the Surgeon General was established in 1871 , originally known as the Supervising General. The US Public Health Service Commissioned Corp is a uniformed, military branch that employs over 6,000 public health workers and is charged with the delivery of public health promotion and disease prevention programs. In 1946 the Communicable Disease Center, now known as the Centers for Disease Control (CDC) opened to first tackle malaria control in the Southeast United States. Today the CDC has an extensive and varied practice area addressing all medical processes from prevention, surveillance, treatment, and control.

I collected data in regard to publications produced by the Centers for Disease Control and Prevention (CDC), using CDC Stacks (https://stacks.cdc.gov/welcome). CDC Stacks is a digital archive of scientific research and literature published and archived by the CDC. I refined the search function to include "all collections" and used the search term "women's health."

The Centers for Disease Control and Prevention publishes a variety of periodicals. These include: the Morbidity and Mortality Weekly Report (MMWR), Emerging Infectious Diseases (EID), and Preventing Chronic Disease (PCD). Further, the CDC publishes special reports, vital statistics of United States, annual reports on vital and health statistics, recommendations for research methods, and emerging and/or emergent public health concerns.

The CDC publishes a variety of public health papers and journals specific to women. These include works related to preconception, maternal health, women's aging, cervical, uterine and breast cancers, violence against women, etc. Specifically, the CDC publishes the 
Journal of Women's Health that tackles a myriad of issues impacting the health status of women. This journal focuses on research and health issues impacting girls and women in the US and beyond. The Journal and the Office of Women's Health are attempting to ameliorate historical health inequities. The CDC also produces a e-newsletter, Health Matters for Women, that offers information about what is happening in women's health at the CDC and related agencies.

Figure 5.4 illustrates CDC publications and reports regarding women's health by year. The CDC reports on women's health minimally until 1987 when there is a dramatic increase (80 publications), and this is repeated again in 2015 (117 publications). In 1986, the CDC began surveillance of maternal mortality, which is defined as the death of a woman during pregnancy, during childbirth, or within the time period immediately following termination of a pregnancy (CDC Office of Research on Women's Health 2013). In review of this data, the overall number of CDC and Agency for Toxic Substances and Disease Registry publications increases dramatically from the 1980 s to current. 
Figure 5. 4 CDC Publications - Women's Health

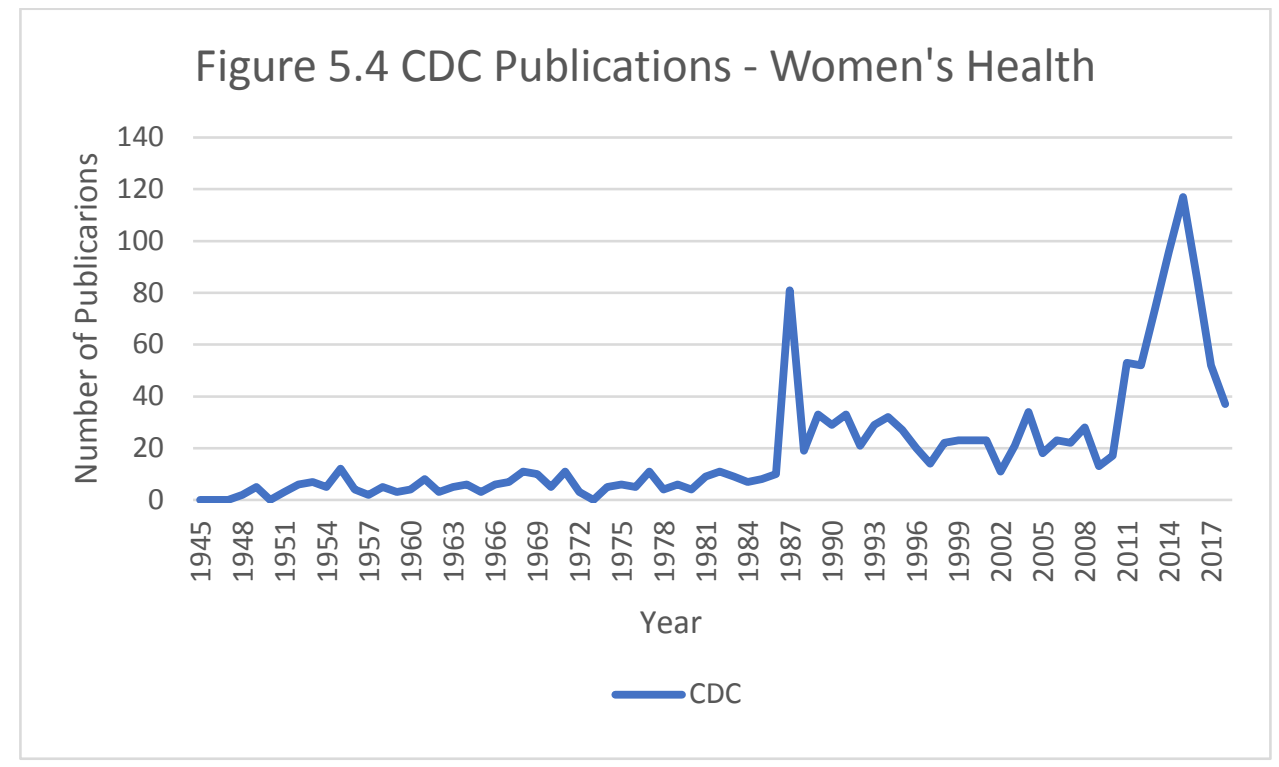

Further, I examine the Agency for Healthcare Research and Quality (AHRQ), which publishes Evidence Based Practice Reports and sponsors the development of various other reports to assist public and private-sector organizations. Their mission is to improve the quality of health care in the United States, using evidence-based practice (Agency for Healthcare Research and Quality). These reports provide comprehensive, science-based information on common (yet often very costly) medical conditions and new health care technologies. Evidenced Based Practice Reports review all relevant scientific literature on a wide spectrum of clinical and health services topics. The Agency for Healthcare Research and Quality is a division of US Department of Health and Human Services. Specifically, the AHRQ surveils the nation's health delivery system, promotes best practice in developing and training healthcare systems and professionals, and encourages best practices in the evaluation of the methods used to manage data by providers and policymakers. The AHRQ publishes a variety of periodicals data 
explanations, including consumer guides, and other technical journals intended to offer utilitarian guidance for a variety of healthcare organizations and providers.

My search results include released evidence reports, comparative effectiveness reviews, technical briefs, Technology Assessment Program reports, and U.S. Preventive Services Task Force information. I used the search term "women" (www.arhq.gov).

Figure 5.5 tracks publications by the AHRQ from 1945-2018. There are relatively few publications across the time period, with only one punctuation occurring in 2012. This result seems reasonable as assessment of the Patient Protection and Affordable Care Act would be relevant at this time. Additionally, the AHRQ also published a special report in 2011 concerning health care quality and disparities among women (Agency for Healthcare Research and Quality, 2012). Which may also account for an increase in attention to women's health generally and with regard to the evidence in this corresponding distribution.

Figure 5. 5 AHRQ Publications - Women's Health

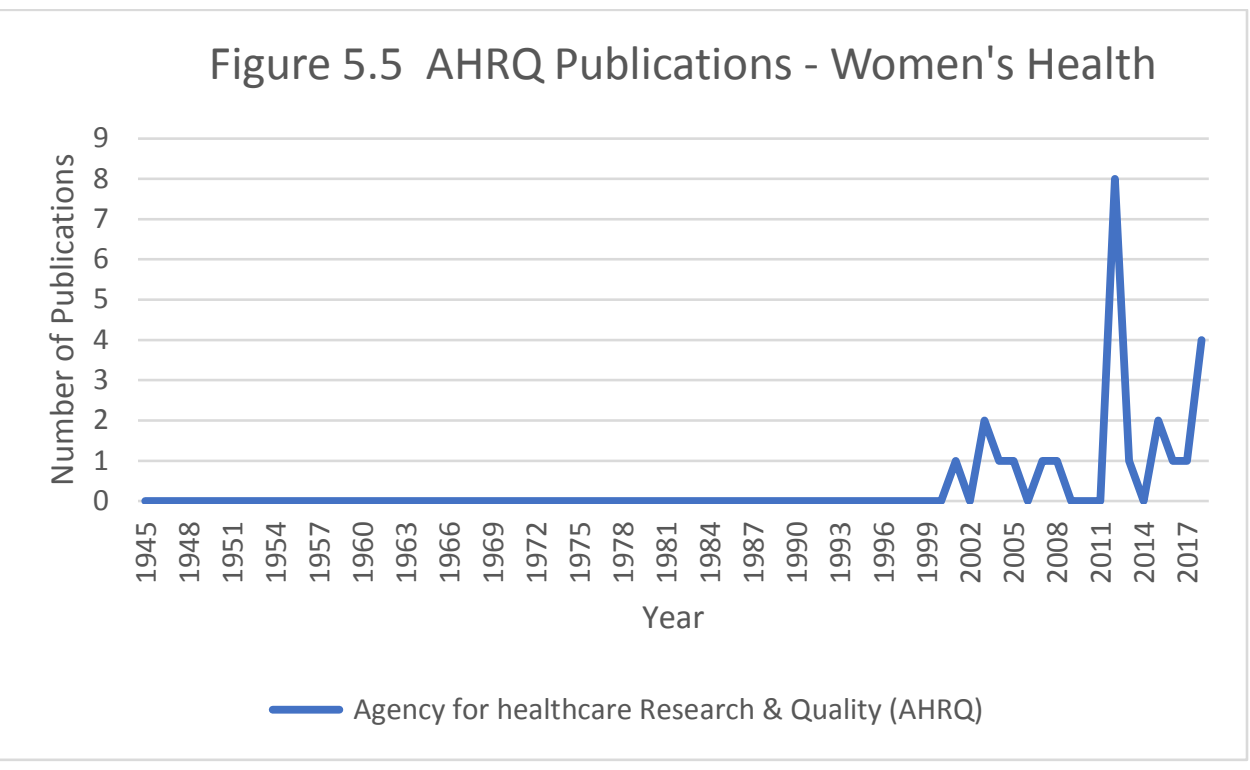




\section{ACADEMIC SCHOLARLY PUBLICATIONS}

In order to get at academic scholarly and expert research, I conducted a search of PubMed.gov, which is maintained by the U.S. National Library of Medicine National Institutes of Health (https://www.ncbi.nlm.nih.gov/pubmed). PubMed.gov is comprised of more than 29 million citations from biomedical literature found on MEDLINE, in roughly 5,400 life science and biomedical journals and online books. Citations include links to full-text content from PubMed Central and other various publisher web sites from 1946-present. This source provides an appropriate measure of scholarly activity during the time period studied. Using an advanced search, I limit my search to publications for "women's health."

Figure 5.6 illustrates the number of scholarly publications from 1947-2018. Publications begin to steadily rise from 1979 (125 publications) to 2018 (14,454 publications). There is a period of more dramatic increase beginning in 2012. In the late 1980s, advocates fought to increase the representation of women in clinical studies of diseases, disorders, and drug treatments. Women's health research in scholarly publications seems to reflect this shift toward inclusion of women in medical research. From 1990 to 2017 scholarly publications in medical journals (available through PubMed) increased about 5\%, whereas publications related to women's health specifically increase $272 \%$. This increase for women's health research is significant and demonstrates a dramatic rise in focused expert attention. 
Figure 5. 6 PbuMed Publications - Women's Health

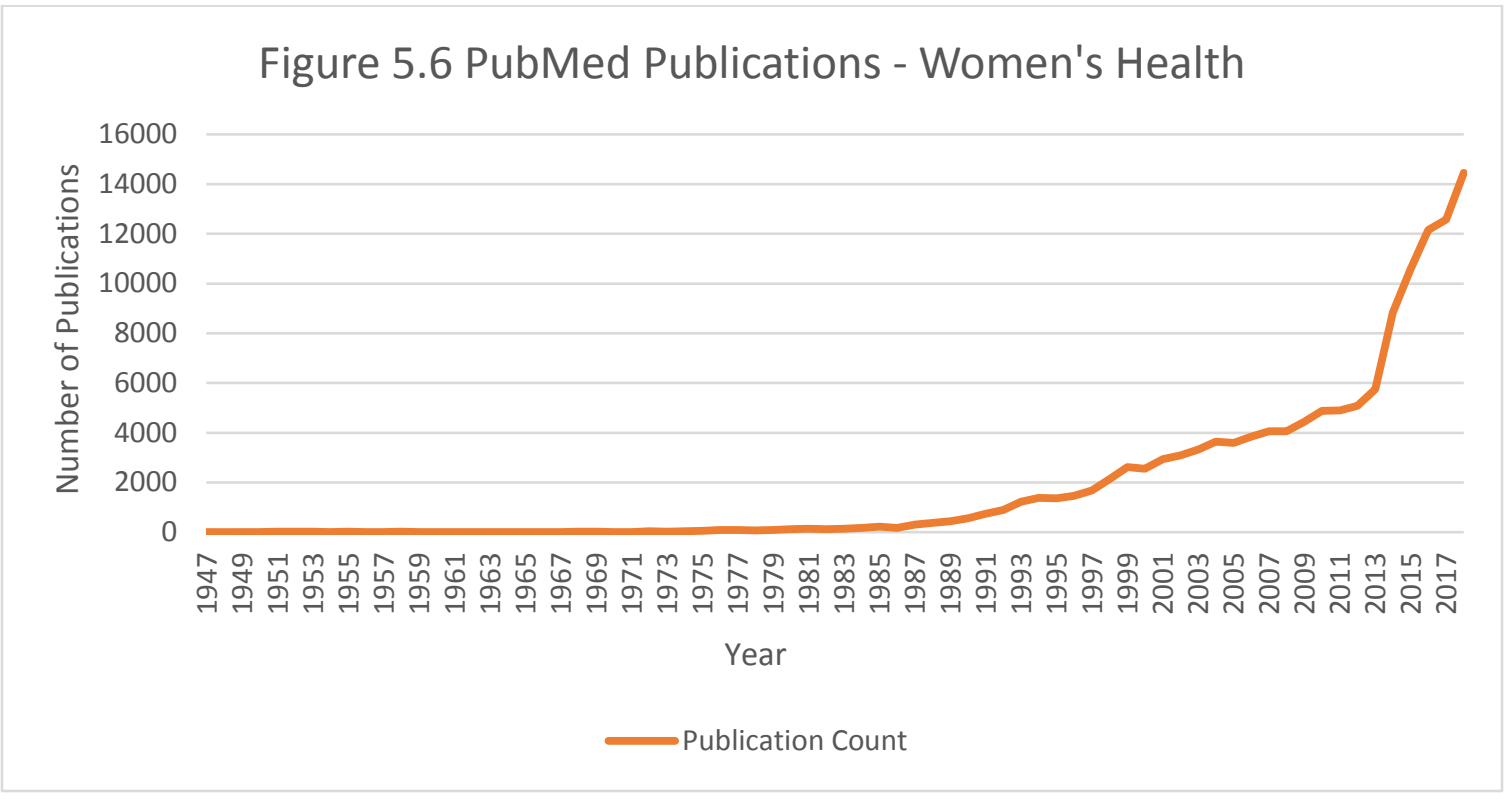

Table 5. 1 Scholarly Publications 1990-2017

\begin{tabular}{|c|c|c|c|}
\hline Publications 1990-2017 & \# Published 1990 & \# Published 2017 & \% Change \\
\hline All & 388,191 & $16,626,705$ & $5 \%$ \\
\hline Women's Health & 562 & 114,375 & $272 \%$ \\
\hline
\end{tabular}

\section{EXPERT ATTENTION AND CONGRESSIONAL ATTENTION}

In Figure 5.7, I compare presidential attention data gathered, using presidential papers available through The American Presidency Project (Figure 3.17) and bill introductions, collected using the legislative subject term "women's health" on Congress.gov, as a measure of congressional attention (Figure 3.14) to publications from policy experts, professional organizations and administrative agencies in the medical establishment. (This includes all publication data collected from the IOM, NIH, USSG, CDC, and AHRQ - Figures 5.2 - 5.5). It is interesting that bill introductions seem to peak first in 1985 , but publications in the medical establishment follow closely with an uptick in 1987. Medical publications peak again in 2003 
and bill introductions follow in 2009 , where we begin to see a dramatic increase in medical publications. Presidential attention illustrates an overall increase, with a slight uptick in 2013. The convergence of government and expert attention is informed by the following discussion of the policy context. It is interesting to note that increased attention by one group is not necessarily mirrored by the other. In this case, and in the case of public attention, one would expect considerable lag time. The expert community is bound by research and publishing limitations, and the President and Congress either respond or shift attention according to the congressional calendar and election cycle. Further discussion of the policy environment and political context is needed to best interpret these connections.

Figure 5. 7 Who Pays Attention to Women's Health

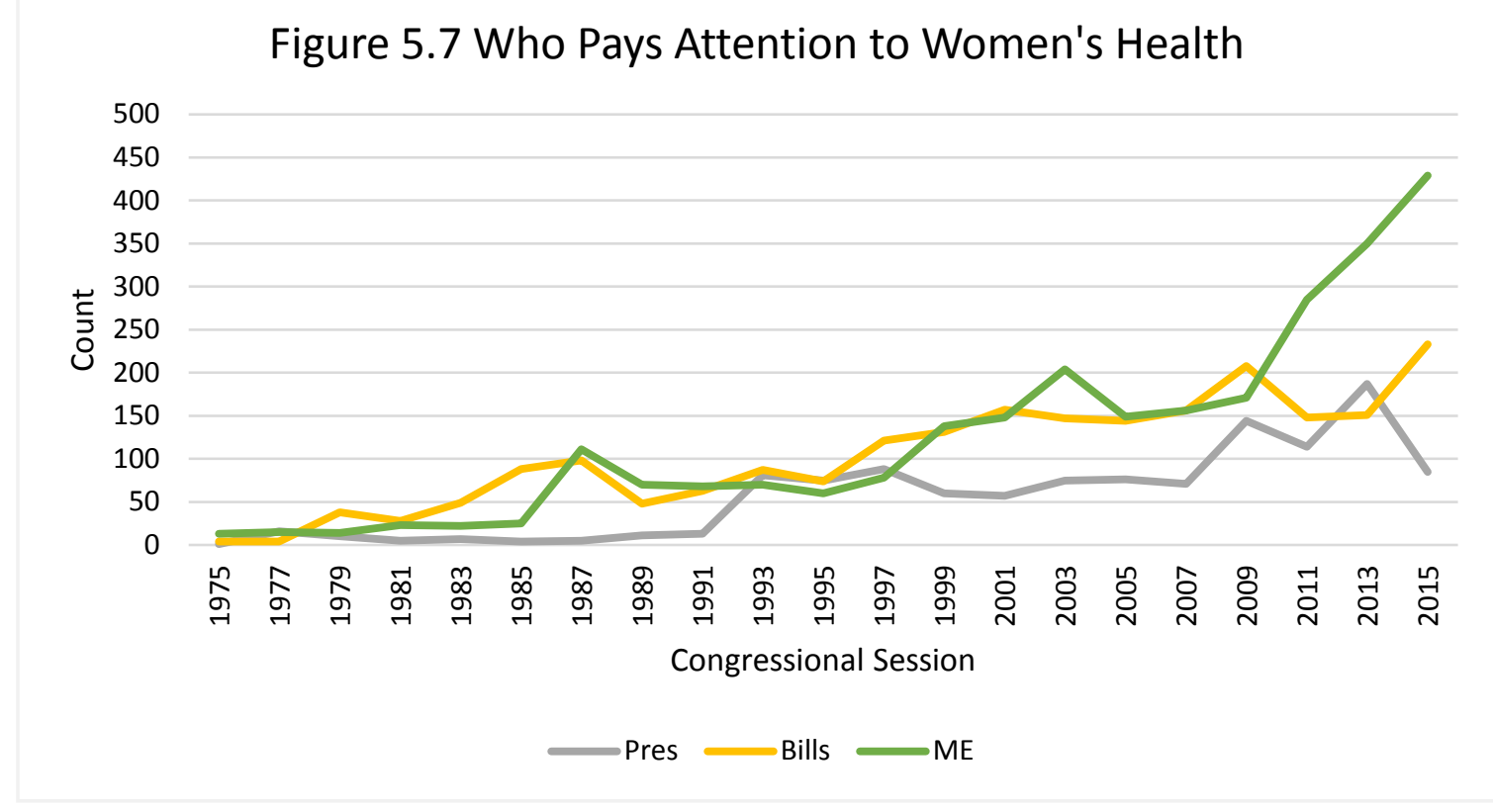

\section{POLICY EVOLUTION}

As the literature suggests, it is evident that women's health, both by the government and the medical established, was initially defined through childbirth. The American Medical Association affirmed in 1883 that "women's health troubles are largely caused by their ovaries 
and other sexual organs" (Masci 2003). The treatment of women's health through childbirth dates from the mid-19th century when male doctors first defined childbirth as a surgical procedure (Masci 2003). Until that time, female midwives had largely been responsible for childbirth and "women's ailments" (Msci 2003). All that changed, however, once social mores permitted male doctors to examine women's genital areas. From the late 1950 s to 1970 s birth defects caused by the drug thalidomide prompted medical professionals and federal agencies to action to reduce the risks of experimental drugs.

As these concerns increased, women started to campaign for more responsive health care (Glazer 1994). In 1970, a primer on women's health was published by Boston feminists. Our Bodies, Ourselves was a 93-page booklet that dared to address sexuality and reproductive health, including abortion. In response to the unsafe practices of thalidomide and mounting social pressures, Congress created the National Commission for the Protection of Human Subjects of Biomedical and Behavioral Research, which focused on issues and guidelines limiting research on pregnant women and fetuses (PHSBBR). It was not until 1976, however, that the National Women's Health Network was founded as a watchdog group to monitor and influence federal health policies dealing with women. This coincides with the beginnings of focused women's health legislation in Congress (see chapter three). By the 1980s, women of the baby-boom generation start to reach mid-life and experience breast cancer and other illnesses at growing rates, and with the increasing numbers of female medical school graduates, researchers begin questioning the amount of attention paid to women's health.

In 1983, the Assistant Secretary for Health Edward Brandt established a Public Health Service Task Force on Women's Health Issues (Kirschstein 1991). Subsequently, The 
Department of Health and Human Services established the Coordinating Committee on Women's Health (CCWH) to advise the Assistant Secretary for Health on activities to safeguard and improve the physical and mental health of women in the United States (Kirschstein 1991). In 1985, The Public Health Service Task Force on Women's Health Issues concluded that the historical lack of attention to women's health concerns has "compromised the quality" of health care that women receive (Glazer, 1994). As a result, the NIH developed new policies encouraging applicants for research funding to include women in clinical trials.

By the late 1980s and early 1990s, attention to women's health gained momentum, both in terms of expert attention and congressional attention. Two critical events helped to thrust women's health issues into the medical, public, and congressional spotlight. Harvard University reported in 1989 (Harvard's Physicians Health Study) that taking an aspirin every other day could prevent heart disease, most news reports implied that the results applied to all adults. But the Physicians' Health Study involved 22,000 male doctors, and no women. However, Harvard researchers noted that all the benefit was confined to men older than 50 (Glazer 1994). Then in June 1990 The Government Accountability Office (GAO) published a report highlighting the lack of women included in federally funded clinical studies and the NIH. This report served a springboard for much of the increased attention by women in Congress and resulted in policy and regulation change for agencies (Kirschstein 1991).

By August 1990, Senator Barbara Mikulski (D-MD) introduced the Women's Health Equity Act (WHEA). The WHEA was an omnibus bill authorizing additional funding for breast cancer and other women's diseases and required a mandate that women be included in clinical trials (Lee 2015). Representatives Patricia Schroeder (D-CO) and Olympia J. Snowe (R-ME) 
reintroduced the bill in 1991, but it never gained traction. Representatives Schroeder and Snowe both demonstrated substantial entrepreneurial activity in advancing this policy as evidenced in chapter four. In September 1990, the NIH established the new Office of Research on Women's Health (NIH 2018).

Many prominent women in the medical community believed that medical differences between the sexes had been neglected by researchers (not just heart disease). Florence Haseltine, director of the Center for Population Research at the National Institutes of Health $(\mathrm{NIH})$ in Bethesda, MD commented, "Basically, what we need to do is rethink how we look at the disease process," and "that there is a difference between men and women in itself is interesting" (Glazer 1994).

In 1991, Bernadine Healy, the first female director of NIH, launched the Women's Health Initiative (WHI), a \$625 million study of some 160,0000 women (Glazer 1994). The NIH Women's Health Initiative was a 14-year study of women's health followed up by WHI Extension Studies (2005-2010, 2010-2020). \$. The initiative will examine three diseases of crucial importance to women: heart disease, breast cancer and osteoporosis WHI has published over 1,400 articles and approved and funded 289 ancillary studies (Women's Health Initiative). According to the report's findings, the WHI has impacted women's health in medical practice in the U.S and around the world by helping women and their health care providers make more informed decisions, particularly in regard to the use of hormone therapy and menopause treatments (Women's Health Initiative).

Under pressure from the Congressional Caucus for Women's Issues, led by Representatives. Patricia Schroeder (D-CO) and Olympia Snowe (R-ME, among others, Congress 
required the NIH to include women in all applicable clinical trials of medical treatments. The Food and Drug Administration (FDA) also issued guidelines last year encouraging researchers to include women in tests of new drugs and lifted its 1977 ban on including women of childbearing age in early studies (Lee 2015).

In 1992, Johnson, an assistant clinical professor of psychiatry at the University of California-San Francisco, proposed in a "debate" in the Journal of Women's Health that a new medical specialty be created and certified in women's health. She argued that "two or more physicians are required to provide complete care [for women], an inefficient and expensive process" (Glazer 1994). However, not all medical professionals were on the same page. Some were discouraged by the legislation, especially the requirement that researchers include enough women participants to perform a "valid analysis" of the differences between the sexes. In a later response, New England Journal of Medicine Editor Marcia Angell (1992) expressed this viewpoint when she protested that the requirements "assume that clinically important differences between men and women are the rule rather than the exception -- a biologically implausible assumption."

With the election of President Bill Clinton in 1992, the women's health debate began to shift toward abortion issues. One of Clinton's first acts on January $22^{\text {nd }}$, the anniversary of the Supreme Court's 1973 decision in Roe v. Wade, was to lift the executive orders banning abortion counseling in federally funded family planning clinics and the use of fetal tissue for medical research (1993 CQ Weekly Report, p. 182). This presidency fueled a resurgence in attention to concerns over abortion, federal funding, and definition of family planning. The 
controversial Clinton Health Care Reform (1993) package prompted women's health issues related to abortion to resurface.

Although though 1992 saw the most women elected into Congress, their policy fights for women's health care were often sidelined in favor of debate over funding or more divisive rights issues surrounding abortion. With the election of President Clinton and the addition of twenty-four women to the House (all of whom ran on pro-choice platforms) it was predicted that the Freedom of Previous Choice Act would pass through Congress in the first six months of that year (Bettelheim, 2009). This was not the case, however, as Congress balked at supporting a number of the bill's key provisions and abortion debates concerning federal funding were particularly relevant in the House (Bettelheim 2009).

However, June of 1993, President Clinton signed the NIH Revitalization Act, which legally required the inclusion of women in clinical trials and research funded by the NIH. For the first time in several years, NIH reauthorization passed with relatively little controversy. The NIH Revitalization Act authorized $\$ 10.7$ billion in spending, with a significant portion focused on research of reproductive system cancers. The bill also increased the power of the Office of AIDS Research and added programs for women and minorities (Rubin \& Zuckman 1993). Following this legislation, a panel appointed by the Institute of Medicine which recommended that pregnant women be "presumed eligible" for participation in clinical studies as well (Glazer 1994).

During the Clinton - Bush campaign, abortion was not the only women's health issue up for debate, which was a clear sign of limited space on the agenda and issue crowding. Democrats had long supported the Family and Medical Leave Act, and its passage in 1992 
reflected an important social policy difference between President Clinton and former President George H. W. Bush. The bill passed both chambers in 1991 but idled in Congress until a conference agreement cleared the following year. Bush vetoed the measure in September 1992 (Rubin \& Zuckman 1993). The same bill passed Congress shortly after Clinton took office in 1993. It allows workers to take up to twelve weeks of unpaid leave during any twelve-month period because of the birth or adoption of a child; the need to care for a child, spouse or parent with a serious health condition; or the worker's own serious illness (Rubin \& Zuckman 1993).

In 1998-1999, women's health policy briefly returned to issues of funding and research. The omnibus spending bill (HR4328) signed by President Clinton on October 21, 1999 allocated $\$ 15.6$ billion to the National Institutes of Health (Kirchhoff and Carey 1998). NIH funding an authorization was again used as a vehicle for advancing women's health through research. The bill represented a $15 \%$ increase from the previous fiscal year and marked the beginning of a five-year push to greatly expand the agency's budget (Kirchhoff and Carey 1998). Overall, the bill provided about $\$ 290$ billion in spending for health, education and labor programs.

The pattern of increased $\mathrm{NIH}$ funding was accompanied by increased pressure to dedicate some of the NIH budget to research of specific diseases. Representative John Edward Porter (R-IL)., 1998 chairman of the House Labor-HHS Appropriations Subcommittee, fought efforts to earmark NIH funding. He believed, as did his predecessor, William Natcher (D- KY), that those decisions should be left to experts. Women's health concerns, however, have been presented in very specific terms. For example, the $1999 \mathrm{NIH}$ authorization included provisions supported by Senator Alfonse M. D'Amato (R-NY) to require health insurers to cover breast reconstruction after mastectomies. 
Just five years later, NIH reporting again brought women's health concerns to the forefront. A practice initially thought to protect women, using hormone replacement therapy (HRT), actually increased the risk of breast cancer, heart disease and stroke. (Lawton, McLeod, and Dowell 2003). The Women's Health Initiative study (WHI), sponsored by the US National Institutes of Health (NIH), found that HRT significantly increases the risk of invasive breast cancer. It also reported higher risks of heart attack, stroke, and blood clotting. The NIH took the unusual step of halting the WHI trial and recommended that women stop taking HRT for mild menopausal symptoms. (Lawton, McLeod, and Dowell 2003).

This step signaled a strong agency response not usually taken. For example, the National Cancer Institute $(\mathrm{NCl})$ waited until 2002 to declare that hormone-replacement therapy raised women's cancer risks, although the NIH Women's Health Study reported its findings a decade earlier (Clemmitt 2009). And as early as 1994, research strongly linked talcum powder use to ovarian cancer, especially in black women, the Food and Drug Administration (FDA) did not issue an immediate response (Clemmitt 2009).

Today over thirty years have passed since The Public Health Service Task Force on Women's Health Issues first noted the historical lack of attention to women's health concerns. In light of this policy review, and the previously discussed developments (chapters one - four), medical research has often been the catalyst for funding and advancing women's health policy. Though other dimensions including reproductive health, abortion, and maternal care are very much a part of the conversation. Congressional reauthorization of critical funding bills, the efforts of women's issues advocates, professional organizations of practitioners, and those conducting research come together at this critical juncture. The work of the NIH Women's 
Health Initiative and subsequent studies have changed the nature of health research and fueled the expansion of a much broader and inclusive system. With the addition of the Affordable Care Act (2010), access and measures of preventative medicine are more readily available to the most vulnerable populations. The Kaiser Family Foundation, in particular, specifically focuses on the challenges faced by women at risk for experiencing access barriers including: low income, Medicaid recipients, the uninsured, as well as racial and ethnic minorities. The annual Kaiser Women's Health Survey is a nationally representative survey of women ages 18 to 64 on their coverage, use, and access to health care services (Kaiser Women's Health Survey 2017). Their analysis has been important in preparing key policy briefs on key trends and issues that disproportionately affect women and inform current policy debates. Many of these concerns have implications across the health spectrum for both men and women. This work is indicative of the evolution of women's health policy from the mid-1980s. 


\section{CHAPTER 6: Conclusions}

In this chapter I will discuss the key findings of the research and summarize the overall study. I also focus on questions of future research that I consider as a result of my investigation. Ultimately, my work examines how women's health care became an important facet of health policy and continues to evolve today. The research in chapter three builds on the work of Baumgartner and Jones' (2005; 2013) Policy Agendas Project, creating a more defined picture of health policy by including women's health care. In chapter four, I track entrepreneurship and explore elements of gender. Finally, in chapter five, I investigate women's health policy in the broader context of its history.

\section{SUMMARY OF FINDINGS AND LIMITATIONS}

In the first empirical chapter, three, I map how women's health gained entrance to the agenda. First, I mapped the overall health agenda, using data available through Baumgartner and Jones' Policy Agendas Project. They do not include women's health as a discrete subtopic. As I have established that women's health care was first defined through policy related to infants and children, I discussed The Policy Agendas Project data for health, specifically related to health care for infants and children. This served as an indicator but did not fully describe the specifics of women's health policy. The final section of the chapter uses original research to track the entry of women's health on the agenda and compares the measures of attention respectively.

My findings supplement the data made available by The Policy Agendas Project and describes women's health policy as part of the overall health agenda. I determine that $22 \%$ of all health bill introductions are women's health related, which is a little more than one in five. 
In regard to congressional hearings, women's health represents about $16 \%$ of all health hearings, and less than $10 \%$ of all health laws passed are directly related to women's health. As health professionals regularly observe health care practices as by divided by sex, congressional attention is not proportionally representative of these distinctions.

Similarly, public attention does not appear to coincide with congressional attention, as New York Times women's health mentions have no relationship to the number of bills introduced, congressional hearings, or passed legislation. There is a correlation between public attention and presidential attention. In the case of presidential attention and bill introductions, however, there is a slightly stronger correlation. I found that when presidential attention increases so does the amount of legislation regarding women's health care. Interestingly, though, it appears as the number of bill introductions increases, the number of congressional hearings decreases. This result potentially warrants further investigation, and begs the question, why would Congress reduce entrepreneurial and oversight activity when presidential attention increases? I offer possible explanations as to this result in the chapter, but a nuanced look at congressional hearings may help to better understand this behavior.

For example, instead of merely tracking the frequency of hearings, one might also account for hearing intensity. This could be accomplished by determining the length of hearings, number of hearings, or even the number of pages that makeup the hearing transcript. Using the current method, all hearings are treated equally and that is not as sensitive to the variations of behavior across committees and over time.

In chapter four, the second empirical chapter, I note occurrences of political entrepreneurship at the committee level as well as the individual level. To capture both 
dynamics, I measured the behavior of congressional committees and members of the House and Senate. I analyzed entrepreneurial activity in three stages: bill sponsorship and legislative introductions, hearing activity, and passed legislation. First, I tracked which committees received referrals to analyze turf control (King 1997). Then I tracked which members sponsored women's health legislation and whether subsequent bills were referred to committees on which they served. In future research I might also consider whether high ranking members served on the committees or if members held leadership positions, as this demonstrates a stronger indicator of entrepreneurship.

To examine hearing activity, I tracked which committees held the greatest number of hearings in women's health and which members testified most. For passed legislation, I determined which members sponsored the most bills and if the number of co-sponsors was related to whether a bill passes. After considering these measures of entrepreneurship, I also focused on what role gender plays among women's health entrepreneurs.

There are clearly dominant committees in the struggle for turf control in both the House and Senate. In the House, the Committee on Energy and Commerce is referred over two thirds of legislation introduced. Likewise, in the Senate, the Health, Education, Labor and Pensions Committee receives referrals for more than half of all women's health bills introduced. In the House, Representatives Maloney, DeLauro, and Waxman are leaders in women's health bill sponsorship. Similarly, in the Senate, Senators Kennedy and Boxer emerge as women's health entrepreneurs. We see these players repeated in measures of hearing activity and passed legislation. 
Co-sponsorship, specifically, is notable as there is a relationship between the number of cosponsors per bill and the number of bills passed. The relationship is stronger in the Senate than in the House. Wawro (2000), attributes co-sponsorship to practices of coalition building and increased entrepreneurship activity. This finding is important not only for bill sponsors but also for professional organizations and practitioners who generate and lobby legislation. I am interested in co-sponsorships by congressional and party leadership as well. I offer a sample of passed legislation but find very little evidence of leadership as co-sponsors. This may be a function of the small sample size or just indicative of the nature of the data. Perhaps sponsor gender would be a stronger indicator to predict legislative success. In either case, my evaluation is holistic, and for the future I would proposed an evaluation of each bill passed and tracked by congressional session.

I also evaluate the proportion of gender among top entrepreneurs in bill sponsorship, hearing testimony, and passed legislation. Women demonstrate higher proportions among this group. However, this result is incongruent to the percentage of women in each chamber. My examination of entrepreneurial activity and gender disparity provides an impression of activity, but formal modeling in future research is needed for determining definitive causal relationships. It appears that there is a relationship between gender, party, and legislative action. It would also be helpful to consider ideology as an additional measure. A multivariate analysis similar to Sewers (2016) work would likely provide stronger causal explanations.

Finally, in the third empirical chapter (chapter five), I evaluate expert and technical media to track attention of the medical establishment and academic and scholarly activity in women's health policy. First, I established key players in women's health policy who produce 
publications as a measure of expert media, professional groups, and agencies. These included the following: Institute of Medicine, National Institutes of Health, Office of the Surgeon General, Center for Disease Control, Department of Health and Human Services, and the Agency for Healthcare Research and Quality. Additionally, I tracked publications among the biomedical scholarly community from 1945-2018.

Then, I considered whether expert attention follows a similar pattern in media coverage of Congress and important changes in congressional behavior. I evaluated attention publications from CQ Magazine (CQ Weekly Reports) and provided narrative discussion to better understand the trends in attention. I evaluated this data relative to findings established in chapter three to determine whether expert media relates to public attention and further informs congressional and agency behavior.

I found that women's health policy was particularly robust in the early 1990s, exhibiting increases in activity across the measures of expert and technical media, as well as Congress. This period was marked by considerable expansion for women's health research. Scholarly and scientific research seems to drive attention among all groups, but funding in Congress is a necessary catalyst to help create policy change. Publications from the Office of the U.S. Surgeon General (USSG) demonstrates a more defined trend line in terms of punctuation, but this is likely a result of the nature of USSG tradition of reporting and the relatively small search returns. In review of congressional, presidential, and medical establishment activity, it should be noted that generally there is an upward trend. It is interesting that women's health bill introductions peak first in 1985, but publications in the medical establishment follow closely with an uptick in 1987. Medical publications peak again in 2003 when the National Institute of 
Health reports the dangers of Hormone Replacement Therapy. There is an increase in bill introductions which follows in 2009 , where we begin to see an unmatched dramatic increase in medical publications concerning women's health.

The relatively higher increase in medical publications in the early 2000 s does not correspond with public or congressional attention and is noteworthy for future research. The discussion on the policy evolution in chapter five describes the changes in current health practice and research that result from changes in legislation. In many respects, women's health research is in its infancy compared to many other medical fields. Future research concerning the policy evolution might uncover further discussion surrounding the importance of data in clinical trials for women and what specific impacts the Patient Protection and Affordable Care Act (2010) will yield for women's health.

\section{AVENUES FOR FUTURE RESEARCH}

From its original conception, the women's health definition has shifted, changed, and arguably returned to its original narrative. Initially, women's health policy was largely defined by childbirth and reproductive health casting women as mothers and caregivers. Part of the later discussion included attention to over population and concerns of birth control, and eventually the discussion became focused on the debate over abortion. While each of these dimensions remained on the agenda in some capacity, attention shifted as a new facet became particularly salient to the public, government, and medical community. The debate over abortion is difficult to constrain as wholly related to health. 
Depending on the particular venue, congressional committees for instance, the debate may be related to the ethics of funding, religious and moral concerns, civil rights, or health and safety of the mother. For example, if a bill is referred to the Judiciary Committee, one would expect a debate on the merits of rights as opposed to the necessity of funding agency programs related to patient education or safe practices. Later developments in women's health centered on a more holistic approach to women's health with evidenced based medical research and attention to funding for programs that expanded access, provided screenings, and supported specialized cancer treatment. While I consider these dynamics, the focus is on who is paying attention when, but not necessarily how they are paying attention where. Future research building on the data collected might consider how committee venue alters attention to women's health and the type of policy created. A closer look at the relationship between committees and administrative agencies would also provide an additional dynamic.

\section{Agenda Crowding}

In addition to the dimensions and definition of women's health, I also consider agenda capacity and how women's health fits into the overall health agenda. In chapter three, I determined that health policy garners a moderate amount of attention, when compared to say defense policy. In comparison to all other policy topics tracked by Baumgartner and Jones in The Policy Agendas Project, health is near the middle. I then use infants and children's policy as a first measure and substitute for women's health. Infant and Children's policy accounts for a very small fraction of all health policy. This is potentially a result of the Agendas' Project coding system, but it is all an indicator of the limited agenda space. Women's health accounts for an even smaller fraction of the agenda. In chapter three I illustrate that $22 \%$ of all health bill 
introductions are women's health related, and in terms of congressional hearings, women's health represents about $16 \%$ of all health hearings. Less than $10 \%$ of all health laws passed are directly related to women's health.

This result is demonstrating the competition among all other health topics vying for attention. In some regards, abortion is included as part of women's health policy but in others, it could be treated as a separate policy issue. Women's health bleeds over to other health concerns of affordability and access, federal grant programs, and clinical research as women as a group are targeted for entitlement programs and fulfill the role as mother and caregiver.

These large number of health issues vying for space on the agenda result in issue crowding. Future research might include other facets of women's health that are emerging and competing for space. In particular, contraception has become especially relevant. Similar to abortion, contraception has become an issue targeted by conservative religious groups. In 2012 Congress debated an amendment to allow health insurance plans to deny coverage for provisions of medical services that run counter to the plan sponsor or employer's religious beliefs (CQ Almanac 2012). For several weeks in early 2012, Republicans' opposition to the rule gained headlines and national attention.

The debate tapped into several contentious areas: the health care law, women's health issues and religious freedom. Republican leaders maintained that the rule violated religious freedoms of employers that did not qualify as religious institutions. Supporters, defended it as necessary to protect women's health and an important part of the health care law's coverage of preventive services. In early February, House Speaker John A. Boehner, R-Ohio, made a rare floor speech pledging to undo the rule and put the Energy and Commerce Committee in charge 
of finding a legislative way to reverse it (CQ Almanac 2012). Ultimately House Republicans stood their ground on the issue, but the Senate reversed the amendment and S 1813 passed without Republican support. While contraception is not always tied to women's health or even religious freedom, the debate has certainly renewed since the passage of the Affordable Care Act (2010), which brings women's health policy back to a question of motherhood.

Future research including contraception as part of the agenda crowding component to women's health attention would add another, possibly more explanatory, dimension to the narrative. As society progresses toward more egalitarian representation, both substantively an descriptive, we can expect increased agenda crowding. As we expand the narrative to include underrepresented groups in the health discussion, space will become more limited. As science and society now challenge the traditional binary definitions of sex and gender, the proverbial pandora's box has opened. Health care professionals are first on the ground in response to new notions of gender and we can expect that policy makers will have to respond. Gender equity and emerging science place new demands on the policy process. This study brings increased understanding to the ways in which women's health issues gain entrance into the formal agenda. 


\section{REFERENCES}

Adler, E. Scott and John Wilkerson, Congressional Bills Project: (1945-2017), NSF 00880066 and 00880061. The views expressed are those of the authors and not the National Science Foundation.

Angevine, S. 2017. "Representing All Women: An Analysis of Congress, Foreign Policy, and the Boundaries of Women's Surrogate Representation." Political Research Quarterly, 70(1), 98-110. Retrieved from http://www.jstor.org.www.libproxy.wvu.edu/stable/26384903

Alcohol Beverage Health Warning Statement (99R-507P). 2001. Federal Register, 66(99). pp. $28135-28137$.

Aldrich, J. 1994. A Model of a Legislature with Two Parties and a Committee System. Legislative Studies Quarterly, 19(3), 313-339.

Arnold, D. 1990. The Logic of Congressional Action. New Haven, CT: Yale University Press.

Austin, Jay. 2010. "Edward M. Kennedy: Liberal Icon and Legendary Legislator." CQ Almanac 2009, Washington, DC: CQ-Roll Call Group, 65: pp.5-3-5-8. -

Austin, Jay. 2010. "Landmark Health Care Overhaul: A Long, Acrimonious Journey." CQ Almanac 2009, Washington, DC: CQ-Roll Call Group, 65: pp.13-3-13-14.

Austin, Jay, 2012. "Repeal of Health Care Overhaul Law Defeated in Democratic Senate." In CQ Almanac 2011, Washington, DC: CQ-Roll Call Group, 67: 8-3-8-4.

Banks, J. 1989. Agency Budgets, Cost Information, and Auditing. American Journal of Political Science,33(3), 670-699. doi:10.2307/2111068

Baumgartner, Frank R. and Bryan D. Jones. 1993. Agendas and Instability in American Politics. Chicago: University of Chicago Press. 
Baumgartner, Frank R. and Bryan D. Jones. 2002. Positive and Negative Feedback in Politics.

In Frank R. Baumgartner and Bryan D. Jones, ed., Policy Dynamics. Chicago, IL: Chicago Press.

Baumgartner, Frank R. and Bryan D. Jones. 2005. The Politics of Attention: How Government Prioritizes Problems. Chicago: The University of Chicago Press.

Baumgartner, Frank R., Jones, Bryan D., \& Wolfe, Michelle. 2013. A Failure to Communicate: Agenda Setting in Media and Policy Studies. Political Communications Journal, pp. 175192.

Bettelheim, A . 2009. "Obama Reverses Bush Policies." CQ Weekly: 184-85. http://library.cqpress.com.www.libproxy.wvu.edu/cqweekly/weeklyreport111000003017558.

Binder, Sarah A., and Lee, Frances E. 2013. "Negotiating Agreement in Politics: Report of the Task Force on Negotiating Agreement." Politics American Political Science Association.

Birkland, T. 1998. Focusing Events, Mobilization, and Agenda Setting. Journal of Public Policy, 18(1), 53-74.

Birkland, T. A. 2017. "Agenda Setting in Public Policy." In Handbook of Public Policy Analysis (pp. 89-104). Routledge.

Boehmke, F. J., Gailmard, S., \& Patty, J. W. 2006. Whose ear to bend? Information sources and venue choice in policy-making. Quarterly Journal of Political Science, 1(2), 139-169.

Boxer, Barbara. 2016, “Biographical Directory of the United States Congress, 1774Present." Almanac of American Politics, Washington, DC: 159.

Canes-Wrone, B. 2006. Who Leads Whom? Presidents, Policy, and the Public.Chicago: University of Chicago Press

Carey, Mary A. 2002. "Sen. Olympia J. Snowe," CQ Weekly: pp. 36. 
Carroll, S. and Dodson, D. 1991. Introduction: In Gender and Policymaking: Studies of Women In Office, ed. DL Dodson, Pg. 1-11. New Brunswick, NJ. Cent. Am. Woman Polit. CAWP: Center for American Women and Politics (Eagleton Institute of Politics at Rutgers, the State University of New Jersey). Women in the U.S. Congress 2018 Fact Sheet, http://www.cawp.rutgers.edu/current-numbers.

Center for Diseases Control and Prevention. 2018. United States Cancer Statistics (USCS) www.cdc.gov/cancer/uscs/public-use.

Chareny, P. 2000. Women's Health: An Evolving Mosaic. Journal of General Internal Medicine, Volume 15 August.

Childs, S. and Mona L. Krook. 2009. Analyzing Women's Substantive Representation: From Critical Mass to Critical Actors. Government and Opposition, 44: 2, 125-145.

Cobb, R., Ross, J.K., \& Ross, M. H. 1976. Agenda Building as a Comparative Political Process. The American Political Science Review, 70(1), pp. 126-138.

Cobb, Roger W. and Charles D. Elder. 1972. Participation in American Politics: The Dynamics of Agenda Building. Baltimore: Johns Hopkins University Press.

Congressional Hearings. ProQuest ${ }^{\oplus}$ Congressional. www.proquest.com. Accessed August 4, 2018.

CQ Almanac 1986.1987. Congress Clears Omnibus Health Legislation. Washington, DC: Congressional Quarterly, 42: pp. 238-44.

CQ Almanac 1986.1987. "Health/Education/Welfare 1986: Overview." Washington, DC: Congressional Quarterly, 42: pp. 229-30. 
CQ Almanac 1986.1987. "Child Nutrition Programs." Washington, DC: Congressional Quarterly, 42: pp. $248-50$

CQ Almanac 1986. 1987. "Infant Formula Regulation. "Washington, DC: Congressional Quarterly, 42: pp.263.

CQ Almanac 1946.1947 "Health Proposals in the 79th Congress." Washington, DC:

Congressional Quarterly, 2: pp. 04-658-04-665.

CQ Almanac 1948. 1949."Social Security." Washington, DC: Congressional Quarterly, 4: pp.143-46.

CQ Almanac 1954.1955. "Health Hearings." Washington, DC: Congressional Quarterly, 10: pp. 04-218-04-220.

CQ Almanac 1949. 1950. "Social Security Extension." Washington, DC: Congressional Quarterly, 5: pp. 04-288-04-292.

CQ Almanac 1946. 1947. "Social Security Act Amendments." Washington, DC: Congressional Quarterly, 2: pp. 04-666-04-671.

CQ Almanac 1968. 1969."Message to Congress: Johnson Asks Expanded Medical-Training Programs in "Health in America" Message." Washington, DC: Congressional Quarterly, 24: pp.20-72-A-20-76-A.

CQ Almanac 1970. 1971. "Population Control: Increased Federal Concern." Washington, DC: Congressional Quarterly, 26: pp. 05-570-05-576.

CQ Almanac 1974. 1975. "Health Policy 1974: Overview." Washington, DC: Congressional Quarterly, 30: pp.375-78.

CQ Almanac 1984. 1985"Federal Abortion Alternatives Cut by Reagan." Washington, DC: Congressional Quarterly, 40: pp.465-69. 
CQ Almanac 1984, 1985."New Cigarette Labels." Washington, DC: Congressional Quarterly, 40: pp.478-80.

CQ Almanac 1974. 1975."Hearings Air Abortion Controversy." Washington, DC: Congressional Quarterly, 30: pp.429-31.

CQ Almanac 1991. 1992. "Disability, Alzheimer's Programs Considered in 1991." Washington, DC: Congressional Quarterly, 47: pp.363-64.

CQ Almanac 1993, 1994."National Institutes of Health (NIH) Bill Focuses on AIDS, Women's Health." Washington, DC: Congressional Quarterly, 49: pp.357-63.

CQ Almanac 1990. 1991. "Stripped-Down NIH Authorization Passed." Washington, DC: Congressional Quarterly, 46: pp.600-604.

CQ Almanac 1965. 1966. "Senate Holds Hearings on Birth Control." Washington, DC: Congressional Quarterly, 21: pp.311-16.

CQ Almanac 1988. 1989. "After Years of Debate, Welfare Reform Clears." Washington, DC: Congressional Quarterly, 44: pp.349-64.

CQ Almanac 1993. 1994. "Congress Reauthorizes Centers for Disease Control (CDC) Programs, Aid for Women's Cancers." Washington, DC: Congressional Quarterly, 49: pp. 369-70. CQ Almanac 1995. 1996. "Abortion Foes Press Their Agenda." Washington, DC: Congressional Quarterly, 51: pp. 7-29.

CQ Almanac 1993. 1994. "Health-Care Debate Takes Off." Washington, DC: Congressional Quarterly, 49: 335-44. 
CQ Almanac 1988. 1989. "After Years of Debate, Welfare Reform Clears." Washington, DC: Congressional Quarterly, 44: pp. 349-64.

CQ Weekly. (Sept 4, 1993): 2319-27. http://library.cqpress.com/cqweekly/WR103402284.

DeLauro, Rosa. 2006. "Prepared under the direction of the Committee on House Administration by the Office of History \& Preservation, U. S. House of Representatives." Women in Congress, Washington: Government Printing Office.

Deavers, Kimberly., and Kavanuagh, Laura., 2010. "Caring for Infants Then \& Now.” U.S. Department of Health and Human Services, Health Resources and Services Administration, Maternal and Child Health Bureau.

Dittmar, K., Sanbonmatsu, K., \& Carroll, S. J. 2018. A Seat at the Table: Congresswomen's Perspectives on why Their Presence Matters. Oxford University Press

Dodson, Debra L. 1998. “Representing Women's Interests in the U.S. House of Representatives." In Women and Elective Office: Past, Present, and Future, Sue Thomas and Clyde Wilcox eds. New York: Oxford University Press.

Downs, Anthony. 1972. "Up and Down with Ecology: The Issue Attention Cycle." Public Interest 28: $38-50$.

Evans, Lawrence C. 2013. Explanatory Power in a Partisan Congress? The Journal of Politics Vol 75 , No, 3, July.

Executive Orders. The Policy Agendas Project at the University of Texas at Austin, 2017. www.comparativeagendas.net. Accessed July 38, 2018.

Fenno, Richard F. 1973. Congressmen in Committees. Little Brown. 
Fowler, J. H. 2006. "Connecting the Congress: A study of cosponsorship networks". Political Analysis, 14(4), 456-487.

Feinstein, B. D. 2017. Congress in the Administrative State. Wash. UL Rev., 95, 1187.

Ferejohn, J., and Krehbiel, K. 1987. "The Budget Process and the Size of the Budget." American Journal of Political Science,31(2).

Frantzich, Stephen. 1979. Who Makes Our Laws? The Legislative Effectiveness of Members of the U.S. Congress. Legislative Studies Quarterly, 4(30), pp.409-428.

Gordon, Linda. 1990. Women, the State, and Welfare. Madison: University of Wisconsin Press.

Gertzog, I. N. 1995. Congressional Women: Their Recruitment, Integration, and Behavior. Westport, CT: Praeger.

Glazer, S. 1994. Women's health issues. CQ Researcher, 4, 409-432. Retrieved from http://library.cqpress.com/.

Godwin, E., \& Llderton, N. 2014. “Presidential Defense: Decisions and Strategies to Preserve the Status Quo." Political Research Quarterly,67(4), 715-728. Retrieved from

Gordon, Linda. 1990. Women, the State, and Welfare. Madison: University of Wisconsin Press. Gunderson, Gordon. 2013. "Child Nutrition Act of 1996" https://www.fns.usda.gov/nslp/history_6

Haeder, S. F., \& Weimer, D. L. 2015. Inching toward universal coverage: state-federal healthcare programs in historical perspective. Journal of Policy History,27(4), 746-770.

Hall, Richard. 1996. Participation in Congress. New Haven, CT: Yale University Press. Hearings. The Policy Agendas Project at the University of Texas at Austin, 2017. www.comparativeagendas.net. Accessed July 26, 2018. 
Hrebenar, R. J., \& Scott, R. K. 2015. Interest group politics in America. Routledge.

Huddy, L., Cassese, E., and Lizotte, M. 2008. Gender, public opinion, and political reasoning. In Political Women and American Democracy ed. Christina Wolbrecht, Karen Beckwith, and Lisa Baldez. Cambridge, MA: Cambridge University Press.

Huber, J., Shipan, C., \& Pfahler, M. 2001. Legislatures and Statutory Control of Bureaucracy. American Journal of Political Science,45(2), 330-345. doi:10.2307/2669344

Jenkins, J., \& Monroe, N. 2016. “On Measuring Legislative Agenda-Setting Power.” American Journal of Political Science, 60(1), 158-174.

Jones, Bryan D. 1995. Reconceiving Decision-Making in Democratic Politics: Attention, Choice, and Public Policy. Chicago: University of Chicago Press.

Jones, B. D., \& Mortensen, P. B. 2018. Punctuated Equilibrium Theory: Explaining Stability and Change in Public Policymaking, Frank R. Baumgartner. In Theories of the Policy Process (pp. 65-112). Routledge.

Kettl, Donald F. 2000. "Public Administration At the Millennium." Journal of Public Administration Research and Theory: J-PART, 10(1): pp. 7-34.

King, David C. 1997. Turf Wars: How Congressional Committees Claim Jurisdiction. Chicago: University of Chicago Press.

Kingdon, John W. 1989. Congressmen's Voting Decisions. Ann Arbor: University of Michigan Press.

Kingdon, John W. 1995. Agendas, Alternatives, and Public Policies. 2nd ed. Boston: Little, Brown, and Company.

Knight, E. K., Benjamin, G. D., \& Yanich, D. 2016. “Framing social determinants of health within 
the professional public health community: research translation and implications for policy change." Journal of Applied Communication Research, 44(3), 256-274.

Kirschstein, Ruth L. 1991. Research on Women's Health. American Journal of Public Health, 81(3).

Kirchhoff, Sue \& Carey, Mary Agnes. 1998. APPROPRIATIONS: Medical Research and Education Are Big Winners in Spending Bill, CQ WEEKLY 2895.

Krause, George A. 2013. "Representative democracy and policy-making in the administrative state: is agency policy-making necessarily better?." Journal of Public Policy, 33(2): pp. 111-135.

Larsen-Price, Heather. 2012. The Right Tool for the Job. The Policy Studies Journal, 40(1), pp. 147-168.

Lawton B, Rose S, McLeod D, Dowell A. 2003. “Changes in use of hormone replacement therapy after the report from the Women's Health Initiative: cross sectional survey of users. BMJ. Oct $11 ; 327(7419): 845-6$.

Lee, N. C. 2015. Public Health Rep. 130(2): 121-22

Legislative Summary: Social Policy. 1993. CQ Weekly. Pp. 2319-2327.

Light, P. 1999. The President's Agenda 3rd Ed. Baltimore, MD: The Johns Hopkins University Press.

Loomis, B. A., \& Schiller, W. J. 2018. The Contemporary Congress. Rowman \& Littlefield. Lowy, Joan. 2003. Pat Schroeder: Woman of the House. Albuquerque, N.M.: University of New Mexico Press. 
Maloney, Carolyn. 2006. "Prepared under the direction of the Committee on House Administration by the Office of History \& Preservation, U. S. House of Representatives." Women in Congress, Washington: Government Printing Office.

Maloney, C. 2008. “Rumors of Our Progress Have Been Greatly Exaggerated: Why Women's Lives Aren't Getting Any Easier--and how We Can Make Real Progress for Ourselves and Our Daughters." Rodal.

Mansbridge, J. 1999. Should blacks represent blacks and women represent women? A contingent "yes". The Journal of Politics, 61: 628-657.

Marvel, J. D., \& McGrath, R. J. 2016. Congress as manager: oversight hearings and agency morale. Journal of Public Policy, 36(3), 489-520.

Masci, D. 2003. Women's health. CQ Researcher, 13, 941-964. Retrieved from: http://library.cqpress.com/

Matland, R.E. 1993. Institutional variables affecting female representation in national legislatures: The case of Norway. J. Polit. 55: pg. 737-55.

Mayhew, David R. 1974. The Electoral Connection. New Haven: Yale University Press.

Mink, G. 1990. The Lady and the Tramp: Gender, Race, and the Origins of the American Welfare State. Women, the State, and Welfare, 92-122.

Mintrom, M. Norman, P. 2009. "Policy Entrepreneurship and Policy Change." The Policy Studies Journal. 37, 4: 649-667.

Miroff, Bruce. 2003. "Entrepreneurship and Leadership." Studies in American Political Development. 17(Fall): 204-211. 
Moe, T. 1994. Integrating Politics and Organizations: Positive Theory and Public Administration. Journal of Public Administration Research and Theory: J-PART, 4(1),

Nelson, B. 2016. "Making an Issue of Child Abuse." Agenda Setting: Readings on Media, Public Opinion, and Policymaking, 161.

Nowlin, M. C. 2016. Policy change, policy feedback, and interest mobilization: The politics of nuclear waste management. Review of Policy Research, 33(1), 51-70.

Norsigian, J. 1992. "The women's health movement in the United States". Women's Global Network for Reproductive Rights. Apr-Jun;(39):9-12

Nownes, A., \& Neeley, G. 1996. Toward an Explanation for Public Interest Group Formation and Proliferation: "Seed Money, Disturbances, Entrepreneurship, and Patronage." Policy Studies Journal, 24(1), 74-92.

Paxton, P., Kunovich, S., and Hughes, M. 2007. "Gender in Politics”. Annual Rev. Social, 33: pg. 263-84.

Patashnik, E. M., \& Peck, J. 2016. Can Congress Do Policy Analysis?. Governing in a Polarized Age: Elections, Parties, and Political Representation in America, 267.

Peters, Guy. B. 2018. American Public Policy: Promise and Performance. Pittsburgh, PA: CQ Press.

Petrocik, John R. 1996. "Issue Ownership in Presidential Elections, with a 1980 Case Study." American Journal of Political Science 40 (3): 825-50.

Phillips, Anne. 1995. The Politics of Presence. New York, NY: Oxford University Press.

Pitkin, Hannah. 1967. The Concept of Representation. Los Angeles, CA: The University of California Press.

Plein, C. 1991. Popularizing Biotechnology: The Influence of Issue Definition. Science, 
Technology, \& Human Values, Vol.16 No.4, 474-490.

Polsby, N. W. 2004. How Congress evolves: Social bases of institutional change. Oxford University Press on Demand.

Ranji, U., Rosenzweig, C., Salganicoff, A. Women's Coverage, Access, and Affordability: Key Findings from the 2017 Kaiser Women's Health Survey, (The Henry J. Kaiser Family Foundation, March 2018).

Robertson, David B., Dennis R. Judd. 1989. The Development of American Public Policy: The Structure of Policy Restraint. Scott Foresman \& Co.

Rochefort, D. and Cobb, R. 1994. The Politics of Problem Definition. Lawrence: The University of Kansas.

Rubin, Alissa J., and Jill Zuckman. 1993. Abortion Funding Rebuff Shows House Divided. CQ Weekly 1735(39). http://library.cqpress.com.www.libproxy.wvu.edu/cqweekly/ WR10340187

Rubin, Alissa J. 1993. Searching for the Middle. CQ Weekly: 1737.

Ruess, Michelle. 1992. “Oakar's Loss a Blunder, Not a Coup.” Biographical Dictionary of Congressional Women, Westport, CT: Greenwood Press, 209.

Rushefsky, M. E., \& Patel, K. 2016. Politics, Power and Policy Making: Case of Health Care Reform in the 1990s: Case of Health Care Reform in the 1990s. Routledge.

Sapiro, Virginia (1990). The Gender Basis of American Social Policy. In Linda Gordon (Eds.) Sabatier, P.A. and Smith, H.J. 1999. The Advocacy Coalition Framework: An Assessment. In P.A. Sabatier (ed), Theories of the Policy Process. Boulder, CO: Westview. Pp. 117-166. Sapiro, Virginia 1990. The Gender Basis of American Social Policy. In Linda Gordon (Eds.) 
Women, the State, and Welfare. (Ch 1) Madison: University of Wisconsin Press.

Schwindt-Bayer, L. and Mishler, W. 2005. "An integrated model of women's representation."

The Journal of Politics, Vol. 67, No. 2: 407-428.

Shapiro, R. and Mahajan, H. 1986. Gender Differences in Policy Preferences: A Summary of Trends From the 1960s to the 1990s. Public Opin. Q. 50 (1): pg. 42-61.

Shepsle, Kenneth A. and Weingast, Barry R. 1995. Positive Theories of Congressional Institutions. University of Michigan Press.

Shiller, Wendy J. 1995. Senators as Political Entrepreneurs: Using Bill Sponsorship to Shape Legislative Agendas. American Journal of Political Science, 39(1), pp. 186-203

Sinai, N. 1947. "Experience and Lessons from Emergency Maternity and Infant Care." American Journal of Public Health, 78: 1097-1103.

Schneider, M., Teske P. \& Mintrom, M. 1995. Public Entrepreneurs: Agents for Change in American Government. Princeton, NJ: Princeton University Press.

Schattschneider, E.E. 1960. The Semi-Sovereign People: A Realist's View of Democracy In America. New York: Holt, Rinehart, and Winston.

Schlesinger, Edward R. 1967. “The Sheppard-Towner Era: A Prototype Case: Study in FederalState Relationships." 57(6): pp. 1024-1040.

Sheingate, A. 2003. Political Entrepreneurship, Institutional Change, and American Political Development. Studies in American Political Development. 17 (Fall): 185-203.

Sheingate, A. 2006. Structure and Opportunity: Committee Jurisdiction and Issue Attention in Congress. American Journal of Political Science, 50 (4), 844-859.

Shiffman, J. 2016. Agenda setting in public health policy. In International encyclopedia of public 
health (pp. 16-21). Elsevier Inc.

Skowronek, S. 1982. Building a New American State: The Expansion of National

Administrative Capacities, 1877-1920. Cambridge University Press.

Stone, Deborah A. 1989. Causal Stories and the Formation of Policy Agendas. Political Science Quarterly. 104(2), pp. 281-300.

Swers, Michele L. 1998. Are Congresswomen More Likely to Vote for Women's Issue Bills Than Their Male Colleagues? Legislative Studies Quarterly, no. 23: 435-48.

Swers, Michele L. 2001. Understanding the Policy Impact of Electing Women: Evidence from Research on Congress and State Legislature. PS, Political Science \& Politics 34 (2): 217220.

Swers, Michele L. 2002. The Difference Women Make: The Policy Impact of Women in Congress. Chicago: University of Chicago Press.

Swers, Michele L. 2005. Women in Congress: Do They Act as Advocates for Women's Issues? Women and Elective Office: Past, Present, and Future, vol. 2: Oxford University Press.

Swers, Michele L. 2013. Women in the Club: Gender and Policy Making in the Senate. Chicago: University of Chicago Press.

Swers, M. 2016. “Pursuing Women's Interests in Partisan Times: Explaining Gender Differences in Legislative Activity on Health, Education, and Women's Health Issues." Journal of Women, Politics \& Policy 37 (3): 249-73.

Tamerius, Karin L. 1995. "Sex, Gender, and Leadership in the Representation of Women." In Gender, Power, Leadership, and Governance, eds. Georgia Duerst-Lahti and Rita Mae Kelly Ann. 
Tan, Y., \& Weaver, D. H. 2007. Agenda-setting effects among the media, the public, and congress, 1946-2004. Journalism \& Mass Communication Quarterly, 84(4), 729-744.

Taylor, A. J. 2013. Congress: a performance appraisal. Westview Press.

U.S. National Library of Medicine. 2003. Dr. Antonia Novello. Retrieved from: https://cfmedicine.nlm.nih.gov/physicians/biography_239.html.

Temkin, E. 1999. Driving Through: Postpartum Care During World War II. American Journal of Public Health, 89(4).

"Two Dozen Votes Illustrate What a Do-Nothing Congress Actually Did." In CQ Almanac 2012, 68th ed., C-3. Washington, DC: CQ-Roll Call Group, 2013.

U.S. National Library of Medicine. 2003. Dr. Antonia Novello. Retrieved from: https://cfmedicine.nlm.nih.gov/physicians/biography_239.html.

VA Provision of Health Care to Women Veterans and Related Issues. 1993. Oversight and Investigations, Committee on Veterans' Affairs. House; Committee on Veterans' Affairs. House.

Vega, Arturo, and Juanita M. Firestone. 1995. “The Effects of Gender on Congressional Behavior and the Substantive Representation of Women." Legislative Studies Quarterly, no. 20: $213-22$.

Volden C., and Wiseman A. E. 2014. Legislative Effectiveness in the United States Congress: The Lawmakers. By. New York: Cambridge University Press

Walker, J.L. 1977. Setting the Agenda in the U.S. Senate: A Theory of Problem Selection. British Journal of Political Science, 7, 423-445. 
Walsh, Katherine Cramer. 2002. "Resonating To Be Heard: Gendered Debate On The Floor Of The House." In Women Transforming Congress. Norman: University of Oklahoma Press. Wawro, Gregory. 2000. Legislative Entrepreneurship in the U.S. House of Representatives. Ann Arbor: University of Michigan Press.

Waxman, H. 2009. The Waxman report: how congress really works. 12.

Wilkerson, John D, T Jens Feeley, Nicole Schiereck and Christina Sue. 2002. "Using Bills to Trace Attention in Congress." In Frank Baumgartner and Bryan Jones, eds. Policy Dynamics. Chicago: University of Chicago Press.

Wehner, J. 2010. Legislatures and the Budget Process: The Myth of Fiscal Control. Springer: NY Wher, Elizabeth and Harrison Donnelly. 1980. "CQ Almanac 1979: Health/Education/Welfare 1979: Overview." Washington, DC: Congressional Quarterly,

Wolbrecht, Christina. 2002. "Female Legislators and the Women's Rights Agenda." In Women Transforming Congress, eds. Cindy Simon Rosenthal. Norman: University of Oklahoma Wolfe, Michelle. 2012. Putting on the Brakes or Pressing the Gas? Political Studies Journal, 40(1) pp. 109-126.

Women's Health Initiative. 2019. Welcome to Women's Health Initiative. Retrieved from: https://cfmedicine.nlm.nih.gov/physicians/biography_239.html.

Workman, Samuel. 2015. The Dynamics of Bureaucracy in the US Government: How Congress and Federal Agencies process Information. Cambridge Press.

Workman, S., \& Shafran, J. S. 2015. Communications Frameworks and the Supply of Information in Policy Subsystems. In Policy Paradigms in Theory and Practice (pp. 239267). Palgrave Macmillan, London.

Woon, J. 2008. Bill sponsorship in Congress: the moderating effect of agenda positions on 
legislative proposals. The Journal of Politics, 70(1), 201-216.

Worsham, J., and Stores, C. 2012. "PET Sounds: Subsystems, Regimes, and Policy Punctuations and the Neglect of African American Farmers, 1935-2006." Policy Studies Journal 40(1): $169-190$.

Worsham, J. 1998. Wavering Equilibriums: Subsystem Dynamics and Agenda Control. American Politics Quarterly 26 (October 4): 485-512. 


\section{APPENDIX}

Bill sponsorship for top entrepreneurs sponsoring a total of 10 or more bills per congressional session

\begin{tabular}{|c|c|}
\hline Member (House) & $\begin{array}{c}\# \\
\text { Sponsored }\end{array}$ \\
\hline Rep. Maloney, Carolyn B. [D-NY-14] & 45 \\
\hline 104th Congress (1995-1996) & 2 \\
\hline 105th Congress (1997-1998) & 5 \\
\hline 106th Congress (1999-2000) & 5 \\
\hline 107th Congress (2001-2002) & 5 \\
\hline 108th Congress (2003-2004) & 7 \\
\hline 109th Congress (2005-2006) & 9 \\
\hline 110th Congress (2007-2008) & 8 \\
\hline 111th Congress (2009-2010) & 2 \\
\hline 112th Congress (2011-2012) & 2 \\
\hline Rep. DeLauro, Rosa L. [D-CT-3] & 42 \\
\hline 103rd Congress (1993-1994) & 1 \\
\hline 104th Congress (1995-1996) & 1 \\
\hline 105th Congress (1997-1998) & 1 \\
\hline 106th Congress (1999-2000) & 2 \\
\hline 107th Congress (2001-2002) & 2 \\
\hline 108th Congress (2003-2004) & 2 \\
\hline 109th Congress (2005-2006) & 3 \\
\hline 110th Congress (2007-2008) & 5 \\
\hline 111th Congress (2009-2010) & 3 \\
\hline 112th Congress (2011-2012) & 4 \\
\hline 113th Congress (2013-2014) & 8 \\
\hline 114th Congress (2015-2016) & 6 \\
\hline 115th Congress (2017-2018) & 4 \\
\hline Rep. Waxman, Henry A. [D-CA-24] & 39 \\
\hline 100th Congress (1987-1988) & 11 \\
\hline 101st Congress (1989-1990) & 1 \\
\hline 102nd Congress (1991-1992) & 9 \\
\hline 96th Congress (1979-1980) & 4 \\
\hline 97th Congress (1981-1982) & 5 \\
\hline 98th Congress (1983-1984) & 5 \\
\hline 99th Congress (1985-1986) & 4 \\
\hline
\end{tabular}




\begin{tabular}{|c|c|}
\hline Rep. Lowey, Nita M. [D-NY-18] & 28 \\
\hline 103rd Congress (1993-1994) & 1 \\
\hline 104th Congress (1995-1996) & 1 \\
\hline 105th Congress (1997-1998) & 5 \\
\hline 106th Congress (1999-2000) & 3 \\
\hline 107th Congress (2001-2002) & 1 \\
\hline 108th Congress (2003-2004) & 3 \\
\hline 109th Congress (2005-2006) & 6 \\
\hline 110th Congress (2007-2008) & 5 \\
\hline 111th Congress (2009-2010) & 3 \\
\hline Rep. Schroeder, Patricia [D-CO-1] & 22 \\
\hline 100th Congress (1987-1988) & 2 \\
\hline 101st Congress (1989-1990) & 5 \\
\hline 102nd Congress (1991-1992) & 4 \\
\hline 103rd Congress (1993-1994) & 8 \\
\hline 104th Congress (1995-1996) & 3 \\
\hline Rep. Lee, Barbara [D-CA-9] & 22 \\
\hline 106th Congress (1999-2000) & 1 \\
\hline 107th Congress (2001-2002) & 1 \\
\hline 108th Congress (2003-2004) & 3 \\
\hline \multicolumn{2}{|l|}{ Rep. Lee, Barbara [D-CA-9] } \\
\hline 109th Congress (2005-2006) & 4 \\
\hline 110th Congress (2007-2008) & 3 \\
\hline 111th Congress (2009-2010) & 5 \\
\hline 112th Congress (2011-2012) & 5 \\
\hline Rep. Morella, Constance A. [R-MD-8] & 21 \\
\hline 101st Congress (1989-1990) & 2 \\
\hline 102nd Congress (1991-1992) & 2 \\
\hline 103rd Congress (1993-1994) & 3 \\
\hline 104th Congress (1995-1996) & 5 \\
\hline 105th Congress (1997-1998) & 3 \\
\hline 106th Congress (1999-2000) & 2 \\
\hline 107th Congress (2001-2002) & 4 \\
\hline Rep. Slaughter, Louise Mclntosh [D-NY-28] & 21 \\
\hline 103rd Congress (1993-1994) & 1 \\
\hline 104th Congress (1995-1996) & 2 \\
\hline 105th Congress (1997-1998) & 3 \\
\hline 106th Congress (1999-2000) & 1 \\
\hline 107th Congress (2001-2002) & 1 \\
\hline
\end{tabular}




\begin{tabular}{|c|c|}
\hline 108th Congress (2003-2004) & 2 \\
\hline \multicolumn{2}{|c|}{ Rep. Slaughter, Louise McIntosh [D-NY-28] } \\
\hline 109th Congress (2005-2006) & 2 \\
\hline 110th Congress (2007-2008) & 4 \\
\hline 111th Congress (2009-2010) & 4 \\
\hline 112th Congress (2011-2012) & 1 \\
\hline Rep. Nadler, Jerrold [D-NY-8] & 16 \\
\hline 103rd Congress (1993-1994) & 3 \\
\hline 105th Congress (1997-1998) & 2 \\
\hline 106th Congress (1999-2000) & 2 \\
\hline \multicolumn{2}{|l|}{ Rep. Nadler, Jerrold [D-NY-8] } \\
\hline 107th Congress (2001-2002) & 1 \\
\hline 108th Congress (2003-2004) & 2 \\
\hline 109th Congress (2005-2006) & 2 \\
\hline 110th Congress (2007-2008) & 1 \\
\hline 111th Congress (2009-2010) & 1 \\
\hline 112th Congress (2011-2012) & 2 \\
\hline Rep. Schakowsky, Janice D. [D-IL-9] & 16 \\
\hline 107th Congress (2001-2002) & 2 \\
\hline 108th Congress (2003-2004) & 1 \\
\hline 110th Congress (2007-2008) & 3 \\
\hline 111th Congress (2009-2010) & 4 \\
\hline 112th Congress (2011-2012) & 2 \\
\hline 113th Congress (2013-2014) & 2 \\
\hline 115th Congress (2017-2018) & 1 \\
\hline 116th Congress (2019-2020) & 1 \\
\hline Rep. Pallone, Frank, Jr. [D-NJ-6] & 15 \\
\hline 105th Congress (1997-1998) & 2 \\
\hline 106th Congress (1999-2000) & 2 \\
\hline 107th Congress (2001-2002) & 1 \\
\hline 108th Congress (2003-2004) & 1 \\
\hline 109th Congress (2005-2006) & 2 \\
\hline 110th Congress (2007-2008) & 1 \\
\hline 111th Congress (2009-2010) & 2 \\
\hline 112th Congress (2011-2012) & 1 \\
\hline 113th Congress (2013-2014) & 1 \\
\hline 114th Congress (2015-2016) & 2 \\
\hline Rep. Oakar, Mary Rose [D-OH-20] & 15 \\
\hline 100th Congress (1987-1988) & 3 \\
\hline 101st Congress (1989-1990) & 3 \\
\hline
\end{tabular}




\begin{tabular}{|c|c|}
\hline 102nd Congress (1991-1992) & 3 \\
\hline Rep. Oakar, Mary Rose [D-OH-20] & \\
\hline 96th Congress (1979-1980) & 1 \\
\hline 97th Congress (1981-1982) & 1 \\
\hline 98th Congress (1983-1984) & 1 \\
\hline 99th Congress (1985-1986) & 3 \\
\hline Rep. Jackson Lee, Sheila [D-TX-18] & 12 \\
\hline 112th Congress (2011-2012) & 2 \\
\hline 113th Congress (2013-2014) & 2 \\
\hline 114th Congress (2015-2016) & 3 \\
\hline 115th Congress (2017-2018) & 5 \\
\hline Rep. Smith, Christopher H. [R-NJ-4] & 12 \\
\hline 107th Congress (2001-2002) & 2 \\
\hline 108th Congress (2003-2004) & 1 \\
\hline 109th Congress (2005-2006) & 2 \\
\hline 113th Congress (2013-2014) & 2 \\
\hline 114th Congress (2015-2016) & 2 \\
\hline 115th Congress (2017-2018) & 1 \\
\hline 116th Congress (2019-2020) & 2 \\
\hline Rep. DeGette, Diana [D-CO-1] & 12 \\
\hline 107th Congress (2001-2002) & 1 \\
\hline 108th Congress (2003-2004) & 1 \\
\hline 109th Congress (2005-2006) & 2 \\
\hline 110th Congress (2007-2008) & 3 \\
\hline 111th Congress (2009-2010) & 2 \\
\hline 114th Congress (2015-2016) & 2 \\
\hline 115th Congress (2017-2018) & 1 \\
\hline Rep. Miller, George [D-CA-7] & 11 \\
\hline 100th Congress (1987-1988) & 2 \\
\hline 102nd Congress (1991-1992) & 2 \\
\hline 106th Congress (1999-2000) & 1 \\
\hline 107th Congress (2001-2002) & 2 \\
\hline 111th Congress (2009-2010) & 1 \\
\hline 97th Congress (1981-1982) & 1 \\
\hline 99th Congress (1985-1986) & 2 \\
\hline Rep. Collins, Cardiss [D-IL-7] & 11 \\
\hline 100th Congress (1987-1988) & 2 \\
\hline 101st Congress (1989-1990) & 2 \\
\hline 103rd Congress (1993-1994) & 1 \\
\hline 104th Congress (1995-1996) & 1 \\
\hline
\end{tabular}




\begin{tabular}{|l|c|} 
97th Congress (1981-1982) & 1 \\
\hline Rep. Collins, Cardiss [D-IL-7] & \\
\hline 98th Congress (1983-1984) & 1 \\
\hline 99th Congress (1985-1986) & 3 \\
\hline Rep. Burgess, Michael C. [R-TX-26] & 11 \\
\hline 108th Congress (2003-2004) & 2 \\
\hline 109th Congress (2005-2006) & 1 \\
\hline 110th Congress (2007-2008) & 2 \\
\hline 113th Congress (2013-2014) & 1 \\
\hline 114th Congress (2015-2016) & 4 \\
\hline 115th Congress (2017-2018) & 1 \\
\hline Rep. Dellums, Ronald V. [D-CA-8] & 10 \\
\hline 100th Congress (1987-1988) & 1 \\
\hline 101st Congress (1989-1990) & 5 \\
\hline 102nd Congress (1991-1992) & 10 \\
\hline 96th Congress (1979-1980) & 6 \\
\hline Rep. Meng, Grace [D-NY-6] & 1 \\
\hline 114th Congress (2015-2016) & 2 \\
\hline 115th Congress (2017-2018) & 10 \\
\hline 116th Congress (2019-2020) & 2 \\
\hline Rep. Mikulski, Barbara A. [D-MD-3] & 10 \\
\hline 96th Congress (1979-1980) & 1 \\
\hline 97th Congress (1981-1982) & 1 \\
\hline 98th Congress (1983-1984) & 1 \\
\hline
\end{tabular}

\begin{tabular}{|l|c|}
\hline Member (Senate) & \# Sponsored \\
\hline Sen. Kennedy, Edward M. [D-MA] & 40 \\
\hline 100th Congress (1987-1988) & 8 \\
\hline 101st Congress (1989-1990) & 1 \\
\hline 102nd Congress (1991-1992) & 5 \\
\hline 103rd Congress (1993-1994) & 6 \\
\hline 105th Congress (1997-1998) & 3 \\
\hline 106th Congress (1999-2000) & 5 \\
\hline 107th Congress (2001-2002) & 2 \\
\hline 108th Congress (2003-2004) & 1 \\
\hline 109th Congress (2005-2006) & 2 \\
\hline 110th Congress (2007-2008) & 1 \\
\hline 95th Congress (1977-1978) & 1 \\
\hline 96th Congress (1979-1980) & 1 \\
\hline 99th Congress (1985-1986) & 4 \\
\hline
\end{tabular}




\begin{tabular}{|c|c|}
\hline Sen. Boxer, Barbara [D-CA] & 39 \\
\hline 104th Congress (1995-1996) & 2 \\
\hline 105th Congress (1997-1998) & 4 \\
\hline 106th Congress (1999-2000) & 5 \\
\hline 107th Congress (2001-2002) & 4 \\
\hline 108th Congress (2003-2004) & 3 \\
\hline 109th Congress (2005-2006) & 2 \\
\hline 110th Congress (2007-2008) & 5 \\
\hline 111th Congress (2009-2010) & 5 \\
\hline 112th Congress (2011-2012) & 4 \\
\hline 113th Congress (2013-2014) & 2 \\
\hline 114th Congress (2015-2016) & 3 \\
\hline Sen. Snowe, Olympia J. [R-ME] & 31 \\
\hline 104th Congress (1995-1996) & 2 \\
\hline 105th Congress (1997-1998) & 6 \\
\hline 106th Congress (1999-2000) & 5 \\
\hline 107th Congress (2001-2002) & 6 \\
\hline 108th Congress (2003-2004) & 4 \\
\hline 109th Congress (2005-2006) & 2 \\
\hline 110th Congress (2007-2008) & 4 \\
\hline 111th Congress (2009-2010) & 1 \\
\hline 112th Congress (2011-2012) & 1 \\
\hline Sen. Murray, Patty [D-WA] & 28 \\
\hline 105th Congress (1997-1998) & 1 \\
\hline 110th Congress (2007-2008) & 2 \\
\hline 111th Congress (2009-2010) & 2 \\
\hline 112th Congress (2011-2012) & 2 \\
\hline 113th Congress (2013-2014) & 4 \\
\hline 114th Congress (2015-2016) & 5 \\
\hline 115th Congress (2017-2018) & 9 \\
\hline 116th Congress (2019-2020) & 3 \\
\hline Sen. Mikulski, Barbara A. [D-MD] & 26 \\
\hline 100th Congress (1987-1988) & 2 \\
\hline 101st Congress (1989-1990) & 2 \\
\hline 102nd Congress (1991-1992) & 1 \\
\hline 103rd Congress (1993-1994) & 1 \\
\hline 105th Congress (1997-1998) & 1 \\
\hline 107th Congress (2001-2002) & 2 \\
\hline 108th Congress (2003-2004) & 5 \\
\hline
\end{tabular}




\begin{tabular}{|c|c|}
\hline 109th Congress (2005-2006) & 3 \\
\hline \multicolumn{2}{|l|}{ Sen. Mikulski, Barbara A. [D-MD] } \\
\hline 110th Congress (2007-2008) & 3 \\
\hline 111th Congress (2009-2010) & 1 \\
\hline 112th Congress (2011-2012) & 2 \\
\hline 114th Congress (2015-2016) & 3 \\
\hline Sen. Durbin, Richard J. [D-IL] & 23 \\
\hline 107th Congress (2001-2002) & 4 \\
\hline 108th Congress (2003-2004) & 3 \\
\hline 109th Congress (2005-2006) & 1 \\
\hline 110th Congress (2007-2008) & 3 \\
\hline 111th Congress (2009-2010) & 3 \\
\hline 112th Congress (2011-2012) & 3 \\
\hline 113th Congress (2013-2014) & 2 \\
\hline 114th Congress (2015-2016) & 2 \\
\hline 115th Congress (2017-2018) & 2 \\
\hline Sen. Harkin, Tom [D-IA] & 23 \\
\hline 100th Congress (1987-1988) & 2 \\
\hline 101st Congress (1989-1990) & 2 \\
\hline 102nd Congress (1991-1992) & 2 \\
\hline 105th Congress (1997-1998) & 2 \\
\hline 106th Congress (1999-2000) & 2 \\
\hline 107th Congress (2001-2002) & 1 \\
\hline 108th Congress (2003-2004) & 2 \\
\hline 109th Congress (2005-2006) & 2 \\
\hline 110th Congress (2007-2008) & 2 \\
\hline 111th Congress (2009-2010) & 2 \\
\hline 112th Congress (2011-2012) & 2 \\
\hline 113th Congress (2013-2014) & 2 \\
\hline Sen. Stabenow, Debbie [D-MI] & 21 \\
\hline 108th Congress (2003-2004) & 1 \\
\hline 109th Congress (2005-2006) & 1 \\
\hline 110th Congress (2007-2008) & 2 \\
\hline 111th Congress (2009-2010) & 4 \\
\hline 112th Congress (2011-2012) & 4 \\
\hline 113th Congress (2013-2014) & 3 \\
\hline 114th Congress (2015-2016) & 2 \\
\hline 115th Congress (2017-2018) & 4 \\
\hline Sen. Inouye, Daniel K. [D-HI] & 17 \\
\hline 100th Congress (1987-1988) & 2 \\
\hline
\end{tabular}




\begin{tabular}{|c|c|}
\hline 102nd Congress (1991-1992) & 1 \\
\hline Sen. Inouye, Daniel K. [D-HI] & \\
\hline 107th Congress (2001-2002) & 2 \\
\hline 108th Congress (2003-2004) & 1 \\
\hline 109th Congress (2005-2006) & 1 \\
\hline 110th Congress (2007-2008) & 1 \\
\hline 96th Congress (1979-1980) & 2 \\
\hline 97th Congress (1981-1982) & 2 \\
\hline 98th Congress (1983-1984) & 2 \\
\hline 99th Congress (1985-1986) & 3 \\
\hline Sen. Hatch, Orrin G. [R-UT] & 16 \\
\hline 100th Congress (1987-1988) & 1 \\
\hline 103rd Congress (1993-1994) & 2 \\
\hline 107th Congress (2001-2002) & 1 \\
\hline 108th Congress (2003-2004) & 1 \\
\hline 111th Congress (2009-2010) & 1 \\
\hline 112th Congress (2011-2012) & 1 \\
\hline 113th Congress (2013-2014) & 1 \\
\hline 114th Congress (2015-2016) & 1 \\
\hline 115th Congress (2017-2018) & 1 \\
\hline 97th Congress (1981-1982) & 2 \\
\hline 98th Congress (1983-1984) & 2 \\
\hline 99th Congress (1985-1986) & 2 \\
\hline Sen. Clinton, Hillary Rodham [D-NY] & 15 \\
\hline 107th Congress (2001-2002) & 1 \\
\hline 109th Congress (2005-2006) & 5 \\
\hline 110th Congress (2007-2008) & 9 \\
\hline Sen. Menendez, Robert [D-NJ] & 13 \\
\hline 109th Congress (2005-2006) & 2 \\
\hline 110th Congress (2007-2008) & 1 \\
\hline 111th Congress (2009-2010) & 3 \\
\hline 112th Congress (2011-2012) & 1 \\
\hline 113th Congress (2013-2014) & 2 \\
\hline 114th Congress (2015-2016) & 2 \\
\hline 115th Congress (2017-2018) & 2 \\
\hline Sen. Casey, Robert P., Jr. [D-PA] & 13 \\
\hline 111th Congress (2009-2010) & 2 \\
\hline 112th Congress (2011-2012) & 2 \\
\hline 113th Congress (2013-2014) & 3 \\
\hline 114th Congress (2015-2016) & 4 \\
\hline
\end{tabular}




\begin{tabular}{|c|c|}
\hline 115th Congress (2017-2018) & 2 \\
\hline Sen. Daschle, Thomas A. [D-SD] & 13 \\
\hline 100th Congress (1987-1988) & 1 \\
\hline 105th Congress (1997-1998) & 4 \\
\hline 106th Congress (1999-2000) & 4 \\
\hline 107th Congress (2001-2002) & 1 \\
\hline 108th Congress (2003-2004) & 3 \\
\hline Sen. Feinstein, Dianne [D-CA] & 13 \\
\hline 105th Congress (1997-1998) & 2 \\
\hline 106th Congress (1999-2000) & 1 \\
\hline 107th Congress (2001-2002) & 2 \\
\hline 108th Congress (2003-2004) & 1 \\
\hline 112th Congress (2011-2012) & 1 \\
\hline 113th Congress (2013-2014) & 2 \\
\hline 114th Congress (2015-2016) & 3 \\
\hline 115th Congress (2017-2018) & 1 \\
\hline Sen. Leahy, Patrick J. [D-VT] & 13 \\
\hline 100th Congress (1987-1988) & 1 \\
\hline 105th Congress (1997-1998) & 1 \\
\hline 106th Congress (1999-2000) & 1 \\
\hline 107th Congress (2001-2002) & 1 \\
\hline 108th Congress (2003-2004) & 2 \\
\hline 109th Congress (2005-2006) & 1 \\
\hline 110th Congress (2007-2008) & 1 \\
\hline 112th Congress (2011-2012) & 2 \\
\hline 113th Congress (2013-2014) & 3 \\
\hline Sen. Bingaman, Jeff [D-NM] & 12 \\
\hline 103rd Congress (1993-1994) & 1 \\
\hline 107th Congress (2001-2002) & 4 \\
\hline 108th Congress (2003-2004) & 1 \\
\hline 109th Congress (2005-2006) & 2 \\
\hline 110th Congress (2007-2008) & 1 \\
\hline 111th Congress (2009-2010) & 2 \\
\hline 112th Congress (2011-2012) & 1 \\
\hline Sen. Biden, Joseph R., Jr. [D-DE] & 12 \\
\hline 102nd Congress (1991-1992) & 1 \\
\hline 105th Congress (1997-1998) & 2 \\
\hline 107th Congress (2001-2002) & 1 \\
\hline 108th Congress (2003-2004) & 1 \\
\hline 109th Congress (2005-2006) & 3 \\
\hline
\end{tabular}




\begin{tabular}{|c|c|}
\hline 110th Congress (2007-2008) & 4 \\
\hline Sen. Gillibrand, Kirsten E. [D-NY] & 11 \\
\hline 111th Congress (2009-2010) & 2 \\
\hline 112th Congress (2011-2012) & 4 \\
\hline 113th Congress (2013-2014) & 2 \\
\hline 115th Congress (2017-2018) & 2 \\
\hline 116th Congress (2019-2020) & 1 \\
\hline Sen. Akaka, Daniel K. [D-HI] & 10 \\
\hline 103rd Congress (1993-1994) & 1 \\
\hline 104th Congress (1995-1996) & 1 \\
\hline 105th Congress (1997-1998) & 1 \\
\hline 106th Congress (1999-2000) & 1 \\
\hline 109th Congress (2005-2006) & 1 \\
\hline 110th Congress (2007-2008) & 1 \\
\hline 111th Congress (2009-2010) & 3 \\
\hline 112th Congress (2011-2012) & 1 \\
\hline Sen. Dodd, Christopher J. [D-CT] & 10 \\
\hline 100th Congress (1987-1988) & 1 \\
\hline 107th Congress (2001-2002) & 1 \\
\hline 108th Congress (2003-2004) & 1 \\
\hline 109th Congress (2005-2006) & 2 \\
\hline 110th Congress (2007-2008) & 1 \\
\hline 111th Congress (2009-2010) & 2 \\
\hline 98th Congress (1983-1984) & 1 \\
\hline 99th Congress (1985-1986) & 1 \\
\hline Sen. Rockefeller, John D., IV [D-WV] & 10 \\
\hline 101st Congress (1989-1990) & 1 \\
\hline 103rd Congress (1993-1994) & 2 \\
\hline 107th Congress (2001-2002) & 1 \\
\hline 108th Congress (2003-2004) & 1 \\
\hline 110th Congress (2007-2008) & 2 \\
\hline 111th Congress (2009-2010) & 1 \\
\hline 112th Congress (2011-2012) & 1 \\
\hline 113th Congress (2013-2014) & 1 \\
\hline Sen. Shaheen, Jeanne [D-NH] & 10 \\
\hline 111th Congress (2009-2010) & 2 \\
\hline 112th Congress (2011-2012) & 1 \\
\hline 113th Congress (2013-2014) & 2 \\
\hline 114th Congress (2015-2016) & 2 \\
\hline 115th Congress (2017-2018) & 3 \\
\hline
\end{tabular}




\begin{tabular}{|c|c|}
\hline Sen. Cranston, Alan [D-CA] & 10 \\
\hline 100th Congress (1987-1988) & 1 \\
\hline 101st Congress (1989-1990) & 1 \\
\hline 102nd Congress (1991-1992) & 2 \\
\hline 96th Congress (1979-1980) & 1 \\
\hline 97th Congress (1981-1982) & 1 \\
\hline 98th Congress (1983-1984) & 2 \\
\hline 99th Congress (1985-1986) & 2 \\
\hline Sen. Klobuchar, Amy [D-MN] & 10 \\
\hline 111th Congress (2009-2010) & 1 \\
\hline 113th Congress (2013-2014) & 3 \\
\hline 114th Congress (2015-2016) & 4 \\
\hline 115th Congress (2017-2018) & 2 \\
\hline Sen. Murkowski, Lisa [R-AK] & 10 \\
\hline 109th Congress (2005-2006) & 1 \\
\hline 111th Congress (2009-2010) & 3 \\
\hline 112th Congress (2011-2012) & 2 \\
\hline 113th Congress (2013-2014) & 2 \\
\hline 114th Congress (2015-2016) & 2 \\
\hline Sen. Chafee, John H. [R-RI] & 10 \\
\hline 100th Congress (1987-1988) & 2 \\
\hline 102nd Congress (1991-1992) & 1 \\
\hline 103rd Congress (1993-1994) & 1 \\
\hline 105th Congress (1997-1998) & 2 \\
\hline 106th Congress (1999-2000) & 2 \\
\hline 97th Congress (1981-1982) & 1 \\
\hline 99th Congress (1985-1986) & 1 \\
\hline
\end{tabular}

